\title{
DESIGN MODIFICATIONS TO THE
}

SRE DURING FY 1960

NAA-SR-5348
G. E. DEEGAN
R. J. HALL
M. D. DERMER
R: B. HINZE
J. S. FLANAGAN
D. H. JOHNSON
G. C. GOWER
R. W. KEATEN

By

\author{
W. H. OLSON
}

\section{ATOMICS INTERNATIONAL}

A DIVISION OF NORTH AMERICAN AVIATION, INC. P.O. BOX 309 CANOGA PARK, CALIFORNIA 


\section{LEGAL NOTICE}

This report was prepared as an account of Government sponsored work. Neither the United States, nor the Commission, nor any person acting on behalf of the Commission:

A. Makes any warronty or representation, express or implied, with respect to the accuracy, completeness, or usefulness of the information contained in this report, or that the use of any information, apparatus, method, or process disclosed in this report moy not infringe privately owned rights; or

B. Assumes any liabilities with respect to the use of, or for dameges resulting from the use of information, apparatus, method, or process disclosed in this report.

As used in the above, "person acting on behalf of the Commission" includes any em. ployee or contractor of the Commission to the extent that such employee or contractor propores, handles or distributes, or provides occess to, ony information pursuant to his employment or contract with the Commission. 


\section{CONTENTS}

Page

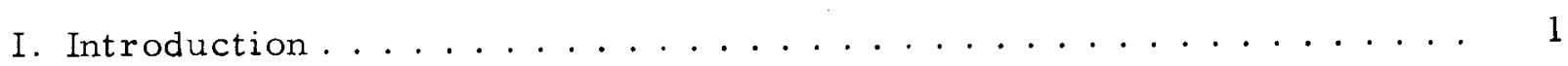

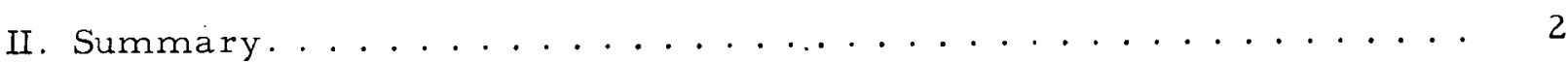

A. Elimination of Tetralin .................. 2

B. Sodium-System Changes .................. 4

C. Fuel Washing System ................... 4

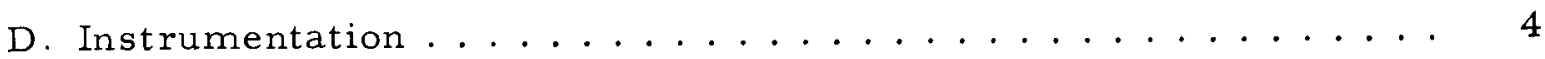

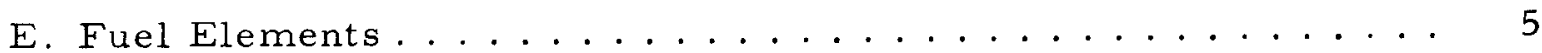

III. Elimination of Tetralin ................... 7

A. Selection of Service Coolant................ 7

1. Service-Coolant Requirement ............. 7

2. Discussion of Tetralin. ............... 7

3. Survey of Service Coolants................ 8

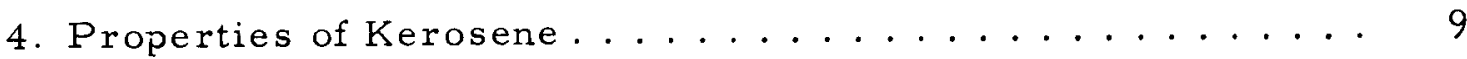

B. Component Modifications to Prevent Organic Leakage...... 12

1. Valve Freeze Seals.................... 12

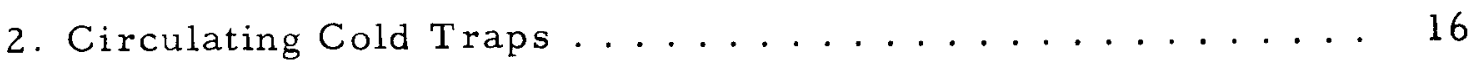

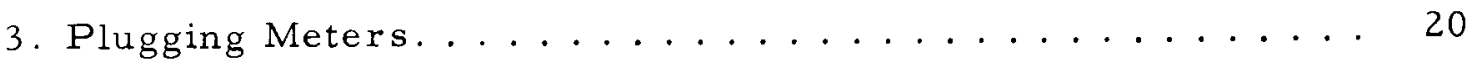

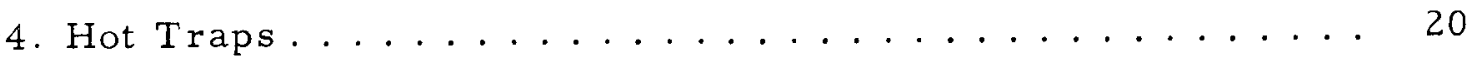

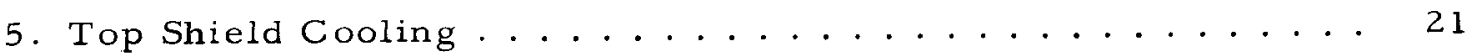

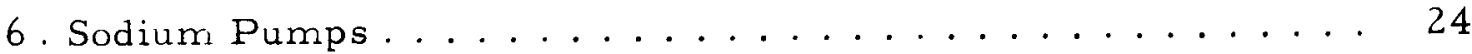

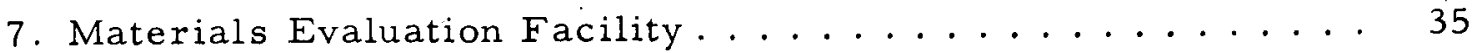

IV . Sodium System Changes. . . . . . . . . . . . . . . 38

A. Moderator Coolant Eductor ..................... 38

B. Main Secondary Bypass.................... 42

C. Freeze Traps ........................... 42

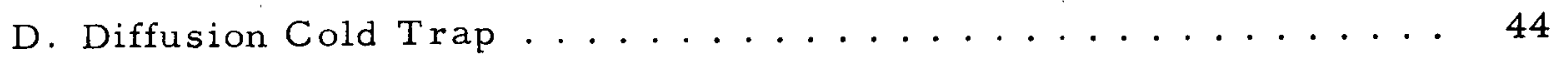

V. Fuel washing System......................... 46

A. Wash Cell Experience....................... 46

B. Fuel Washing Experiment ................. 46

C. Modified Washing System. ................... 52 


\section{CONTENTS}

Page

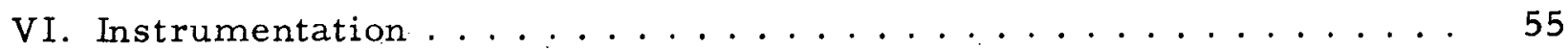

A. Diagnostic Instrumentation. . . . . . . . . . . 55

1. Fission Product Monitor . . . . . . . . . . . . 55

2. Reactor Transient Monitor. . . . . . . . . . . . 57

3. Reactor Temperature Measurements............. 60

4. Operations Event Recorder ................ 64

B. Control Instrumentation .................. 65

1. Neutron flux/power deviation circuit ............ 65

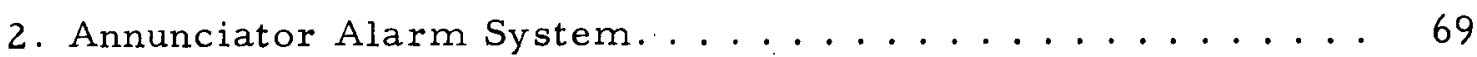

VII. Fuel Elements ........................ . . 70

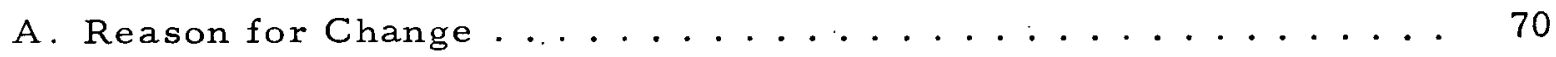

B. Fuel-Element Geometry ................... . 70

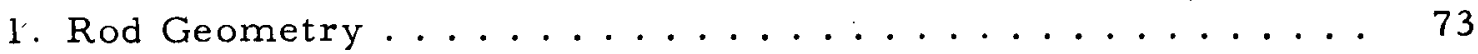

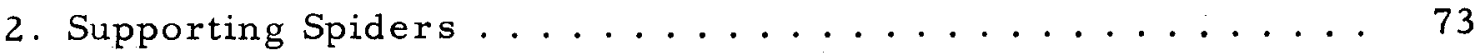

3. Top Guide Vanes ....................... 73

4. The Bottom Guide...................... 74

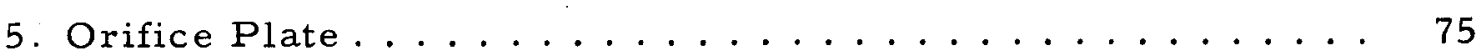

6. Fuel-Channel-Exit Thermocouple ............ 75

7. Hanger Rod and Holddown Tube............. 75

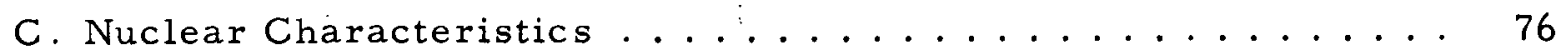

1. Individual Element Worths . . . . . . . . . . . 76

2. Reactor Characteristics with Five-Rod Thorium-Uranium Fuel 77

a. Control-Rod Worths ................. 77

b. Reactivity Coefficients . . . . . . . . . . . 79

c. Reactivity Changes Due to Long-Term Effects with
Thorium-Uranium Alloy Fuel.................. 81

D. Hydraulic Characteristics of Fuel Channels ........... 81

1. Normal Flow Conditions ................. 81

E. Fuel Temperatures...................... 82

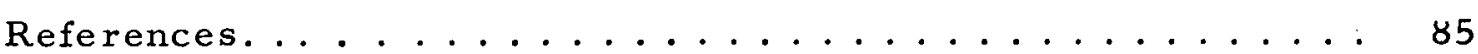




\section{CONTENTS}

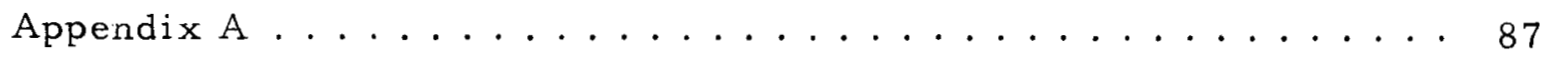

System P \& I Diagrams . . . . . . . . . . . . . . . . . 87

1. Primary Sodium System.................. A 1

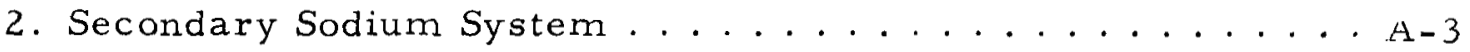

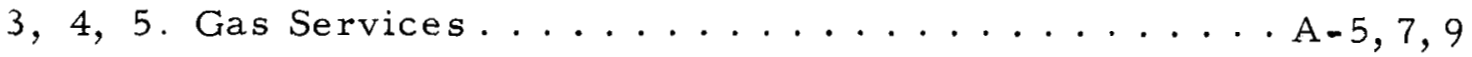

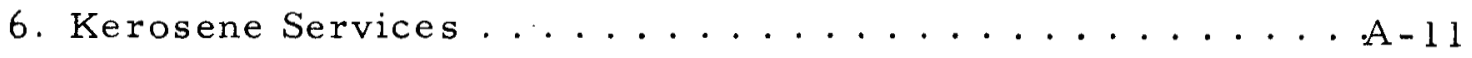

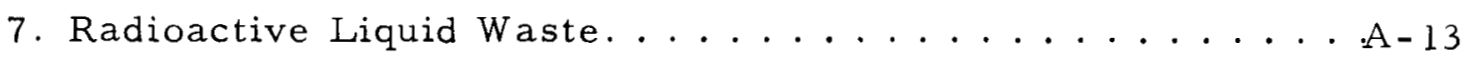

\section{TABLES}

I. Concentration of Unsaturated Compounds in Kerosene........ 9

II. Kerosene Physical Properties. . . . . . . . . . . . . . . 9

III. Cold-Trap Operating Parameters . . . . . . . . . . . . . 19

IV. Limited Volume Kerosene System Parameters . . . . . . . . . . 24

V. Eductor Requirements and Performance . . . . . . . . . 39

VI. Calculated Physics Parameters for the First and Second Cores . . 78

VII. Calculated Temperature Coefficients of Reactivity . . . . . . . . 80

VIII. Calculated Steady-State Power Coefficients . . . . . . . . . . 80

IX. Calculated Void Coefficients ................. 80

\section{FIGURES}

1. Kerosene and Sodium Pressure-Temperature Relationship

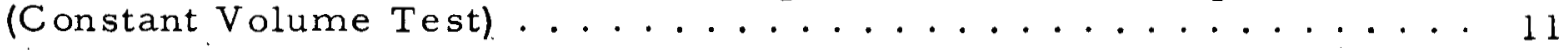

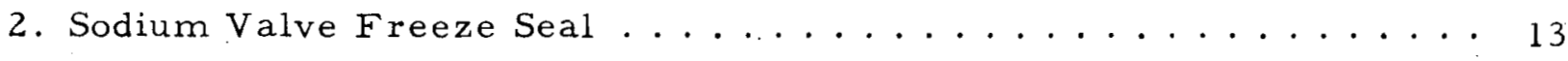

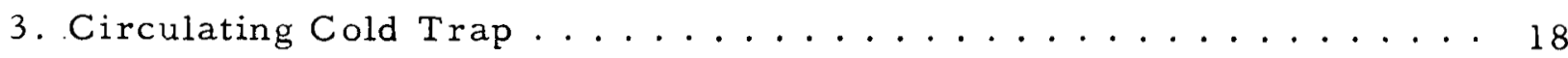

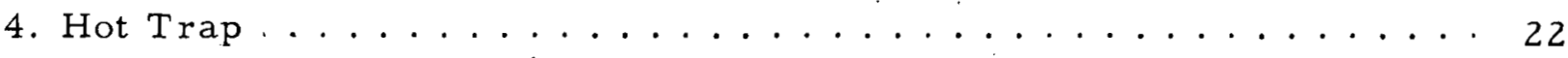

5. Main Secondary Sodium Pump . . . . . . . . . . . 25

6. Pump-Coolant-System Process and Instrumentation Diagram . . . . 27

7. NaK Panel, Pump Coolant System ................. 31

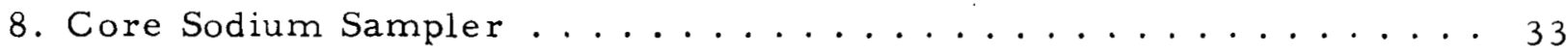




\section{FIGURES}

Page

9. Sodium Sample Gas Lock . . . . . . . . . . . . . . . . 36

10. Simplified Flow Diagram, Main Primary Sodium System . . . . . . 38

11. Moderator Coolant Eductor. . . . . . . . . . . . . . . 39

12. Eductor Test Results. . . . . . . . . . . . . . . . . . . 40

13. Predicted Eductor Hydraulics . . . . . . . . . . . . . . . . 41

14. Main Secondary Bypass Loop Hydraulics . . . . . . . . . . . . . 43

15. Tubular Freeze Trap. . . . . . . . . . . . . . . . . . 43

16. Fuel Element Holddown Tube . . . . . . . . . . . . . . 47

17. Typical Hydrodynamic Pressure, Time Trace . . . . . . . . . 49

18. Collapsed Dummy Fuel Rods. . . . . . . . . . . . . . . . 50

19. Flow Diagram of Modified Fuel Washing System . . . . . . . . . 53

20. Modified Fuel Washing Assembly. . . . . . . . . . . . . . 54

21. Fission-Product-Monitor Flow Diagram ............. 56

22. Magnetic Tape Recorder ....................... 58

23. Fuel Element Instrumentation . . . . . . . . . . . . . 61 61

24. Fuel Thermocouple Location, Second Core Loading. . . . . . . . . 62

25. Fuel Channel Outlet Thermocouple Installation . . . . . . . . . 63

26. SRE Neutron Flux/Power Deviation Limit Circuit. . . . . . . . . . 67

27. SRE Fuel Element Configuration ................. 71

28. SRE Five-Rod and Seven-Rod Element Clusters . . . . . . . . . 72

29. Increase In Core Outlet Temperature Due to Blocking of the

Strainer on the Five-Rod Cluster. ............... 74

30. Core Pressure Drop vs Channel Flowrate. . . . . . . . . . . 82

31. Orifice Hole Size vs Channel Flowrate (five-rod cluster) . . . . . . 83

32. Axial Fuel-Temperature Distribution for 34 Five-Rod Elements . . . 84

33. Axial Fuel-Temperature Distribution for 31 Seven-Rod Elements . . 84 


\section{INTRODUCTION}

A number of SRE fuel elements were found to be damaged after a low power run in July 1959. Tetralin leakage into the primary sodium system just prior to July 26, 1959 has been considered to be the cause of the fuel damage. ${ }^{1}$ Tetralin entered the system through a small rupture in the shaft freeze seal gland of the main primary pump. The tetralin decomposed, partially plugging the fuel channels. Decomposition products, principally carbon, were dispersed throughout the sodium system. These carbonaceous products can result in carburization of fuel element cladding, reactor and coolant system components. The presence of carbon will limit the maximum operating temperature until the carbon content can be reduced to an acceptable level.

To prevent a recurrence of this situation, organic cooling was eliminated from components where the possibility of direct leakage into the sodium system existed.

Other changes were made to the SRE to correct existing functional difficulties or to provide for improved reliability. A steam fuel washing facility was designed to permit safe and effective removal of sodium residue from SRE core elements. Instrumentation was added to monitor additional reactor parameters and to provide alarms for off-normal conditions. The number of rods in the SRE fuel clusters has been reduced from seven to five to provide additional clearance in the channel. Other fuel hardware changes have been made to improve structural and hydraulic characteristics of the element.

The purpose of this report is to describe all of these design changes. 


\section{SUMMARY}

\section{A. ELIMINATION OF TETRALIN}

Tetralin is no longer used at the SRE. A survey of alternate coolants and a review of $\mathrm{SRE}$ equipment and heat loads resulted in the selection of nitrogen gas, $\mathrm{NaK}$, and kerosene as service coolants for this reactor. Nitrogen gas, the inert.atmosphere of the pipe galleries, is used to cool the primary cold trap and plugging meter, and backup freeze seal section of the block valves. NaK is used to cool the pump freeze seals. Neither of these coolants was suitable for cooling the reactor top shield; an organic liquid was needed because of the tube size and materials in the existing cooling coils.

In the search for a suitable organic, attention was directed to saturated compounds, particularly to a petroleum fraction, kerosene. Saturated compounds do not have the active carbon-hydrogen groups of the aromatics; and hence do not form the complex sodium compounds. Neither do they have the tendency to form peroxides that is common to alkyl aromatics such as tetralin. Kerosene can be evaporated to dryness in the presence of air without the for mation of peroxides. Kerosene was selected because of the extensive industrial experience with this product and the following suitable physical properties:

$$
\begin{array}{ll}
\text { Boiling point range }\left({ }^{\circ} \mathrm{F}\right) & 436 \text { to } 570 \\
\text { Viscosity at } 100^{\circ} \mathrm{F} \text { (centistokes) } & 2.85 \\
\text { Flash point }\left({ }^{\circ} \mathrm{F}\right) & 190
\end{array}
$$

For cooling of the valve freeze seals and the top shield, where it was impractical to use inorganic coolants, double barriers are provided to prevent leakage of kerosene into sodium systems. A small (90-gal), separate cooling system has been installed to cool the top shield. An accurate indicator-alarm on the surge tank level will permit early detection of any leakage.

In addition to modifications made to prevent organic leakage into sodium systems, changes were made to improve component performance and system reliability.

1) Valve freeze seals have gas cooling as backup to maintain the freeze seals if kerosene cooling is lost. 
2) Circulating-cold-trap internal design follows HNPF practice, which has been experimentally demonstrated to have a higher trapping rate and greater oxide capacity than the former SRE design.

3) The hot trap will be disposed of as a unit. This will simplify changing the gettering charge by eliminating the insert removal operation. Operational experience has demonstrated that insert removal is difficult because of the possibility of spreading radioactive contamination.

4) Changes to the sodium circulating pumps, to permit $\mathrm{NaK}$ cooling, have resulted in a superior bearing housing which is not subject to the leakage problems associated with the original housing. Freeze seal redesign provided a unit in which the coolant coils are protected from the shaft by a perforated sleeve. The coils are free to move, and thus a seal of low stress is provided. There are no welds in the seal tubing where it is subjected to a temperature gradient or where it is in contact with sodium. These changes will greatly improve integrity of the coolant chambers and reduce the possibility of leakage. A system of this type has been successfully operated for more than 6 months in the main primary system of SRE.

$\mathrm{NaK}$ circulation and cooling is assured by providing double pumping capacity and an emergency source of power for the units.

The amount of $\mathrm{NaK}$ which can leak into the sodium system by a failure in the $\mathrm{NaK}$ system is limited by the use of an independent $\mathrm{NaK}$ system on each sodium pump. With the instrumentation provided, sufficient warning can be obtained to take corrective action (balance the sodium head with gas pressure) to prevent sodium from entering the pump casing even though the seal temperature is above the sodium melting point.

5) Sodium samples for physical and chemical analysis may be obtained during reactor operation. Carburization test specimens may also be removed when the reactor is in operation. The specimens will be removed from the reactor by a simple gas lock. 


\section{B. SODIUM SYSTEM CHANGES}

The modifications effected will increase system reliability and operational flexibility.

1) The moderator coolant eductor has a simple structural design with circular cross sections. The eductor replaces a linear induction pump that had flat throat sections which were subject to deformation during preheating and operation. The eductor requires no electrical supply system. The simplicity of this new component will give higher reliability than the former pump.

2) The main secondary bypass line will increase temperature stability of the reactor, and the temperature range in which isothermal reactor physic tests can be made. The magnitude of the time required to change from isothermal circulation to flow through the steam generator will be reduced from days to hours. Operational flexibility will be enhanced.

3) The new freeze traps will add to operating efficiency by speeding sodium filling and draining procedures.

\section{FUEL WASHING SYSTEM}

Experimental evidence has demonstrated the desirability of using steam rather than water for removing residual sodium from core components. The sodium-steam reaction can be controlled by the steam flowrate to hold the element temperature within any desired limits. A new wash cell has been installed at the SRE which incorporates the design improvements developed by the experimental program. Twenty elements from the core have been successfully washed in the new system, which operates as designed.

\section{INSTRUMENTATION}

SRE fuel damage which occurred in July 1959 pointed out the need for additional instrumentation which would provide the operating staff with more information on behavior of the system. The fission-product monitor will provide a continuous record of the activity in the reactor cover gas. A fuel cladding rupture will thus be readily detected. 
The reactor transient monitor will provide continuous recordings of selected variables whenever such information is required. This data will be used for analysis of reactor behavior or any unusual event. Thes data, used in conjunction with the operations event recorder and other recorded reactor data,will permit a much more complete analysis of these events and provide valuable information on the behavior of the reactor complex.

Eight fuel elements in the thorium-uranium fuel loading will have thermocouples in the fuel; the readout instruments, with visual and audible alarms for abnormal temperatures, will be located so as to be under constant surveillance of the reactor operators. The fuel channel exit temperature thermocouples have been placed directly in the sodium stream to increase the rate of response. They have been extended below the orifice plate to eliminate possible errors from convective circulation and/or heat conduction from the upper plenum.

In the area of control instrumentation, the flux/power deviation circuit will provide an additional channel of safety instrumentation. Its action will not alter in any way the functioning of the normal plant protective system. It will provide additional protection against transients in the low power region where the high power trip is least effective in protecting the reactor. This circuit will protect against high or low sodium flow, and high or low reactor power as compared with heat removal capability, by providing an alarm, setback, or scram depending upon the degree of deviation.

Relocation of the annunciator panels permits direct view of all windows displaying alarm warnings, and permits more prompt corrective action.

\section{E. FUEL ELEMENTS}

A new fuel-cluster geometry is used with five standard peripheral rods arranged in a concentric ring around a 3/8-in. -diameter stainless-steel support rod. The radial clearance between wire wrap on the fuel rods and the coolant channel wall is increased from 0.029 to 0.162 in. A filter screen at the bottom of the fuel element prevents particles of foreign material (larger than one third the radial clearance of 0.162 in.) from entering the fuel channel. 
Nuclear characteristics for the 34-element, five-rod, thorium-uranium loading are not significantly different from the 31-element, seven-rod, thoriumuranium loading. The reactivity coefficients and rates of reactivity change from rod withdrawal are very close to, and in most cases either the same as, or between, those for the unalloyed-uranium core on which the SRE was previously operated and the seven-rod thorium-uranium core reported in NAA-SR-3175 $(\operatorname{Rev})^{20}$ which was previously approved for the SRE. The fuel-temperature coefficient of reactivity for the five-rod thorium-uranium loading $\left(-1.7 \times 10^{-5}\right.$ $\Delta \mathrm{k} / \mathrm{k}$ per ${ }^{\circ} \mathrm{F}$ ) is not as strongly negative as for the seven-rod thorium-uranium loading $\left(-2.2 \times 10^{-5} \Delta \mathrm{k} / \mathrm{k}\right.$ per $\left.{ }^{\circ} \mathrm{F}\right)$ but is more strongly negative than for the first core uranium loading $\left(-1.4 \times 10^{-5} \Delta \mathrm{k} / \mathrm{k}\right.$ per $\left.{ }^{\circ} \mathrm{F}\right)$. The fuel-temperature coefficient is the most prominent factor in the stability of the SRE because of its short time constant. The void coefficient for the five-rod thorium-uranium element loading $\left(6.5 \times 10^{-5} \Delta \mathrm{k} / \mathrm{k}\right.$ per \% void $)$ is lower than for the first core uranium loading $\left(8.6 \times 10^{-5} \Delta \mathrm{k} / \mathrm{k}\right.$ per $\%$ void), although slightly higher than for the seven-rod thorium-uranium loading $\left(4.9 \times 10^{-5} \Delta \mathrm{k} / \mathrm{k}\right.$ per $\%$ void $)$.

Hydraulic characteristics for five-rod fuel elements are not significantly different from those for seven-rod fuel elements. Most of the core pressure drop occurs across the orifice plate which has been relocated to the top of the element. The orifice plate now resides within a machined surface in the spacerring hardware at the top of the moderator can, thus permitting closer tolerances and ensuring uniform peripheral leakage of sodium flow and resultantly more uniform fuel-channel-exit sodium temperature distribution. The hydraulic characteristics of the new fuel element have been determined experimentally. 


\section{ELIMINATION OF TETRALIN}

\section{A. SELECTION OF SER VICE COOLANT}

1. Service-Coolant Requirement

A service coolant is needed to establish and maintain sodium freeze seals on pumps and valves, to cool piping galleries and biological shielding, to remove afterglow heat from fuel storage cells, and to remove heat from cold traps and plugging meters.

\section{Discussion of Tetralin}

Tetralin (tertahydronaphythlene) has been used as the service coolant since SRE operation started. However, tetralin has certain disadvantages as a coolant. Tetralin forms peroxides upon exposure to air. Any peroxides present in tetralin will concentrate in the residue during evaporation, and experience at other facilities has shown that these peroxides are unstable and can react violently. ${ }^{2,3}$ At the SRE the use of a nitrogen cover gas above the free surface in the tetralin surge tank, and the use of an amine as an anti-oxidant resulted in peroxide concentrations less than $0.05 \%$ in the service coolant system; no peroxide decomposition reactions were observed. However, high concentrations of peroxides conceivably could occur in portions of the SRE system during shutdowns, or after components have been removed from the system. There would be an explosion hazard if these residues were heated. Tetralin has been removed from the coolant system, eliminating this hazard.

Tetralin had certain other disadvantages for SRE service. Naphthalene, a tetralin decomposition product, will readily add sodium to active carbonhydrogen groups in the unsaturated rings. The resulting naphylsodium compound formed is very reactive, and pyrophoric. After tetralin had leaked into the primary sodium system, pyrophoric particles were observed in a sample of reactor cover gas. In common with all organics, carbonaceous residues result from the tetralin-sodium reaction. Blockage of fuel coolant channels, which was a cause of the fuel damage experienced in 1959, has been attributed to tetralin decomposition products. 1 Tetralin also is an excellent solvent for rubber, neoprene, and other common gasket materials. As a consequence, leakage at fittings was a problem. 


\section{Survey of Service Coolants}

Gaseous nitrogen appears to be an ideal service coolant for applications where the heat flux, coolant flow area, and temperature driving force (temperature difference between sodium and the service coolant) permit its use. The low heat transfer film coefficient (compared to liquids) minimizes thermal shock of the sodium component. Nitrogen gas is used only at low pressures in the new components designed for the SRE. In these low-pressure applications, nitrogen pressure is less than sodium pressure, so there can be no leakage of gas into the sodium system. In the event of a sodium leak into the coolant annulus there will be no chemical reaction, since nitrogen behaves as an inert gas with sodium. The gas itself is compatible with inexpensive materials of construction and presents no special handling or safety problems.

A literature search was made to select the optimum liquid coolant for use with a sodium system. 4 The criteria were a suitable melting - boiling point range and the absence of carbon. Of the 39 compounds that satisfied these criteria, all but $\mathrm{NaK}$ and water were eliminated on the basis of potential corrosiveness, neutron-absorption cross section, or the requirement of a relatively expensive auxiliary system.

The sodium-potassium eutectic alloy ( $\mathrm{NaK}$ ) will be used to remove heat from the sodium-pump freeze seals. Its use is required by the heat flux, coolant flow area, available temperature driving force, and need for a coolant that does not react with sodium.

Water has been used successfully in the component development program and may well be the optimum liquid coolant, particularly for accessible components. However, the SRE service system is not designed for use with water. Rather than undertake a substantial redesign of the system, it was decided to use other liquid coolants where liquids were required.

An organic liquid coolant will be used to cool the reactor top shield, since, there is a double barrier between the service coolant and the sodium system. Neither NaK nor nitrogen was suitable for this application because of the tube size and the materials in the existing cooling coils.

In the search for a suitable organic, attention was directed to saturated compounds, particularly to the petroleum fraction, kerosene. The saturated 
compounds do not have the active carbon-hydrogen groups of the aromatics, and hence do not form the complex sodium compounds. Neither do they have the tendency to form peroxides that is common to alkyl aromatics such as tetralin. Kerosene can be evaporated to dryness in the presence of air without the formation of peroxides.

\section{Properties of Kerosene}

Kerosene has suitable physical properties for use as a service coolant. The grade of kerosene meeting specification MIL-F-25558B was selected for the SRE because of this grade's low content of unsaturated compounds and high flash point. The concentrations of unsaturated compounds are listed in Table I.

TABLE I

CONCENTRATION OF UNSATURATED COMFOUNDS IN KEROSENE

\begin{tabular}{lcc} 
Type & $\begin{array}{c}\text { Maximum } \\
\text { Permitted (vol \%) }\end{array}$ & $\begin{array}{c}\text { Typical } \\
\text { (vol \%) }\end{array}$ \\
\cline { 2 - 3 } & 5.0 & 3.6 \\
Aromatics & 1.0 & 0.5
\end{tabular}

As noted in the preceding paragraph, a low unsaturated-compound concentration is necessary to prevent the formation of reactive compounds. Purchase of kerosene to this specification as sured rigid manufacturing controls in the refine $r y$. The high fla sh point of this grade $\left(190^{\circ} \mathrm{F}\right.$ minimum, $200^{\circ} \mathrm{F}$ typical) minimizes any fire hazard during handling of the material. In fact the Fire Code ${ }^{5}$ does not include in the "flammable list" liquids with flash points above $200^{\circ} \mathrm{F}$. Physical properties of kerosene pertinent to this application are listed in Table II.

TABLE II

\section{KEROSENE PHYSICAL PROPERTIES}

\section{Distillation Range ( $\left.{ }^{\circ} \mathrm{F}\right)$}

Initial boiling point $\quad 430$

End point

Viscosity at $100^{\circ} \mathrm{F}$ (centistokes)

Specific Gravity 
The high initial boiling point of this kerosene (approximately the same as the boiling point of tetralin) willassure a one-phase system during normal operations. The viscosity permits the use of existing pumps. Normal gasket materials can be used with kerosene. Kerosene has low toxicity; it has only a slightly irritating effect on the skin.

While the aromatic compounds suffer less radiation damage than other classes of organics, the difference is not significant in this application. The average dosage received to date by the tetralin has been estimated to be $6 \times 10^{6}$ roentgens. This is considerably less than the dosage of $5 \times 10^{8}$ roentgens required for minor damage to kerosene. In the event of significant damage after long exposures, the kerosene in the system can be easily replaced.

Compatibility of a commercial-grade ${ }^{*}$ kerosene with sodium has been determined experimentally. The closed-system pressure-temperature relationship has been established for kerosene and for kerosene-sodium up to $1200^{\circ} \mathrm{F}$; the relationship is shown on Figure 1. The apparatus and method were similar to that used by McKisson and Horton ${ }^{6}$ in their study of tetralin-sodium compatibility. The curves show several regions. The linear portion below $450^{\circ} \mathrm{F}$ represents the expansion of argon gas, showing ideal behavior. The region between $450^{\circ} \mathrm{F}$ and $630^{\circ} \mathrm{F}$ can be explained by the vaporization of kerosene. The discontinuity at $630^{\circ} \mathrm{F}$ indicates the end of vaporization. Between $630^{\circ} \mathrm{F}$ and approximately $850^{\circ} \mathrm{F}$ one visualizes the expansion of a nonideal gas mixture of argon and kerosene vapor, with a small amount of decomposition products on curve $B$. The presence of these decomposition products accounts for the displacement of curve $B$ from the curve for kerosene alone. About $900^{\circ} \mathrm{F}$ the pressure rises very rapidly with temperature, indicating that decomposition is occurring. Above $900^{\circ} \mathrm{F}$ thermal cracking of kerosene is enhanced by the presence of sodium. Above $950^{\circ} \mathrm{F}$ the evolution of gas is much more rapid in the presence of sodium than it was in its absence. The presence of sodium makes no appreciable difference in the temperature at which rapid decomposition is initiated. These observations indicate that the interaction of sodium with kerosene becomes rapid only after thermal cracking of the kerosene has commenced. Then the sodium interacts with the gaseous fragments. A carbonaceous residue, having

*Pearl Oil, Standard Oil Company of California 


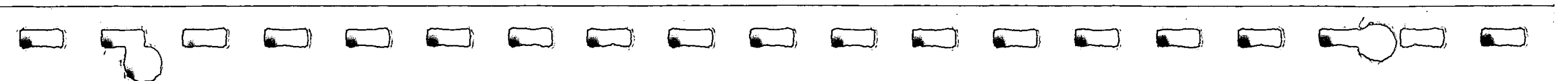

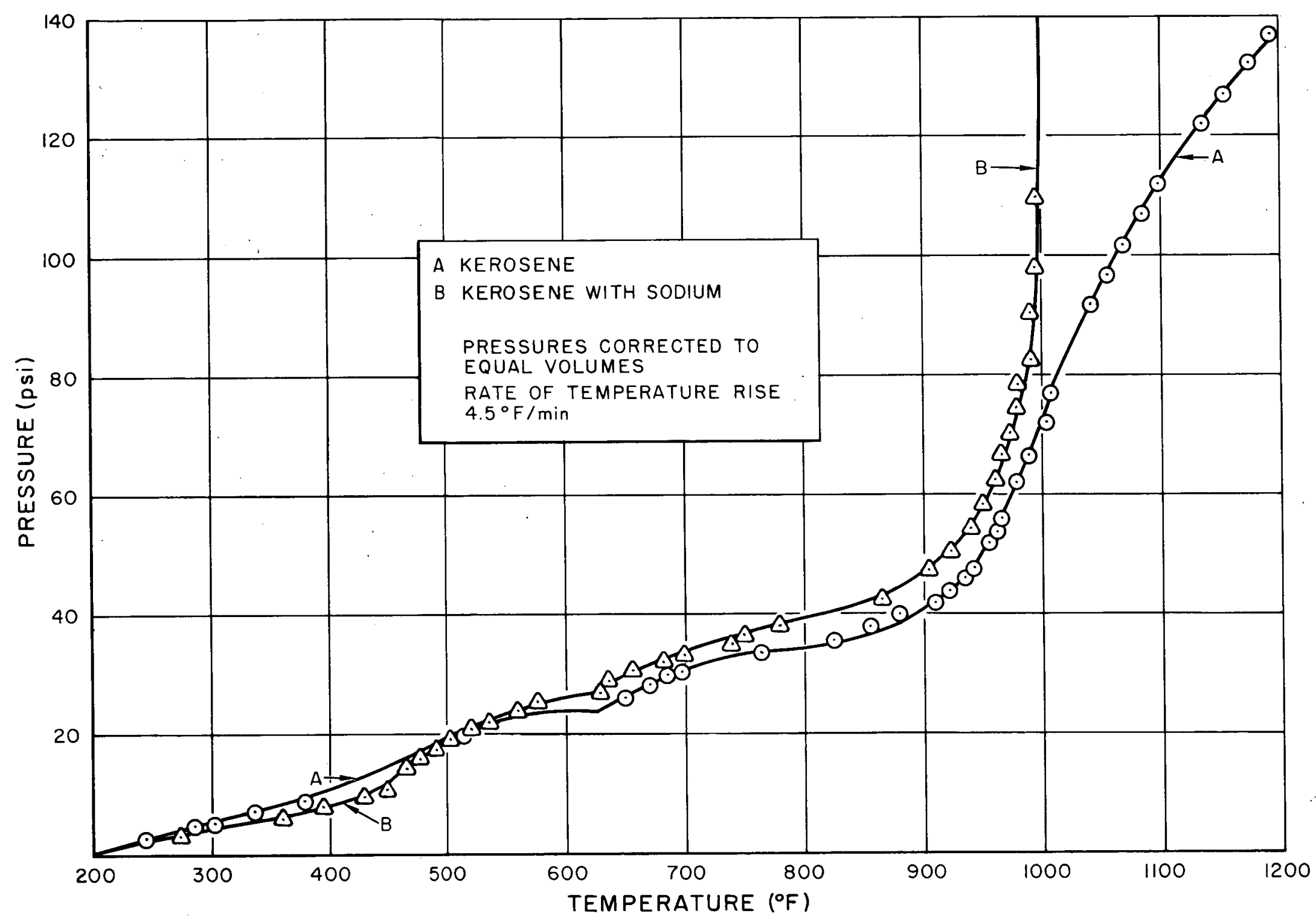

Figure 1. Kerosene and Sodium Pressure-Temperature Relationship (Constant Volume Test) 
the appearance of soot, remained in the capsules after these tests. The residues were inert; there was no indication of the presence of any pyrophoric compounds.

The compatibility of MIL-F-25558B kerosene with sodium is being investigated. Initial results indicate that cyclic compounds predominate in this material. The pressure-temperature curve for this kerosene with sodium was identical to curve $B$ in Figure 1.

One of the principal reasons for the choice of kerosene was the extensive industrial experience that has been accumulated on the use of this material. Kerosene has been refined in the United States since the beginning of the petroleum industry in the $1850^{\prime} \mathrm{s}$. The production rate has been substantially increased in recent years as a result of its demand as an aircraft fuel. The safety experience gained through this wide usage has been reported. $7,8,9$ Kerosene will react chemically only under the strongest oxidizing conditions. 9 The only hazard is that of fire during handling or leakage from the system. The high flash point $\left(200^{\circ} \mathrm{F}\right)$ of the grade selected for the SRE minimizes this hazard. One large consumer has reported that they have had no incidents because of fire due to accidental ignition of fuel since they have been using kerosene. ${ }^{10}$ In none of the reports was there any mention of the formation of any unstable compounds such as peroxides which could cause explosions.

\section{B. COMPONENT MODIFICATIONS TO PREVENT ORGANIC LEAKAGE}

\section{Valve Freeze Seals}

The original primary- and secondary-system block valves were provided with an organic cooling jacket which was separated by a single wall from the sodium system. With only a single containment, the possibility of undetected organic leakage into the sodium existed.

The primary system block valves have been modified by mounting a new, two-region freeze seal above the original seal (Figure 2). The existing coolant jacket was cleaned to remove all tetralin and peroxides. The tetralin tubing was disconnected and the jacket left open. The stem extension and new seal section were shop fabricated and installed on the valves in the galleries. The original yoke, gears, and operator were then mounted on an extension bracket. The lower section of the new seal is a kerosene coil cast in aluminum block. The 


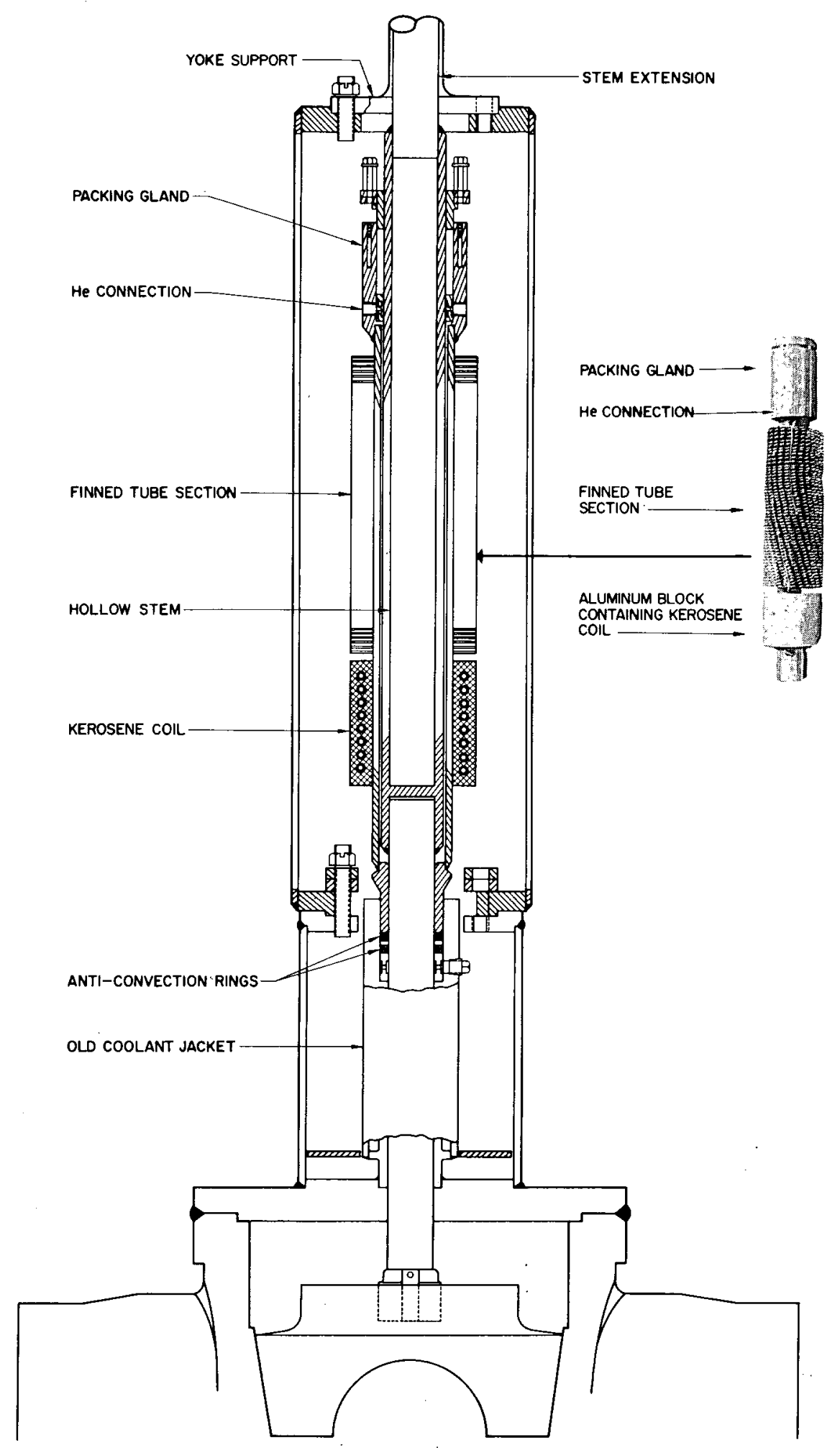

Figure 2. Sodium Valve Freeze Seal 
inside of the aluminum toroid is machined to give a close fit on the seal tube. The upper section of the seal consists of finned tubing. Design of this gas-cooled section has been based on free-convection heat transfer to nitrogen at $150^{\circ} \mathrm{F}$. However, in the galleries under normal circumstances, incoming nitrogen at $50^{\circ} \mathrm{F}$ from the gallery dehumidification system will be blown over the finned section. Both the kerosene coil and gas-cooled section of the block valves are designed for $1200^{\circ} \mathrm{F}$ sodium in the valve body; the moderator coolant valves are designed for $700^{\circ} \mathrm{F}$ sodium in the line. Either of these sections alone will be sufficient to establish a freeze seal around the stem.

Heat transfer design of the se freeze seals was based on a modified-fin development. This method has been reported by McDonald. ${ }^{11}$

The freeze seal of a spare 6-in. sodium block valve was modified, and the valve tested in the laboratory with $1000^{\circ} \mathrm{F}$ sodium flowing through the valve. The seal was maintained, during operation of the valve, with a 70-psi pressure difference across the seal. The seal was also successfully maintained in a 12-hour test without kerosene cooling. Ambient temperature around the seal was maintained at $150^{\circ} \mathrm{F}$ during the test.

The pumps of the plant service coolant system are normally driven by electric motors; pumping reliability is assured by the standby gasoline engine. The possibility of a leak in the coolant line serving a valve or a loss of coolant due to a leak elsewhere in the organic system exists. To prepare for the contingency of loss of the liquid-coolant flow, the kerosene-cooled region of the freeze seal will have a gas-cooled region as backup. The average gallery gas temperature is 125 to $150^{\circ} \mathrm{F}$. Since the exact gas temperature in the immediate vicinity of the valves is not known (it is likely higher than the average temperatures), $\operatorname{cool}\left(50^{\circ} \mathrm{F}\right)$ nitrogen returning from the dehumidification system will be ducted to each valve freeze seal toassure the integrity of the gas-cooled seal. The cool return gas will also maintain the seal during outages of moderate duration of the gallery kerosene coolant tubing. This modified valve freeze seal will provide for increased system reliability for the following reasons:

a) There are three barriers between the kerosene and the sodium, which will prevent any leakage of kerosene into the sodium system.

b) The gas-cooled section provides a backup in event of los s of kerosene cooling. 
The secondary block valves were removed from the system and thus did not require modification. Removal of these valves has been made possible by the disconnection of the main airblast heat exchanger, and the presence of four 8-in. bellows seal valves which were installed with the $C E$ steam generator. These four bellows seal valves will be sufficient to provide flow control and blockage for both the CE and the $B \& W$ steam generator.

A number of other methods for removing heat from these seals were considered during the investigation:

a) Forced- or free-convection NaK loops utilizing the existing coolant jacket on the valve stems, with NaK to water or kerosene heat exchangers located in the galleries, were evaluated. An individual loop for each valve would have been required to minimize NaK entry in the sodium. These would be rather complicated, expensive loops. It would have been very difficult to clean the existing cooling jacket thoroughly enough for safe use with NaK.

b) Free-convection gas cooling was selected as the optimum method for cooling valves in the secondary system, located outdoors, if modification of the se valves is ever required. However, in the galleries, local ambient temperatures are not predictable due to proximity to sodium piping. Local temperatures may exceed $180^{\circ} \mathrm{F}$ on rare occassions. This method was deemed unacceptable for the primary valves.

c) Forced-convection gas cooling with ducts directing $50^{\circ} \mathrm{F}$ nitrogen to each valve was considered as part of an expansion of the gallery dehumidification. It was proposed that the entire gallery-space cooling load as well as valve, cold-trap, and plugging-meter cooling be added to the duty of this system. In the expanded system there would have been three cooling units, only two of which would be required to handle the vital loads. Hence, there would be an "operating spare" unit for backup. This alternative was considered very attractive from a technical standpoint, but the proposal was dropped because it would require extensive redesign. 
d) Use of kerosene coils outside of the existing tetralin jacket was also considered. A laboratory test showed that a satisfactory seal could be maintained. However, there were certain disadvantages which caused rejection of this alternative. These were:

1) The test was performed with a clean jacket. Jackets on SRE valves might contain carbonaceous material that could not be removed. Jacket-to-helix-land contact resistance may have been higher than in the test valve. These factors would make the heat transfer impedance greater in the SRE valves and result in higher seal temperatures than observed in the test.

2) The existing yoke support bracket that is welded to the valve bonnet, would have to be removed for installation of the coolant tubing. No practical plan was formulated for the replacement of this bracket with the precision required for proper yoke alignment.

3) Installation work would be conducted close to the 6-in. pipe in a high radiation field $(\sim 2 \mathrm{r} / \mathrm{hr})$.

\section{Circulating Cold Traps}

The original cold traps provided for SRE sodium pruification were designed for boiling toluene cooling. These traps were replaced in 1958 with a trap cooled by circulating tetralin. ${ }^{12}$ Here again, only a single barrier separated the organic and sodium systems, so a modification was required.

Since this component could be easily designed for gas cooling, this method was selected. There remained the problem of rejecting the heat from the nitrogen gas in the cold-trap vault. Expansion of the gallery dehumidification system to handle the primary cold-trap heat load, as well as other loads listed in the section on valve freeze seal cooling, was considered. With this plan the gas-to-liquid heat exchanger for cold-trap heat rejection would be located outside the gallery in an accessible area. This arrangement would relieve congestion in the vault. While technically sound, this alternative was rejected because of the extensive alterations required. A nitrogen-to-kerosene heat exchanger has been installed in the sodium service vault to remove heat from the cold trap. 
Features of the new primary and main secondary cold traps are shown on Figure 3. The traps are similar to the type developed for the Hallam Nuclear Power Facility. Incoming sodium is cooled as it flows down the annulus. The annulus is packed with stainless mesh to provide sites for the crystallization of sodium oxide, and to filter out precipitated oxide. Sodium oxide crystallizes from the sodium stream when the temperature is lowered below the saturation (or "plugging") temperature. The lowest temperature is reached at the trap bottom; this temperature fixes the system oxygen concentration during steadystate operations. An economizer (sodium-sodium heat exchanger) is an integral part of the trap. Incoming sodium passes over the outside of the economizer tube. Since there is ample clearance around this tube, any oxide that may precipitate on the tube will not obstruct flow.

This trap can be vented during filling through a freeze trap. There is a possibility that gas may collect in the shell during operation. A 1/8-in.-diameter hole is provided in the economizer top to serve as a continuous vent. This hole may plug with oxide when the inlet sodium is saturated, but should be opened by solution when the system has been purified.

The traps are gas cooled: the main secondary trap with air, and the primary with gallery nitrogen. Longitudinal fins (160 fins, 1/8 by 1 by 69-1/4 in.) are mounted on the vessel to increase the heat transfer surface. Flow of gas is in at the bottom and out at top, countercurrent to the sodium in the annulus. A 7-1/2-hp blower is used to circulate air through the main secondary unit, as shown on the secondary-sodium-system P \& I diagram (Appendix A-2). Primarycold-trap cooling equipment arrangement is shown on the primary-sodium-system P \& I diagram (Appendix A-1). A 10-hp blower draws the gallery gas past the trap and through a nitrogen-to-kerosene heat exchanger. The damper on the blower discharge will be adjusted manually with a valve operator. Kerosene flow to the gas cooler will be controlled manually so that the blower discharge temperature will be $150^{\circ} \mathrm{F}$. Performance characteristics of the primary cold trap have been calculated and are shown in Table III. 


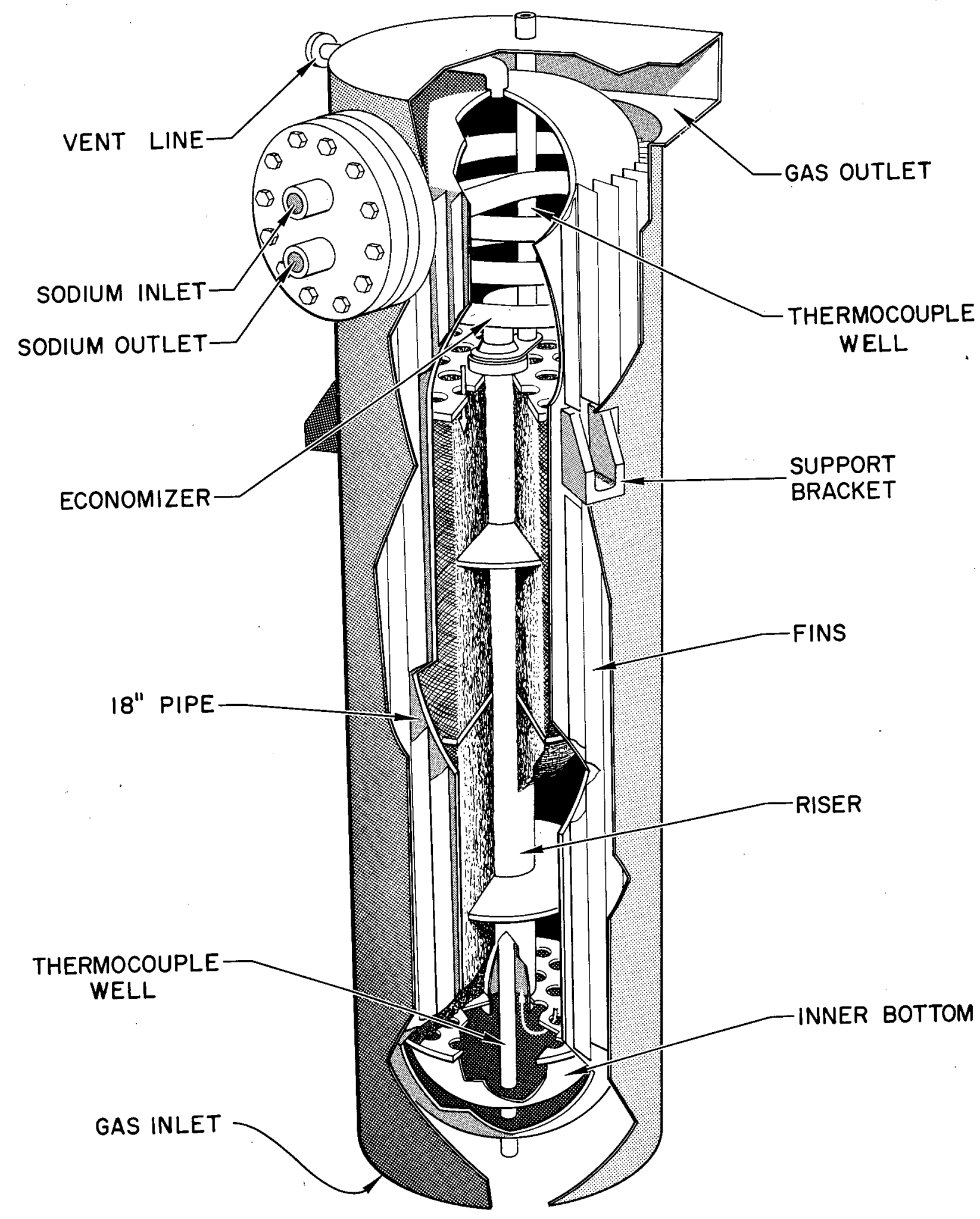

Figure 3. Circulating Cold Trap 
TABLE III

COLD-TRAP OPERATING PARAMETERS

\begin{tabular}{lrr}
\multicolumn{1}{c}{ Nitrogen } & $\begin{array}{r}\text { Low-Temperature } \\
\text { Cleanup }\end{array}$ & $\begin{array}{r}\text { Normal } \\
\text { Operation }\end{array}$ \\
\cline { 2 - 3 } Inlet Temperature $\left({ }^{\circ} \mathrm{F}\right)$ & 150 & 150 \\
Trap Outlet Temperature $\left({ }^{\circ} \mathrm{F}\right)$ & 257 & 302 \\
Gas Flow (cfm) & 1500 & 1500 \\
Cooling Load (Btu/hr) & 152,000 & 217,000 \\
Pressure Drop (in. water) & 11 & 11 \\
Duct Outlet Temperature $\left({ }^{\circ} \mathrm{F}\right)$ & 150 & 13.2 \\
\multicolumn{1}{c}{ Sodium } & & 500 \\
Flow, (gpm) & 26.1 & 386 \\
Inlet Temperature $\left({ }^{\circ} \mathrm{F}\right)$ & 350 & 290 \\
Outlet Temperature $\left({ }^{\circ} \mathrm{F}\right)$ & 305 & 10 \\
Trap Bottom Temperature $\left({ }^{\circ} \mathrm{F}\right)$ & 290 & 10 \\
Outlet Oxygen Concentration $(\mathrm{Ppm})$ & &
\end{tabular}

Conventional heat transfer calculation methods were used in the design. The trapvessel is 18-in. pipe, 78 in. long. This vessel was designed to meet the requirements of the ASME Code. ${ }^{13}$ It is made of carbon steel. This imposes a temperature limitation of $700^{\circ} \mathrm{F}$ on the trap. At higher temperatures, the transfer rate of carbon from carbon steel through the sodium to 18-8 stainless steel becomes significant.

Organic cooling has been removed completely from the cold traps. In addition, the results of the HNPF development program ${ }^{14}$ have demonstrated that the internal design changes will improve the capacity and effectiveness of the trap.

Alternate cooling methods were considered during conceptual design. Use of a NaK system was discussed; the complexity of a NaK system was not warranted for this application. A kerosene coil around the trap vessel, with $\mathrm{NaK}$ as the third fluid in a jacket around the coil, was also considered. Detection of leakage both into and out of the NaK jacket presented some reliability 
problems. However, the plan was rejected on safety considerations. In two cases where static $\mathrm{NaK}$ had been held for an extended period, explosions occurred during disassembly and cleaning. Potassium superoxide was suspected as the cause of the explosion at Allis-Chalmers. At Argonne National Laboratory an explosion also occurred when a $\mathrm{NaK}$ vessel was being cleaned. It was suspected that foreign organic material in the vessel contributed to the explosion. The plan under consideration here called for a static NaK system, with the possibility of organic inleakage, a situation similar to those which had resulted in explosions during cleaning. Therefore, this alternative was rejected.

\section{Plugging Meters}

Sodium plugging meters, used to determine oxygen concentration in sodium, were formerly tetralin cooled, with only a single wall between organic and liquid metal. The basic plugging-meter loop has not been changed; it is shown on the primary-sodium-system P \& I diagram (Appendix A-1). A gascooled heat exchanger has been provided, with accompanying blower and control damper. The heat exchanger is a 2 -in., schedule 40 pipe, 24 in. long; it has 32 longitudinal fins, $0.050 \mathrm{in.}$ by $3 / 4 \mathrm{in}$. Air will be used in the secondary units, nitrogen in the primary. Operating parameters are:

Gas Inlet Temperature

Primary $\left({ }^{\circ} \mathrm{F}\right)$

Secondary

Gas Flowrate (cfm)

Plugging Valve Minimum

Temperature $\left({ }^{\circ} \mathbf{F}\right)$
150

ambient

150

250

\section{Hot Traps}

The original hot-trap vessels were a permanent part of the piping

system. A cartridge containing the gettering material was suspended from a blind flange at the top of the vessel. A tetralin-cooled freeze section was located just below the ring joint flange to prevent any leakage. Experience with sodium components containing inserts has proven the insert removal operation to be difficult because of the possible spread of radioactive contamination. Special handling equipment, containing an inert atmosphere and gastight gates, would be required. 
In the new hot traps (Figure 4) the freeze seal section and removable cartridge feature have been eliminated. When the gettering charge is spent, the inlet and outlet lines will be cut (both are located at top of trap), and the whole unit removed for disposal. The equipment is designed so that a vessel can be removed without personnel entry to the vault. Operational experience has demonstrated that a primary-sodium-system component of the unitized type can be removed and replaced with an entire new unit in about half the time required to replace an insert. Manufacturing costs for the new vessels are about the same as for the inserts in the old traps.

The new traps will contain stainless steel strip as the gettering agent to extract carbon from the sodium stream. Type 304 stainless steel is the charge in the first trap. Information on the equilibrium distribution of carbon between Type 304 steel and sodium, ${ }^{15}$ and data on the carburization of a Type 304 pipe specimen removed from the hot trap piping at the beginning of the modification period, indicate that this gettering material will extract approximately 5 lb carbon per $500 \mathrm{lb}$ charge. Ninety percent of the equilibrium quantity of carbon will diffuse into the steel in $100 \mathrm{hr}$. Type 410 stainless steel, containing $12 \%$ chromium, will be used in subsequent traps. The Type 410 steel will have about $1 / 3$ greater capability for carbon removal than the Type 304 steel.

A detail of the gettering coil is shown on Figure 4. The corrugations are the same that were used in the earlier zirconium traps. ${ }^{12}$ Stainless steel specimens will be mounted both in the inlet pipe to the trap and in the dome of the vessel. Analysis of the tabs will permit evaluation of trap operation.

The trap will be operated at $1300^{\circ} \mathrm{F}$. Sodium flowrate will be $10 \mathrm{gpm}$.

5. Top Shield Cooling

Reactor biological shielding can be divided into two separate sections:

a) Portion outside the containment vessel

b). Top shield, located directly above the reactor.

The coolant circuits outside the containment vessel are the core cavity, auxiliary cavity nozzle, main cavity nozzle, and instrument thimble circuits. The coolant for these circuits flows through tubing welded to the outside of the 


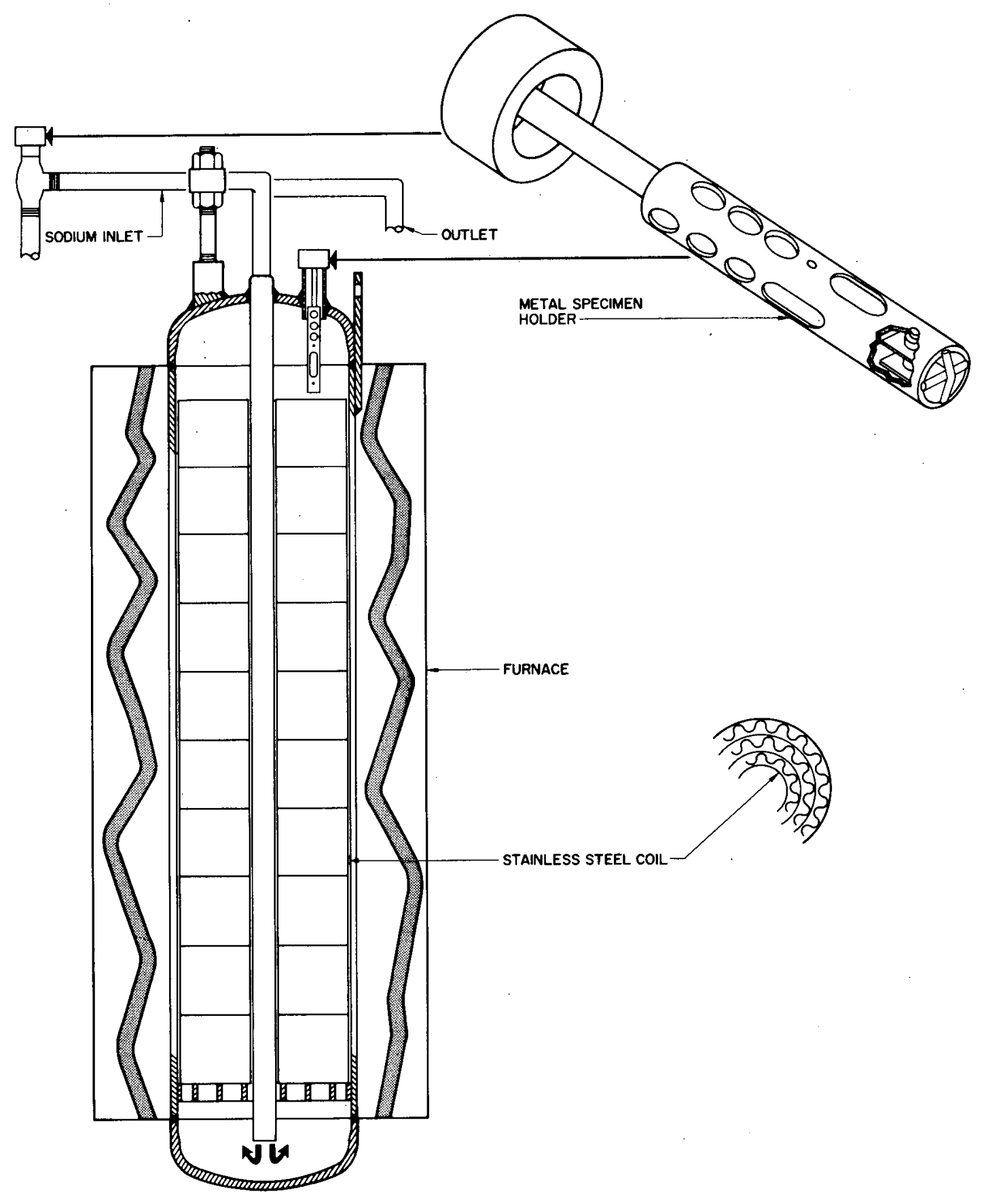

Figure 4. Hot Trap 
cavity liner. It is separated from the primary sodium system by the tubing wall, cavity liner, outer tank, and core tank. These barriers will prevent leakage into the sodium; the circuits remain unchanged, and will be served by the large kerosene system. These circuits are shown on the kerosene services $P$ \& I diagram (Appendix A-6).

The top shield cooling circuits are at the base of the concrete in the ring shield, and top shield plugs (140-in.,40-in., and 20-in. plugs). The cooling tubes are isolated from the reactor by the stainless steel plug bottom plate, providing double containment of the coolant.

Since the coolant is doubly contained, kerosene can be employed. A limited-volume system has been installed, with a positive means for detecting leakage. The nine circuits in the top shield (see Appendix A-6) are connected to a small independent system composed of a surge tank, pump, strainer, heat exchanger, valves, and piping. Kerosene coolant circulates through the nine circuits where it removes heat from the shielding and is then returned to the surge tank. Kerosene flows from the tank through the strainer and into the suction side of the $3 / 4-h p$ canned rotor pump. From the pump the coolant passes through the $82-1 / 2 \mathrm{ft}^{2}$ shell-and-tube heat exchanger where heat is transferred to the large kerosene coolant system.

A small 12.5-gal surge tank is required to allow for coolant expansion and provides a free surface for level detection. A gauge glass is provided on the side of the tank for visual indication of level. A level alarm is mounted on the tank to indicate a leakage of coolant. The level alarm is not temperature compensating and, therefore, it is set at a level corresponding to $60^{\circ} \mathrm{F}$. The alarm will sound in the control room.

Jumper lines are provided to connect the limited-volume top-shield loop to the large organic-coolant system. A quick disconnect is provided for the coupling and the jumper is flexible. The jumper will normally be disconnected so that a possible valve leak cannot change the fixed volume of the top shield loop. The jumper will be employed only in the event of a pump outage. The thermal capacity of the top shield is large; consequently the rate of temperature increase is slow $\left(3^{\circ} \mathrm{F} / \mathrm{hr}\right)$ if the service coolant is shut off. There is ample time to make the temporary connection in the event of a pump outage before the shield temperature would rise more than a few degrees. 
Operating parameters of the top shield cooling system are in Table IV. TAB LE IV

LIMITED-VOLUME KEROSENE SYSTEM PARAMETERS

Approx. Coolant Volume at $70^{\circ} \mathrm{F}$ (gal) 90

Design Flowrate (gpm) 20

Design Heat Load (Btu/hr) 41,320

Normal Coolant Temperature Range $\left({ }^{\circ} \mathrm{F}\right) \quad 70$ ( $\left.\mathrm{min}.\right)$

110 (max.)

Leakage at $70^{\circ} \mathrm{F}$, before alarm (gal) 0.9

Leakage at $110^{\circ} \mathrm{F}$, before alarm (gal) 3.2

Other cooling methods were evaluated for the top shield circuits. Investigation of gas cooling demonstrated that with sufficient flow, nitrogen entering at room temperature could meet the heat transfer requirements. However, the studies indicated that with the small size tubing cast in the plugs (3/8-, 1/2-, 3/4-, and $1-i n$. sizes are used in various plugs) the system would require an average pressure of $70 \mathrm{psi}$ and a total flowrate of $1270 \mathrm{cfm}$ with a $70^{\circ} \mathrm{F}$ temperature increase. The blower power required exceeded $350 \mathrm{hp}$. The high pumping power, bulky blower and heat rejection equipment, and the possibility of a high-pressure gas leak in the top shield caused this alternative to be discarded.

Water and NaK cooling was eliminated because of some aluminum tubing in the circuits, mechanical couplings, and tubing braze materials in use. Neither the materials of construction nor the method used for joining tubing were suitable for $\mathrm{NaK}$ or water service.

6. Sodium Pumps

a. Introduction

Sodium circulating pumps were provided with three separate organic-cooled circuits. These circuits were the shaft freeze seal, the case freeze seal, and the bearing housing. The pumps have been established as a source of tetralin leakage into the sodium system. ${ }^{l}$ The two circuits which have been found to be vulnerable are the shaft freeze seal and the bearing housing. Because these components were a source of contamination to the sodium sys tems, the units were modified and a new cooling fluid was used. Alternate 
\{

$\pi$

$\pi$

1

a

1

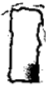

1

7

1

.

1

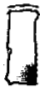

$\pi$

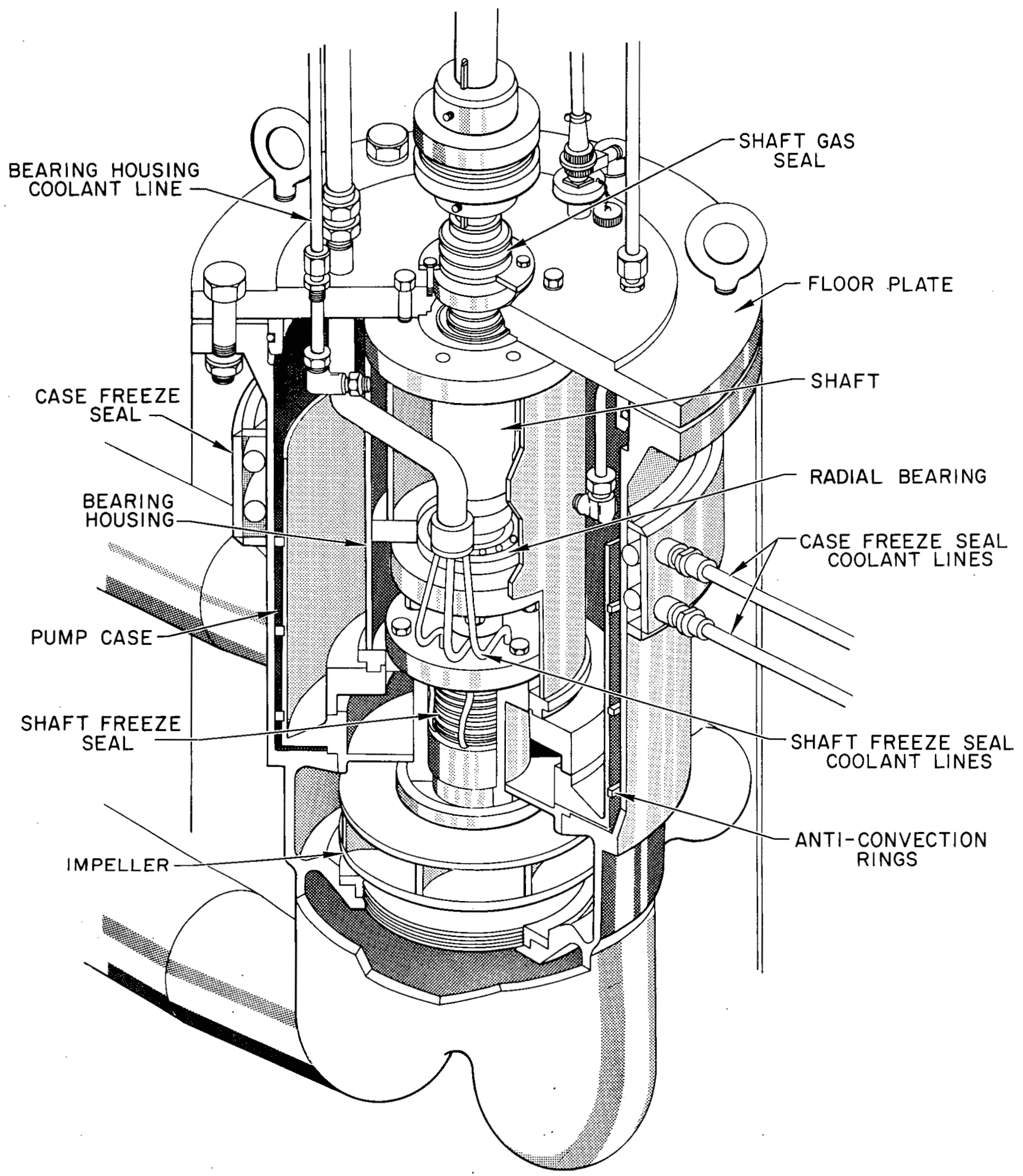

Figure 5. Main Secondary Sodium Pump 
methods were investigated to cool the pumps, and because of the relatively high heat flux and limited space available within the pump casing, NaK was chosen as the cooling medium.

\section{b. Pump Modifications}

The original pumps were supplied with a bearing housing of cast iron. It was designed with a cooling annulus in which tetralin was circulated. Cracking was observed under the bolt hole in the top of the housing on one of the pumps. Because these housings were castings, they were treated with a sealant in order to reduce the porosity of the material. Tetralin, being a solvent, dissolved this sealant and increased the porosity to its original magnitude. Although it has not been definitely established, the possibility of tetralin seeping through the body has existed.

New bearing housings have been fabricated from steel pipe and plate in approximately the same configuration. The cooling annulus is composed of two concentric pipes. These pipe sections are welded at each end to thick steel plates. The plates have been machined in the center to form the bearing surfaces. This configuration is illustrated in Figure 5.

Several designs of shaft freeze seal have been used at the SRE. One of the original designs called for a thermocouple to go through the seal wall and be terminated at the inside wall of the seal. During a previous modification, the thermocouple hole was welded closed. These thermocouples were relocated because the geometry of the seal, and the fabrication led to a high stress concentration at the end of the thermocouple well. This part of the seal was exposed to sodium and the rotating shaft. A tetralin leak occurred at the plugged end of the thermocouple well when the weld failed. This failure was probably due to friction, thermal stress, or a combination of these causes. This weakness in the shaft seal has been eliminated with the latest design.

The new seal is of the single-region, coil type. It has greater heat transfer area than the original annular type. In addition the coils are separated from the shaft by a 1/8-in. -thick sleeve with holes drilled in a staggered pattern to retain rigidity. This type of seal was used on the main primary pump during the last power run with excellent results. 


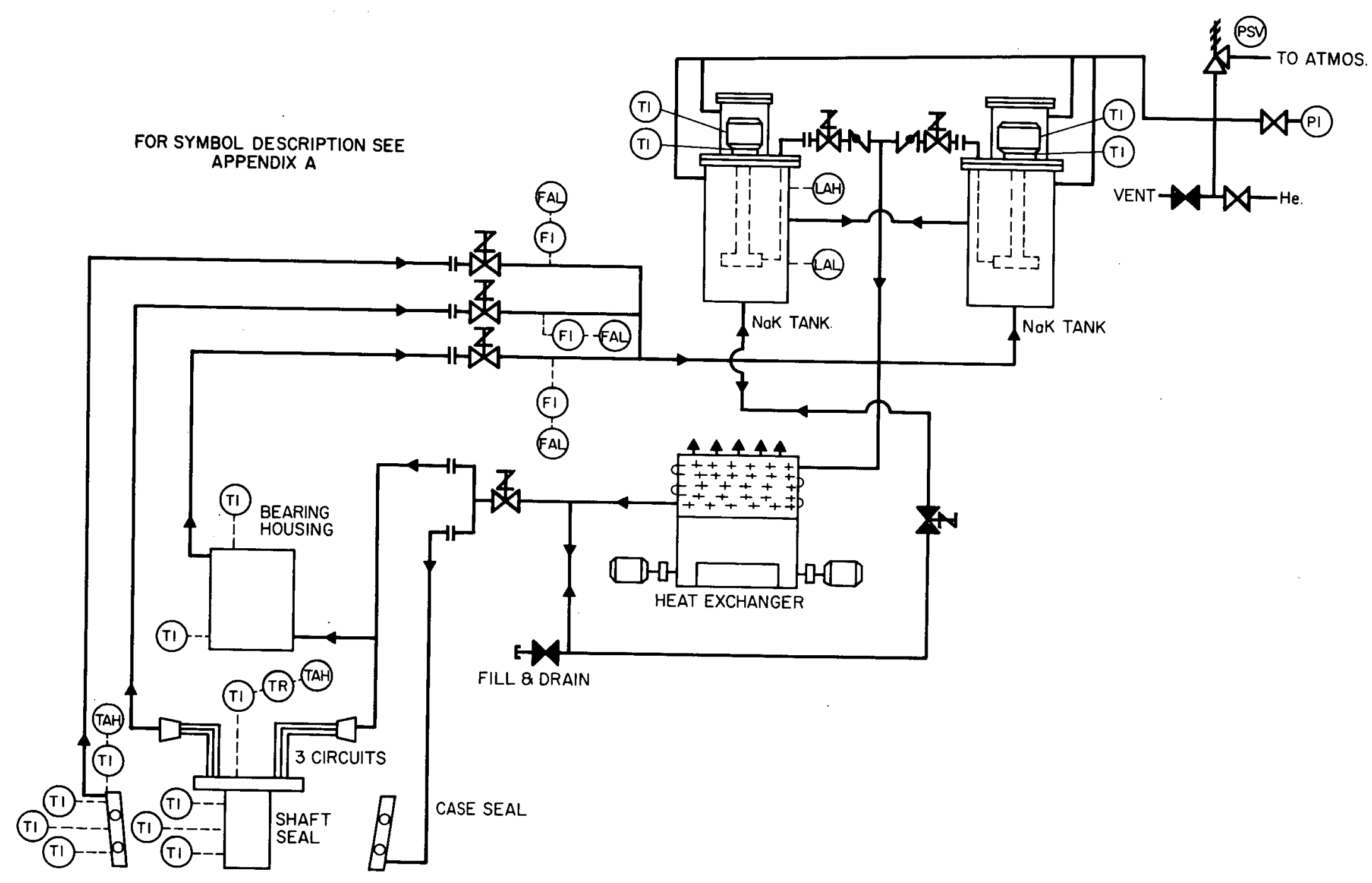

Figure 6. Pump-Coolant-System Process and Instrumentation Diagram 


\section{c. NaK Cooling System}

The NaK cooling system is described in the following paragraphs:

(1) Physical

Each of the four sodium pumps is serviced by a separate $\mathrm{NaK}$ system. All four systems are identical. A typical process diagram can be found in Figure 6. The system consists of the following main components:
a) Two expansion tanks
b) Two immersion pumps
c) Airblast heat exchanger with two motors
d) Sodium-pump shaft seal
e) Sodium-pump bearing housing
f) Sodium-pump case seal.

Sodium pump components are, of course, located within the pump case. All other components will be housed in a NaK panel located near the sodium pump.

Expansion tanks are made of standard-size pipe, cap, and flanges. The motor is canned in a smaller vessel which is flanged at the top for removal of the motor. The expansion tank is provided with a level probe, helium supply, and vent outlet. The two tanks are provided with an interconnecting level equalizing line. The discharge line of each pump is provided with a check valve and a shutoff valve. The motor cans are also provided with a helium supply and vent outlet.

The two NaK pumps are immersion-type, centrifugal pumps driven by a 1 -hp motor and will deliver $15 \mathrm{gpm}$ against a $35-\mathrm{ft}$ head. The shaft is provided with a labyrinth-type seal and a slinger. The bearing grease has been replaced with a high-temperature grease. Although the bearings were sealed to preclude the possibility of having the grease flow out of the bearing when the motor temperature increased, a more viscous grease was substituted. There are two bearings in the vertically mounted motor. There is no bearing on the pump end of the common shaft. 
The heat exchanger is an air-cooled unit consisting of $30 \mathrm{ft}$ of finned tubing. It is cooled by a centrifugal blower delivering air at $2700 \mathrm{cfm}$. The blower, delivering air vertically upward, is powered by one of the two 3/4-hp motors. Each motor is connected to the blower through a centrifugal clutch coupling. An air foil is installed in the air duct on top of the louvers to provide a loss -of-airflow alarm. The louvers are provided with a manual oper ator handle which can be reached through the door on the left, central part of the panel.

The shaft seal consists of three parallel coils of 5/16-in. tubing wrapped approximately threeturns around the seal sleeve. There is no coolant channel in the top flange. The bearing housing(described previously) is supplied with an inlet on the bottom and an outlet on the top. The case seal is the same as used previously. The original lines to the seal have been removed, and stainless steel lines have been installed.

There are two lines feeding cool NaK to the sodium pump. One line goes to the case seal and one line through the pump floor plate to the bearing housing and shaft seal. A reducer is placed just above the shaft seal. From this, three parallel tubes go through the top flange and are expanded into a single line again. The outlet from the bearing housing is an individual return. In the secondary area the case seal lines go directly to the connections on the pump case. In the primary system they go through seal boxes in the high bay floor to the pump case. The outlet lines from the shaft seal, bearing housing, and case seal are all individual returns. These lines are flanged just outside the NaK panel. Inside the panel there is a valve in each line. After passing through the valve the three lines join into a single feed line to the expansion tanks. From the expansion tanks the $\mathrm{NaK}$ is pumped through the heat exchanger to the seals. A fill-and-drain line is located in the lower section of the NaK panel. The line drains from two locations: the bottom of the expansion tanks and from the line just downstream of the heat exchanger. A valve is placed in this line to prevent bypassing.

\section{(2) Electrical}

All four motors of each system are fed from the 440-volt emergency bus. Individual starters and breakers for each motor are mounted in an 
enclosure within their respective panels. This enclosure is mounted behind a hinged door in the lower righthand corner of the panel. There is one main breaker in the electrical equipment room to feed each NaK system.

On the instrument board two lights are mounted which, when lighted, will indicate that the 480 -volt motor power and the 120 -volt instrument power are on: These lights are just below the Panalarm unit on the top of the instrument board.

On the lower part of the instrument board are three selector switches. The left switch is a three-position switch to control the two blower motors. The central position is the "OFF" position for both motors. The middle switch is the NaK pump "OFF" and "ON" switch. The right switch selects either of the two pumps as the lead running pump.

\section{(3) Instrumentation}

Instrumentation on the system consists of thermocouples, flowmeters, low-flow alarms, pressure indicators, low-level alarm, high-temperature alarm, and a pressure switch.

Four alarms will be displayed on the control room annunciator, one for each pump cooling system. Each alarm indicates an abnormal condition on one of the NaK loops. The particular abnormality will be indicated on the individual $\mathrm{NaK}$ system panel. A Panalarm unit on each $\mathrm{NaK}$ panel will indicate the following abnormalities:
a) Low NaK flow
b) Low air flow
c) Low NaK level
d) Standby pump running.

The instrument board can be seen on the NaK panel in Figure 7. The sodium pumps have the following number of thermocouples:
a) Shaft seal
4
b) Case seal
3
c) Bearing housing
2. 


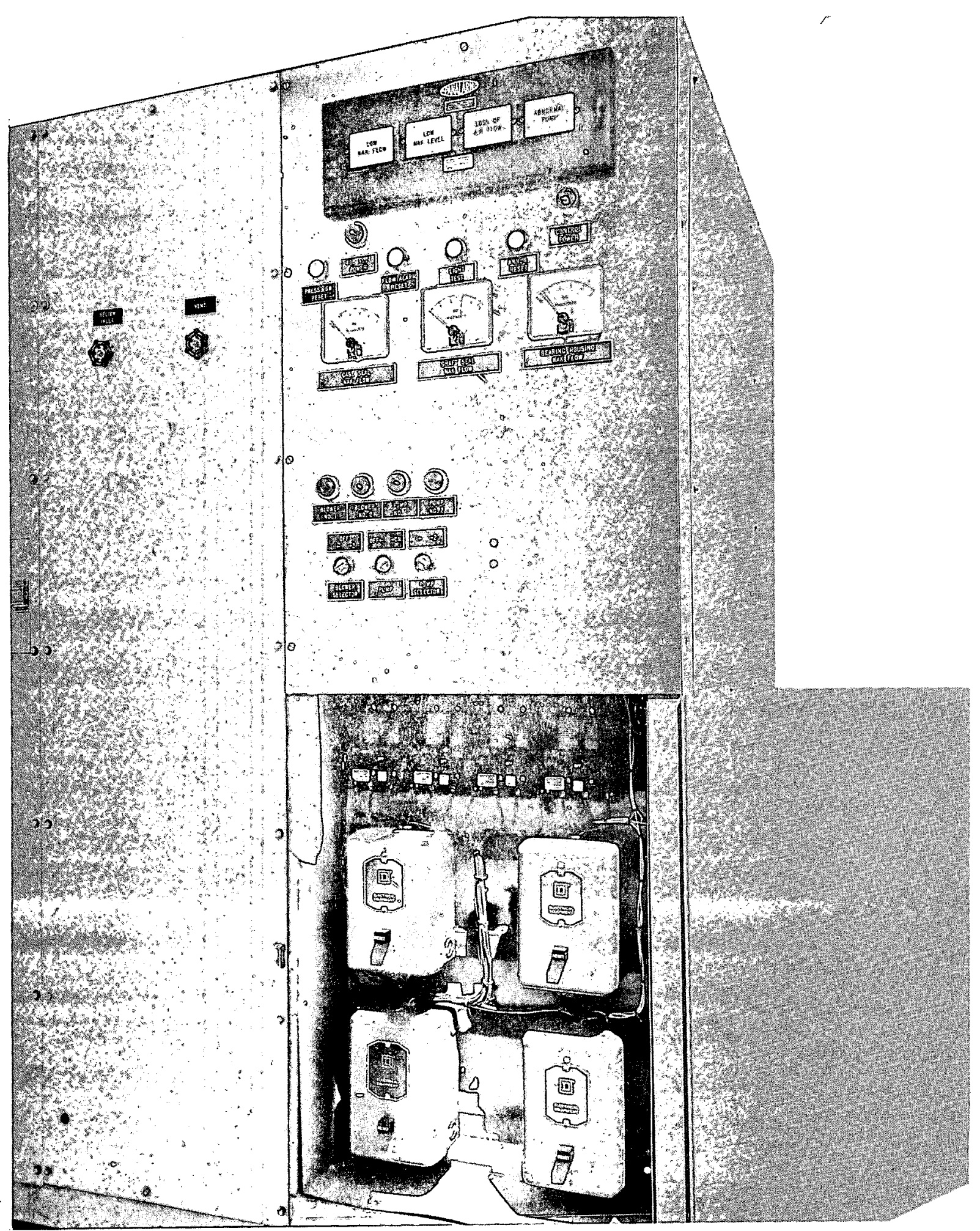

Figure 7. NaK Panel, Pump Coolant System 
A selected thermocouple on each of the freeze seals is recorded in the control room and is provided with a high-temperature alarm.

A flowmeter is located in each of the three return lines from the sodium pump. These are connected to individual flow indicators mounted on the instrument board.

The system is provided with a pressure switch mounted on the discharge side of the NaK pumps. Automatic switchover from one pump to the other is provided by this switch when the running pump fails. An alarm will sound in the control room if a switchover takes place.

Should the flow of air across the heat exchanger diminish for any reason, an alarm will sound. It is necessary manually to switch over to the other blower motor.

Helium atmosphere is supplied from a new helium station with regulating and relief valves. A pressure indicator is mounted on the NaK panel for convenience of observation.

The primary pump NaK system, main and auxiliary, will each contain a total of $145 \mathrm{lb}$ of NaK. Should a failure occur in such a way as to allow the entire volume of any one of the $\mathrm{NaK}$ systems to pass into the sodium system, it would add $2200 \mathrm{ppm}$ potassium to the sodium. The amount of potassium would increase the absorption cross section of the sodium by only $0.37 \%$ which will have a very slight effect on reactivity.

The NaK systems are pressurized with helium to $3.5 \mathrm{psig}$. This pressure, plus the static head pressure of 4.5 psi, gives a total pressure on the seal of the main pumps of 8 psi. Results of a series of tests run on the main pump to determine seal pressure as a function of discharge pressure, show that the maximum pressure on the bottom of the shaft seal will be 7.5 psi. This pressure differential will prevent sodium from entering the NaK loop in case of a failure of the shaft seal tubes.

- The case freeze seal is so located on the pump case that the level of frozen sodium is below the level of the cooling annulus. Should the case wall, which is $1 / 2$ in. thick at the seal section, fail, the frozen sodium itself will act as a plug to prevent sodium from entering the NaK system. 
Should a failure occur in the tubing within the sodium pump case, it will allow NaK to pour into the pump case. It will be possible to remove this through a pumpout tube extending the length of the pump into the bottom of the bucket. This line is valved off outside the top plate of the pump.

During the last reactor power run, an experimental NaK system similar to that described herein, was used on the main primary pump shaft freeze seal with excellent results.

\section{Materials Evaluation Facility}

This facility was provided to obtain sodium samples and to expose metallic samples to the hot and cold leg sodium in the primary system. The freeze seal was tetralin cooled and would have required modification. There were operational problems. For example, it was possible to get gas leakage into the suction of the main primary pump if an improper seal had been cast in the thimble freeze seals. The gas leakage causéd flow variations. To provide simplification of the main heat transfer system, it was decided to remove the materials evaluation facility.

It will be replaced with two separate components. An in-core sodium sampler will provide a means of obtaining a sample of primary sodium while the reactor is operating. A materials exposure facility also will be provided within the reactor to expose metal samples to primary sodium for chemical and metallographic tests.

\section{a. Core Sodium Sampler}

The core sodium sampler consists of a 3/4-in.-diameter by 12 -in. cup (75 ml capacity) attached to a shaft. The cup, shaft, as seals, and shield cylinders are mounted in a plug located in the top shield of the reactor. Figure 8 shows the device both in the sampling and in the decay position. The cup will be held in the top shield for 10 days to permit the decay of $\mathrm{Na}^{24}$. Figure 9 shows the cup being pulled by the extension rod into a lock for removal from the reactor face. 


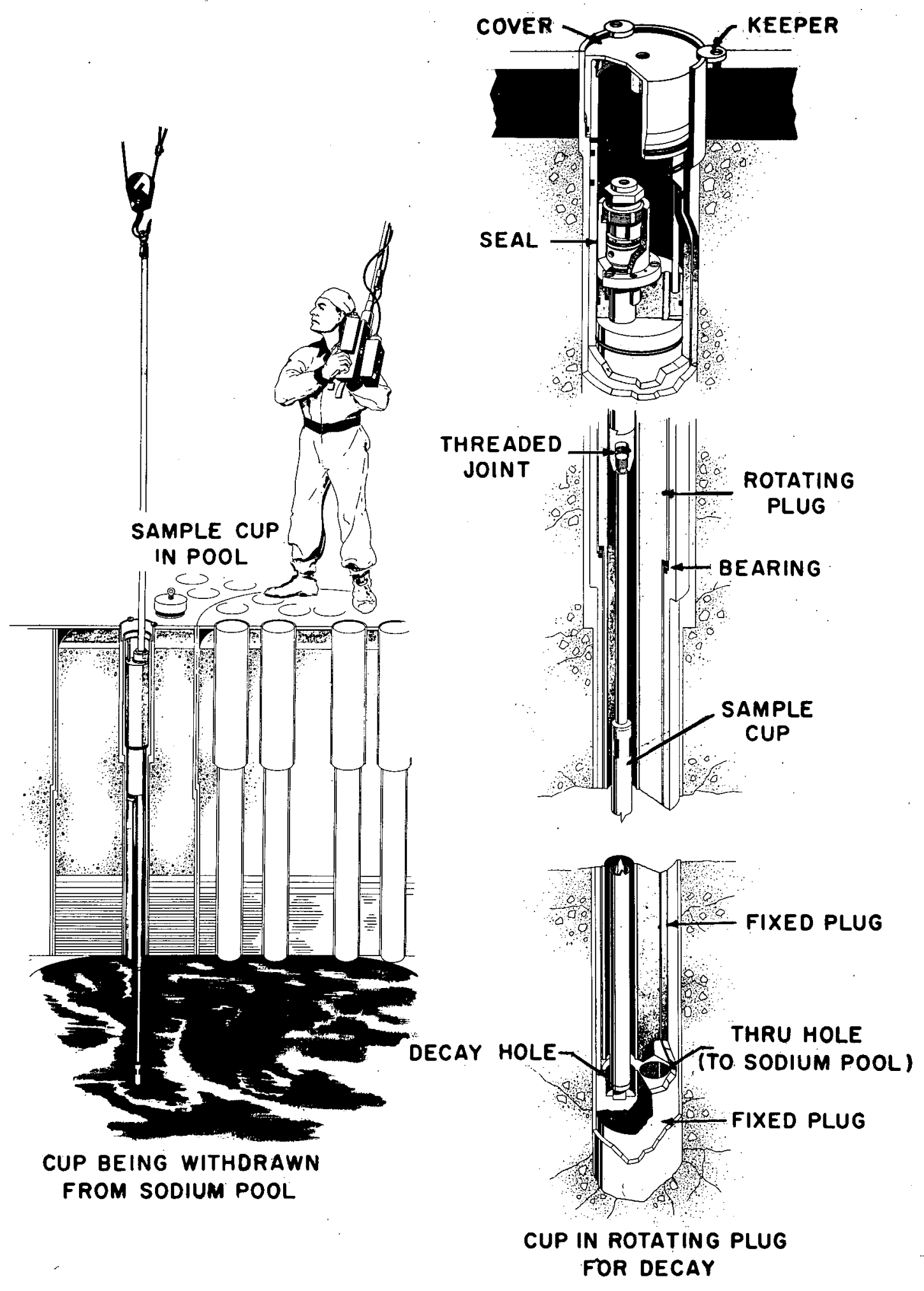

Figure 8. Core Sodium Sampler 
Should a failure occur in the tubing within the sodium pump case, it will allow NaK to pour into the pump case. It will be possible to remove this through a pumpout tube extending the length of the pump into the bottom of the bucket. This line is valved off outside the top plate of the pump.

During the last reactor power run, an experimental NaK system similar to that described herein, was used on the main primary pump shaft freeze seal with excellent results.

7. Materials Evaluation Facility

This facility was provided to obtain sodium samples and to expose metallic samples to the hot and cold leg sodium in the primary system. The freeze seal was tetralin cooled and would have required modification. There were operational problems. For example, it was possible to get gas leakage into the suction of the main primary pump if an improper seal had been cast in the thimble freeze seals. The gas leakage caused flow variations. To provide simplification of the main heat transfer system, it was decided to remove the materials evaluation facility.

It will be replaced with two separate components. An in-core sodium sampler will provide a means of obtaining a sample of primary sodium while the reactor is operating. A materials exposure facility also will be provided within the reactor to expose metal samples to primary sodium for chemical and metallographic tests.

\section{a. Core Sodium Sampler}

The core sodium sampler consists of a 3/4-in.-diameter by 12 -in. cup (75 ml capacity) attached to a shaft. The cup, shaft, as seals, and shield cylinders are mounted in a plug located in the top shield of the reactor. Figure 8 shows the device both in the sampling and in the decay position. The cup will be held in the top shield for 10 days to permit the decay of $\mathrm{Na}^{24}$. Figure 9 shows the cup being pulled by the extension rod into a lock for removal from the reactor face. 


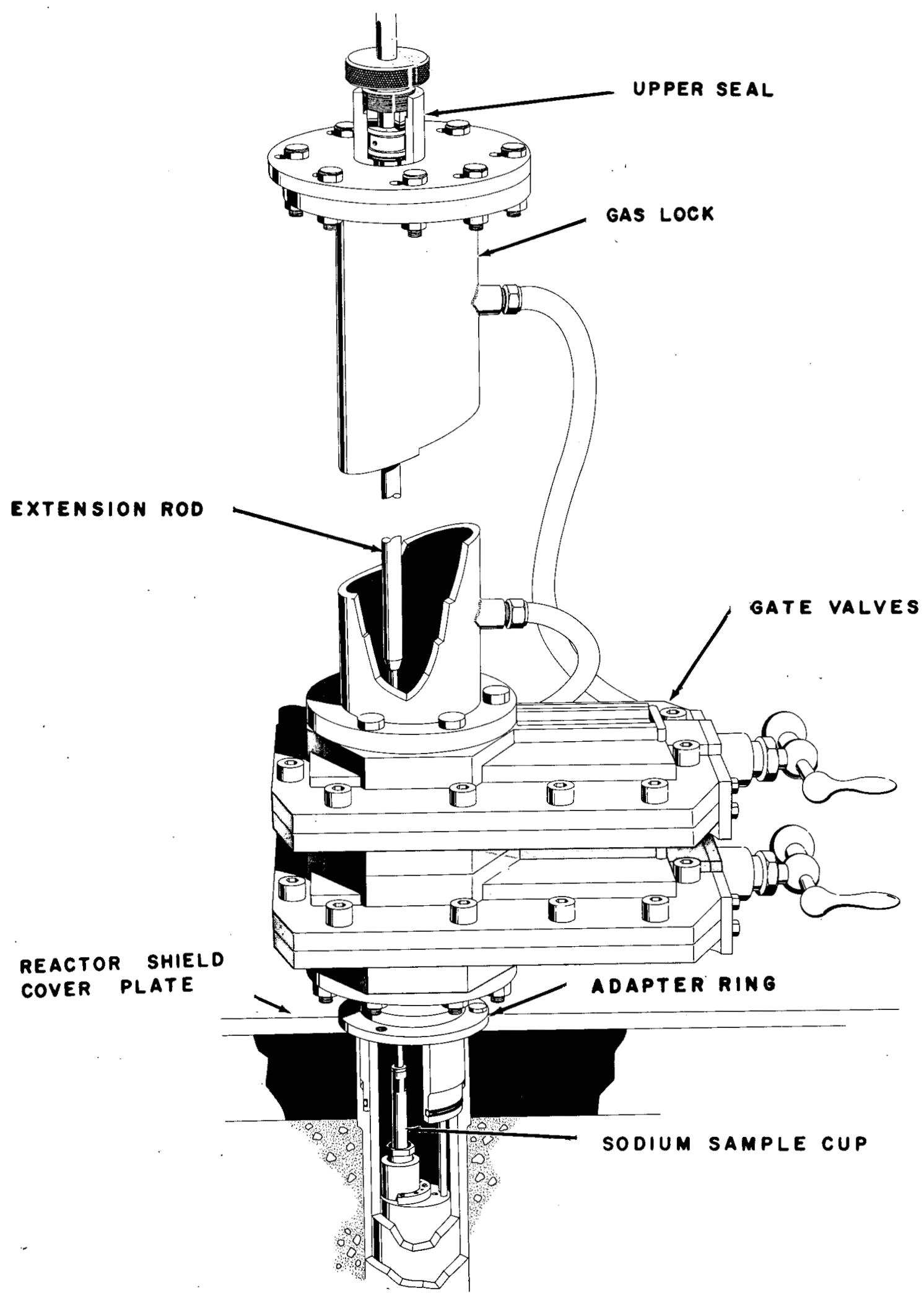

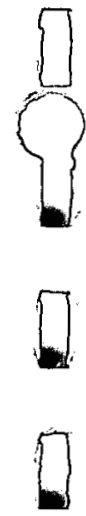

Figure 9. Sodium Sample Gas Lock 


\section{b. Materials Exposure Facility}

The materials exposure facilities will also utilize plugs in the reactor top shield. A basket suspended below one plug will hold up to forty $1 / 2$-in. by $2-1 / 2$-in. samples. These long-term-exposure samples will be removed only when the reactor is shut down. Two carburization specimens will be suspended below another plug, with provision for removal while the reactor is operating. This unit will be similar to the core sodium sampler. 


\section{SODIUM SYSTEM CHANGES}

\section{A. MODERATOR COOLANT EDUCTOR}

Normal cooling for moderator cans in the SRE is through a bypass line which provides approximately $10 \%$ of full reactor flow to the moderator coolant plenum. The flow diagram (Figure 10) shows schematically the main loop flow and the moderator coolant flow. In the past, there had been enough leakage through the

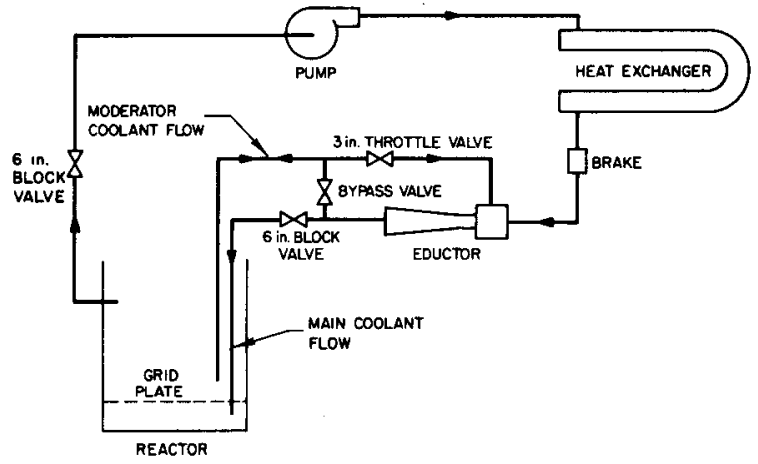

Figure 10. Simplified Flow Diagram, Main Primary Sodium System

grid plate to more than satisfy the cooling requirements of the moderator cans. In order to remove the excess coolant, an electromagnetic pump was installed in the bypass line to pump sodium from the moderator plenum back into the reactor inlet line. This pumpoperated satisfactorily during several power runs but ultimately developed a sodium leak in one of the throat sections. A design study was undertaken to determine if an eductor, or jet pump, could be used to satisfy this pumping requirement.

A 6-in. eductor was designed in accordance with standard practice 16 Construction is simple, with no moving parts and no electrical connections. A . cross section is shown on Figure 11. Except for the diffuser, it was made from standard-size pipe and reducers. The diffuser section was machined from bar stock. In order to minimize pressure drop through the nozzle and diffuser section, the inside surface was polished. Standard 6-in. and 8-in. pipes made up the suction end. These are welded to standard reducers to form into the throat section. 


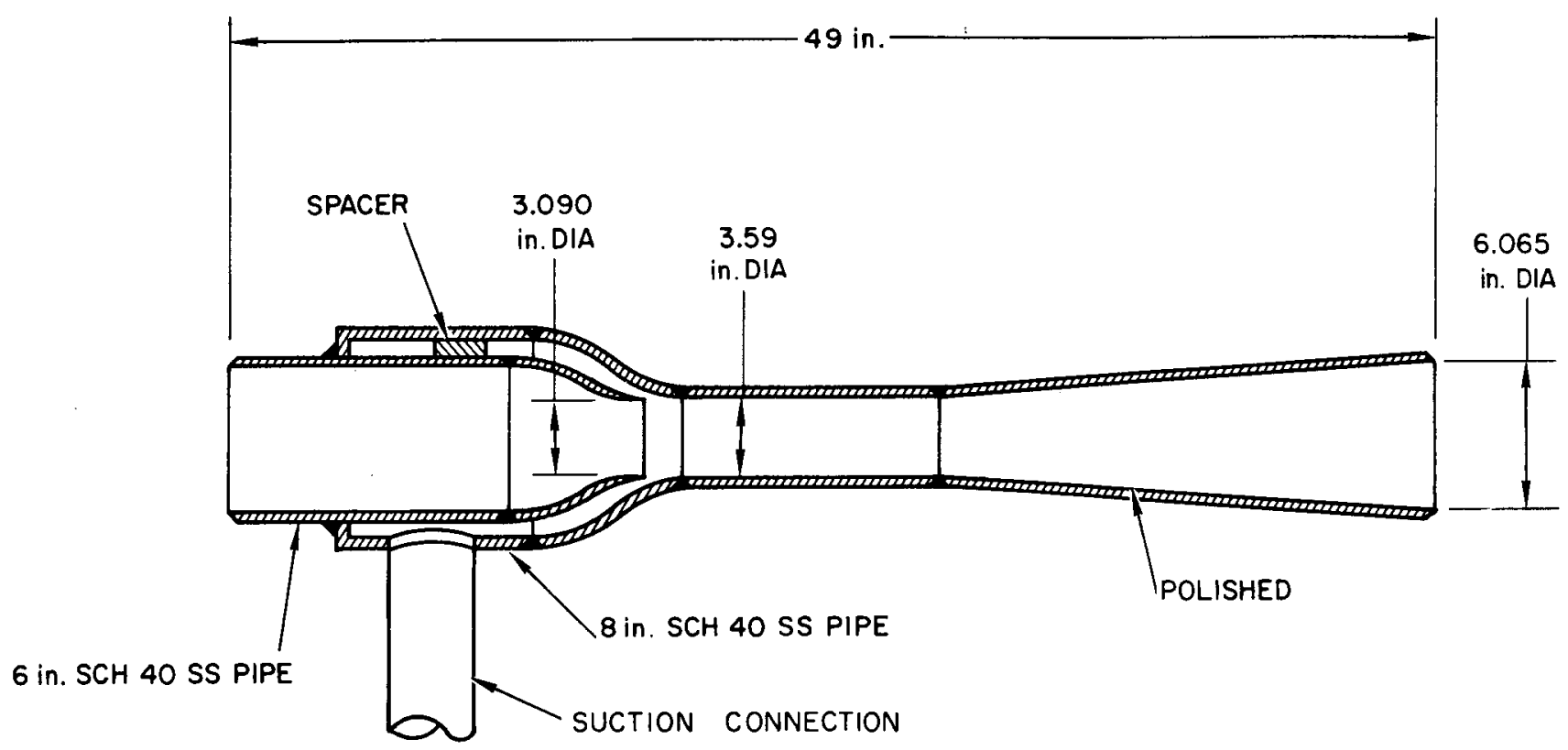

Figure 11. Moderator Coolant Eductor

The eductor was installed in a water test loop. Table V compares the design requirements to actual capability of the eductor as determined in the test. Test conditions were 1450 gpm driving flow through the eductor at a discharge pressure of 8 psi.

\section{TABLE V}

EDUCTOR REQUIREMENTS AND PERFORMANCE

\begin{tabular}{l|c|c}
\hline \hline & $\begin{array}{c}\text { Design } \\
\text { Requirements }\end{array}$ & $\begin{array}{c}\text { Actual } \\
\text { Capability }\end{array}$ \\
\hline $\begin{array}{l}\text { Suction Flow (gpm) } \\
\text { Suction-Line Pressure } \\
\text { Drop (psi) } \\
\begin{array}{c}\text { Eductor Pressure Drop } \\
\text { (psi) }\end{array}\end{array}$ & 100 & 160 \\
\hline
\end{tabular}

Figure 12 is a plot of pressure drop across the eductor versus drive flow at zero suction flow, and a plot of pressure drop and suction flow versus drive flow for a typical test run. These curves show the increased pressure differential and resulting suction flow with increased driving flow. All test data have been converted to the equivalent for sodium flow. 


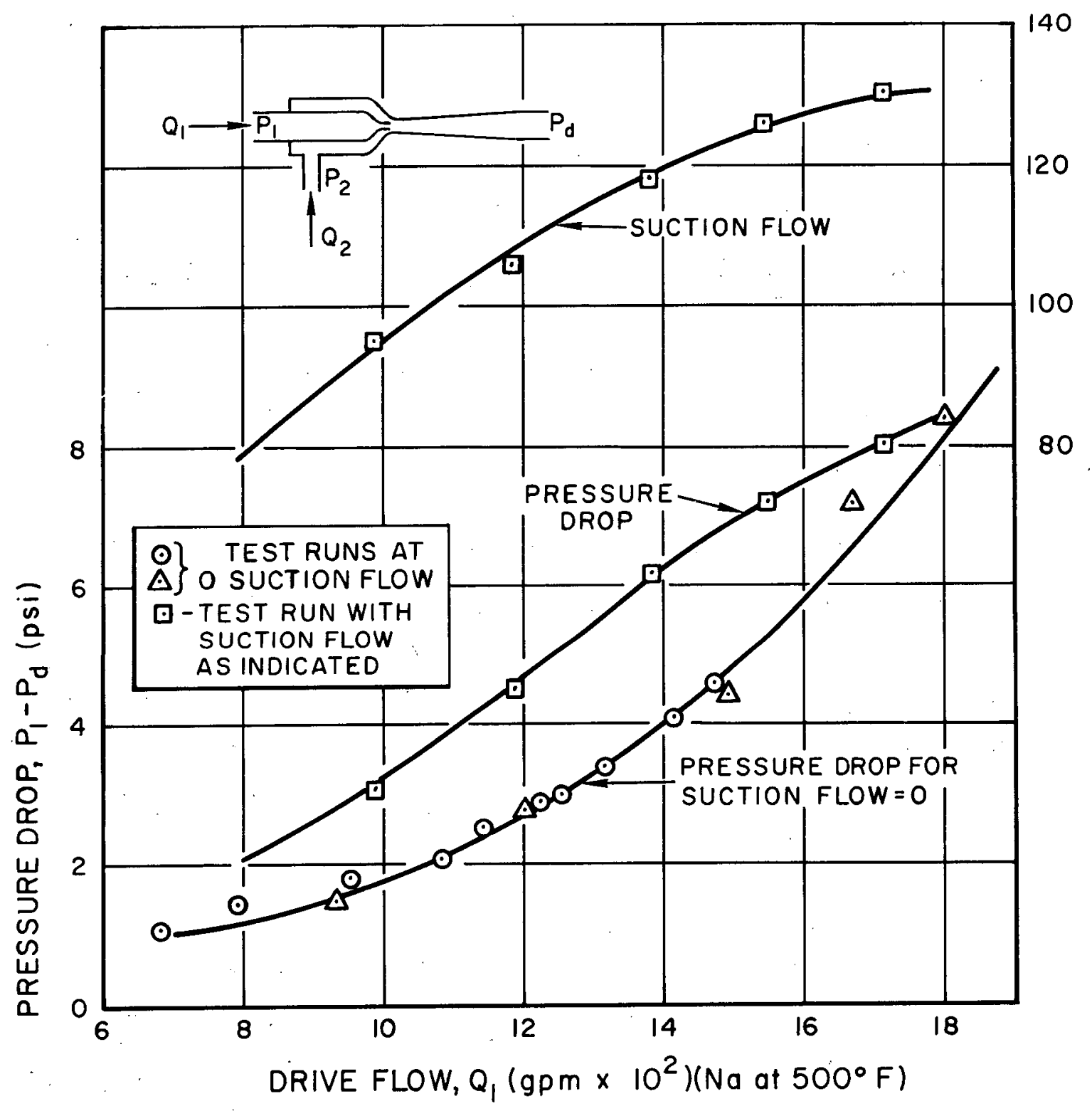

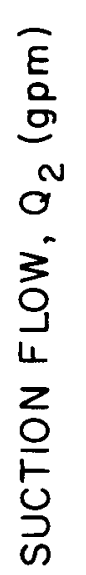

80

Figure 12. Eductor Test Results

In the water test it was not possible to simulate exactly the conditions which are expected in the reactor system because of high pressure losses in eductor suction and discharge lines. However, from a review of test data and estimates of the pressure characteristics of the reactor piping, it was possible to predict performance of the eductor in reactor service. Predicted flow and pressure characteristics are shown in Figure 13. Actual flow is seen to be well in excess of the design requirement. Further testing will be performed in the 
reactor system in order to verify its capabilities, and to determine the flow characteristics more accurately under actual reactor conditions.

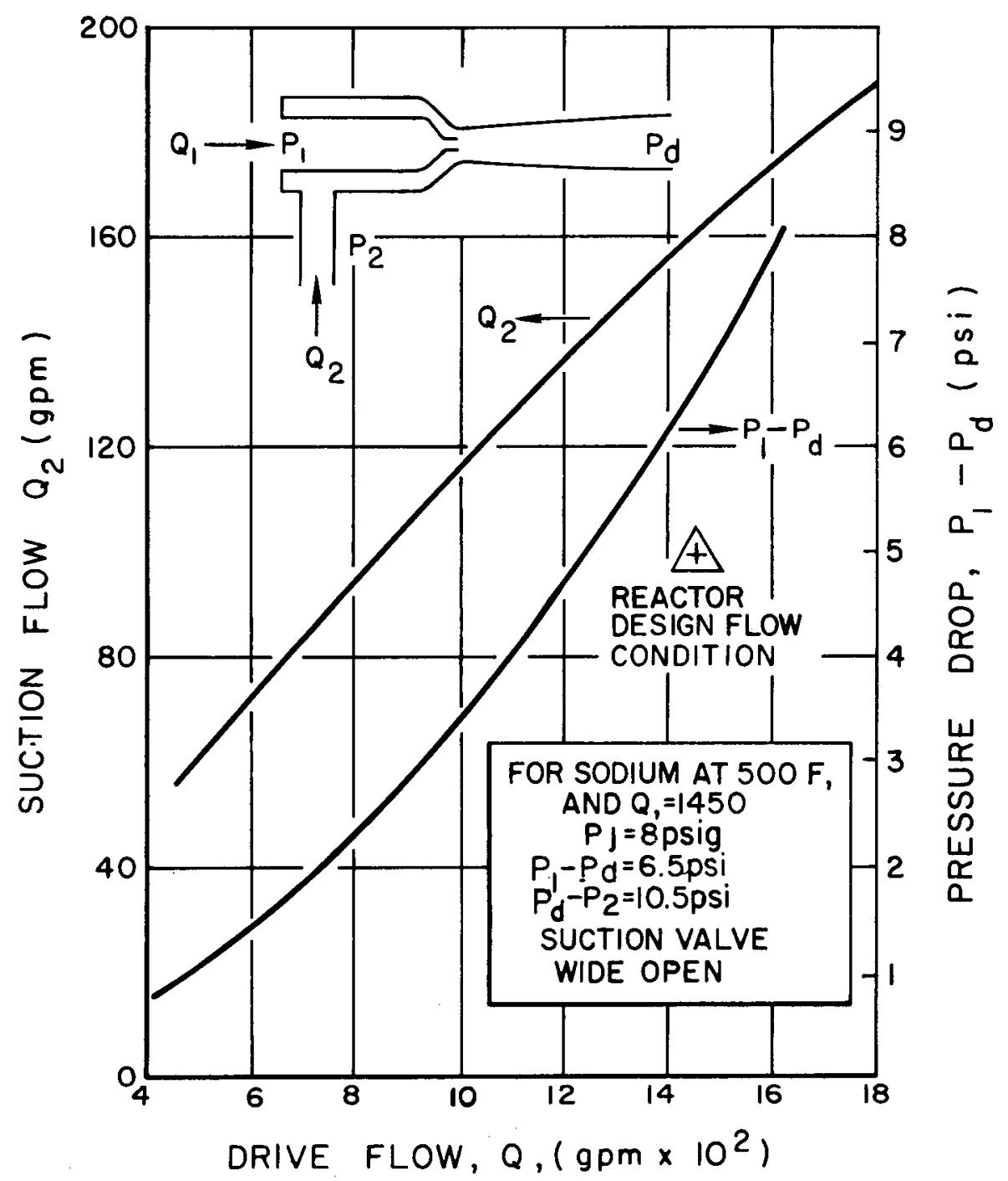

Figure 13. Predicted Eductor Hydraulics

The eductor installation will be superior to the electromagnetic-pump installation primarily because of its simplicity. Tests have indicated that the eductor is quite stable and free from vibration, and that its performance exceeds reactor flow requirements. Since the eductor is driven by the reactor coolant stream, the eductor suction flow will cease automatically when the main pump is stopped. An eductor bypass line has been installed to permit flow into the moderator plenum if this becomes necessary. 


\section{B. MAIN SECONDARY BYPASS}

This modification will permit isothermal circulation in the system without activating a steam generator. It will also allow circulation at higher temperatures (to $700^{\circ} \mathrm{F}$ ) than is feasible through the steam generator; the temperature range in which reactor physics isothermal tests can be made will be increased. During these tests, reactor temperatures will be held constant when the bypass line is used. Sodium temperatures were sensitive to ambient air temperature changes when main airblast heat exchanger was used.

A 2 -in. line had been installed connecting the steam generator inlet and outlet lines. There is a valve in the line, and a freeze trap at the high point. This line (No. 215) is shown on the secondary sodium system P \& I diagram (Appendix A-2).

Operation of the bypass line will be limited by the maximum permissible pressure difference across the intermediate-heat-exchanger tube sheet, (50 psi). When the primary side of the exchanger is empty, 50 psig is the maximum allowable pressure in the shell of the exchanger. An operational limit of 1200 rpm on the main secondary pump will insure that this pressure is not exceeded. At this pump speed, calculated flow through the bypass loop will be $365 \mathrm{gpm}$. Figure 14 is a pressure loss-flow curve for the bypass system. Adherence to the 1200-rpm limitation will insure that the intermediate-heat-exchanger tubesheet maximum differential pressure will not be exceeded even if a block valve in the system is closed.

When the steam generator is in service, the bypass line will be frozen. The frozen sodium plug will back up the valve and insure that there will be no leakage through the line. When there is a temperature gradient on the system, any leakage in the line would lead to excessive thermal stresses in the Weldolet at the junction of the bypass line and the steam generator sodium outlet line. Maximum.temperature in bypass line is $700^{\circ} \mathrm{F}$.

C. FREEZE TRAP

The function of a freeze trap is to prevent the entry of sodium into gas lines. The original SRE freeze traps consist of a 1/4-in. stainless steel tubing coil imbedded in a toroidal aluminum casting. Past operational experience with this 


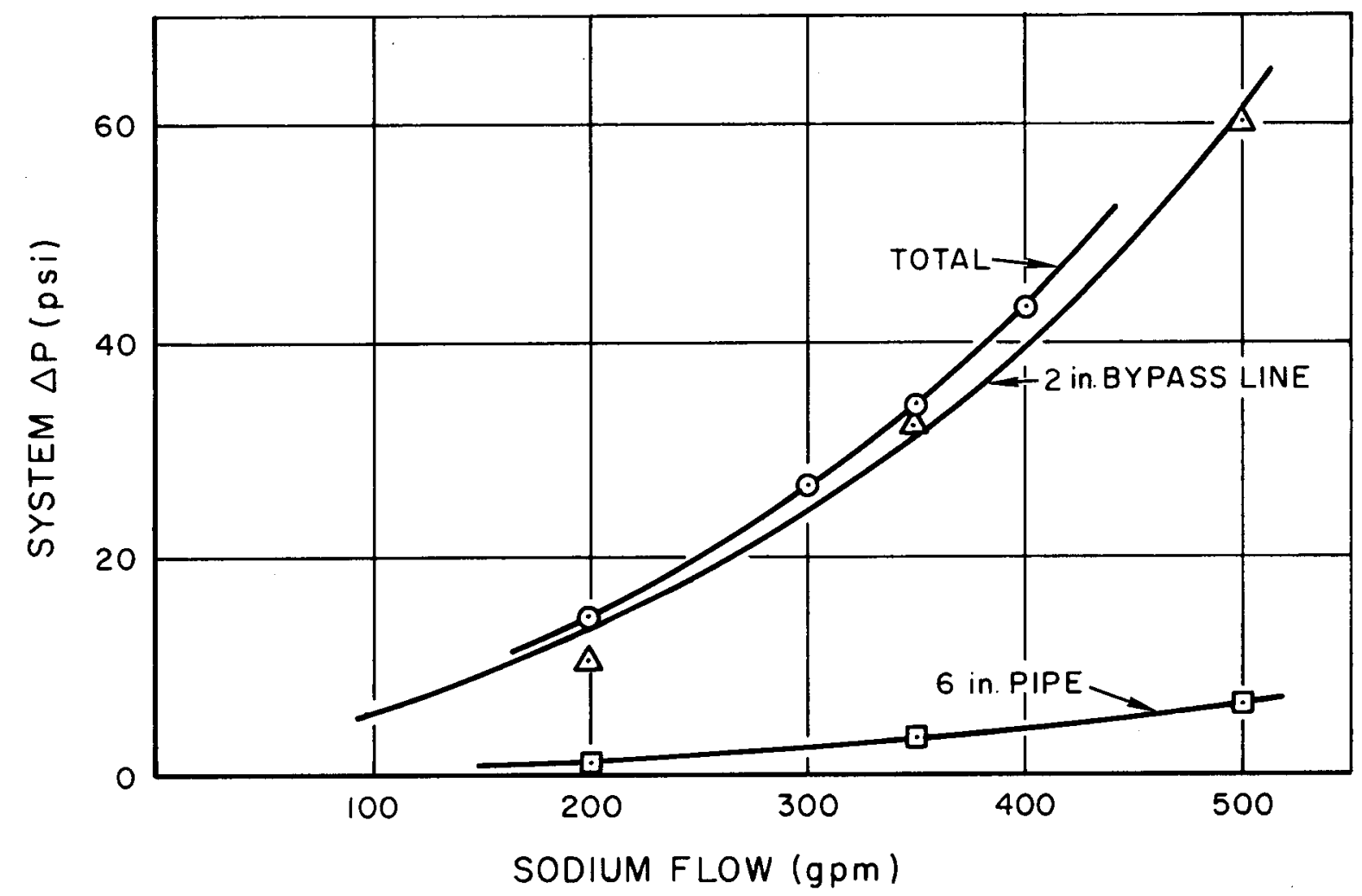

Figure 14. Main Secondary Bypass Loop Hydraulics

type has been unsatisfactory. The mass of aluminum must be heated to approximately $250^{\circ} \mathrm{F}$ to permit displacement of the sodium out of the trap by helium

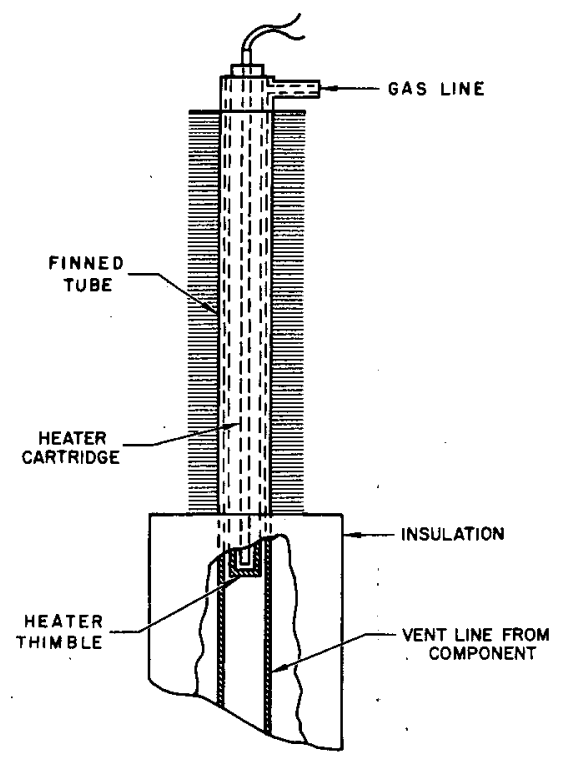

Figure 15. Tubular Freeze Trap prior to venting a component or pipe. The freeconvection cooling rate of the mass of aluminum to the $150^{\circ} \mathrm{F}$ gallery ambient atmosphere is slow, causing delays when a component of the system is to be filled. The existing temperature instrumentation on the pipe nozzles of the freeze trap is inadequate. Only thermocouple wells adjacent to the tubing in the casting give a satisfactory temperature response, and these require a new casting. The new freeze trap is shown on Figure 15. It consists of a 24-in. length of 1 -in.-diameter, finned tubing containing an electric resistance heater in an inner tube. The heater element can be easily replaced. Sodium is frozen in the 0.055-in. annulus. Since thermal 
capacity of the trap is small, thawing time is less than 1 min. After thawing, the trap will cool rapidly by natural convection and be ready for use in a few minutes. This trap has been installed on the new components, and the old traps will be replaced as plant schedule permits.

The gas and vent piping serving one of the new freeze traps is outlined on the Gas Services P \& I Diagram (Appendix A-4), at the right edge of the diagram. A common pressure control station (PC 434) serves three freeze traps. Only one pipe goes into the gallery to serve a particular trap. All gas valves are located outside the vaults where they will be accessible for maintenance.

When the reactor is operating, sodium is frozen in the freeze traps. This freeze seal blocks passage of radioactive gas out to the unshielded vent header. While it is unlikely, one can conceive of a situation where radioactive gas could enter the vent piping just after a reactor shutdown. The radiation level in the vent header after such an occurrencehas been calculated, based on measured activity in the reactor cover gas on August 1, 1959, and extrapolated back to the time of fuel element damage to include short-lived isotopes. The radiation level $3 \mathrm{ft}$ from the vent header would be 0.5 to $1 \mathrm{R} / \mathrm{hr}$. A radiation detector will be mounted next to the vent header with an alarm in the control room to inform the operators if such an event should occur.

\section{DIFFUSION COLD TRAP}

The original cold trap in the auxiliary secondary system (capacity: 50 gal) was a bulb on the bottom of the expansion tank. This trap was never effective in removing oxide from the sodium. The reason for this poor performance is not known, but may have been due to one or more of the following:

1) Small length-to-diameter ratio (1:3)

2) Large diameter connection to tank (4 in.)

3) Flow paths in the tank and trap.

The trap was tetralin cooled. Because of its poor performance, it was decided to deactivate the tetralin coil (disconnect, clean, leave uncapped) and discontinue use of the trap. 
The new trap is of simple design one which has proven its effectiveness in the component development program. It consists of a 2 -ft length of 2-in. pipe vertically mounted below a tee in the system (see the Secondary Sodium System P \& I Diagram, Appendix A-2). The pipe is not insulated; the trap is air cooled by natural convection. The design method utilized heat transfer equations developed for a finite fin, with insulated end. This method has also been used for valve freeze seal design. 1

The trap was designed to have a temperature of $250^{\circ} \mathrm{F}$ at the bottom of the trap with $500^{\circ} \mathrm{F}$ sodium flowing through the tee. The $250^{\circ} \mathrm{F}$ temperature will hold the oxygen concentration of the system at 5-1/2 ppm. 


\section{FUEL WASHING SYSTEM}

\section{A. WASH CELL EXPERIENCE}

In the past, the method used to remove sodium from the SRE core components consisted of the insertion of the component in the wash cell, purging the cell with inert gas and flooding the cell with water admitted at the bottom. The water reacted with the sodium on contact, and the gaseous products of the reaction were vented directly to the radioactive vent system. The water was subsequently drained after a 5-min soak period and the component dried by vacuum techniques. The method just described was successfully used many times. However, in October 1958, when considerable fuel washing was being done to remove foreign deposits, which were believed to be causing high fuel-channel-exit temperatures, one of the washed elements was observed in the hot cell to be severely damaged during the washing process. An investigation into fuel washing was initiated. In the following months several more elements were damaged.

Experiments were planned using a fully instrumented SRE wash cell, but on June 4, 1959, during a routine fuel washing, a pressure surge occurred in this cell which severely damaged the fuel element and ejected the shield plug from the cell. This event precluded the use of this cell as a test facility. An experimental wash cell was obtained and instrumented to carry out the required tests.

\section{B. FUEL WASHING EXPERIMENT}

The objectives of this experiment were to obtain information concerning the destructive mechanism responsible for the fuel element damage and to obtain information necessary to design an improved fuel washing system.

\section{Hydrogen-Oxygen Recombination Theory}

Hydrogen-oxygen recombination in the wash cell was thought to be the cause of the June 4, 1959, pressure surge. Because hydrogen gas is in abundance in the immediate sodium-water reaction zone, the possible sources of oxygen were investigated. Purging effectiveness tests were conducted along with tests using deaerated water at different temperatures. No noticeable effects resulted when sodium charge (30 to $60 \mathrm{gpm}$ ), water temperature, and cell pressure were varied. The results here, coupled with available energy calculations from the $\mathrm{H}_{2}-\mathrm{O}_{2}$ reaction, ${ }^{17}$ did not present an explanation of the June 4 , 1959, pressure surge. 


\section{Possibility of Sodium in Holddown Tube}

Concurrently with the above tests an examination was made of the SRE holddown tube involved in the June.4, 1959, washing event. Inspection of the holddown tube's lower section (Figure 16), indicated the possibility that sodium may have been "trapped" in the tube. This holddown tube was cut open, examined, and sodium residues found. In the worst case, it was calculated that $8 \mathrm{lb}$ of sodium could possibly be retained in the tube. A much larger quantity of sodium than heretofore thought possible entered the wash cell. Recent observations of other unwashed core components have shown the drain holes to be completely plugged in the lower section of the hold-downtube. The potential danger of washing such an element is augmented by the "trapped" sodium being forced to submerge in the rising wash water. Normally, sodium in small gram-size chunks will melt quickly upon being placed in water and, while floating upon the

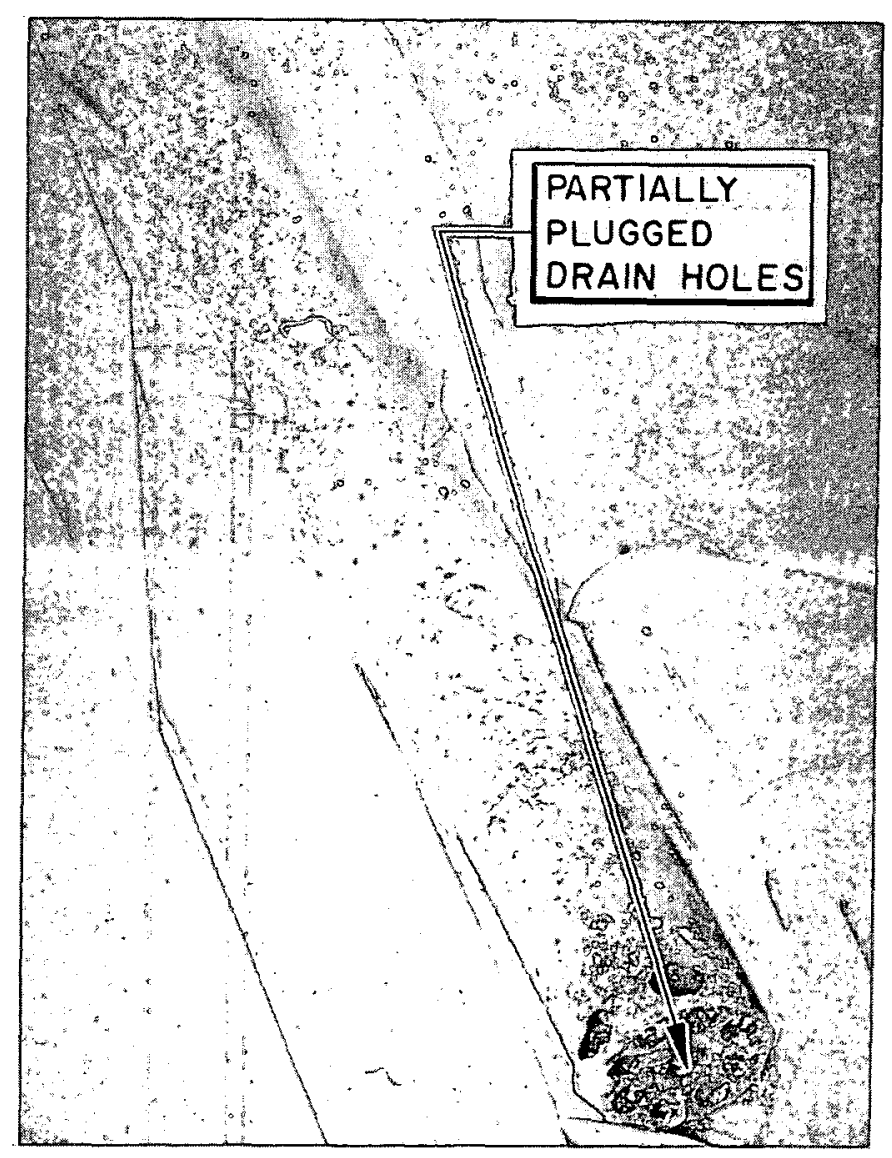

Figure 16. Fuel Element Holddown Tube 
water, reacts noiselessly. It is when the sodium is forced under the water that audible reports are heard.7 Geometry of the holddown tube is such that a jet propulsive force, acting along the axis of the tube, can be produced by the escaping gases resulting from the sodium water reaction.

3. Water Washing

As a result of the above observations, additional tests using water were carried out. This series of tests was conducted using various amounts of sodium (90 to $110 \mathrm{gm}$ ) in several-size chunks placed in a modified test rig designed and constructed to duplicate the conditions of "trapped" sodium in the holddown tube. The highest pressure surge detected at a point under water, 18 in. from the reaction zone, was $690 \mathrm{psi}$ with a rise-time of less than $1 / 4 \mathrm{msec}$. Figure 17 is a typical pressure-time trace as detected by a piezoelectric crystal and produced for viewing and recording by an oscilloscope. The oscilloscope sweep was triggered by the first voltage impulse from the pressure detector. Each test was preceded with the normal purging precautions and conducted with the cell held at 10 in. Hg vacuum. A total of nine shortened dummy fuel rods was positioned during these tests below the test rig so as to be under water and subjected to the pressure surges when they occurred. All nine of these tubes were collapsed in their void sections, some more severely than others. Figure 18 shows eight of these collapsed tubes. Tubes numbered 1 and 6 in this photograph were empty when collapsed; the others were partially filled with water to various heights to simulate the $\mathrm{NaK}$ bond. The tubes shown are replicas of SRE fuel cladding, fabricated from 304 stainless steel tubing, $0.790 \mathrm{in}$. of diameter and $0.010 \mathrm{in.} \mathrm{wall} \mathrm{thickness.} \mathrm{Calculations} \mathrm{indicate} \mathrm{that} \mathrm{tubes} \mathrm{of} \mathrm{this} \mathrm{type} \mathrm{may}$ collapse under external static pressures between 100 and 110 psig, depending upon their ovality. Actual collapsing pressures obtained by tests were found to be between $90^{\circ}$ and 105 psig.

The shield plug used in the tests above was always prevented from being ejected from the wash cell by a cover plate and C-clamps; however, this precaution proved inadequate during the last water wash test in which the modified test rig, mentioned above, was used. During this test part of the shield plug. restraining mechanism failed. Four $1 / 4$-in. threaded bolts parted in tension indicating an, upward force of approximately 10,000 lb, if all were equally loaded. Insufficient information concerning this phenomenon has prevented a 


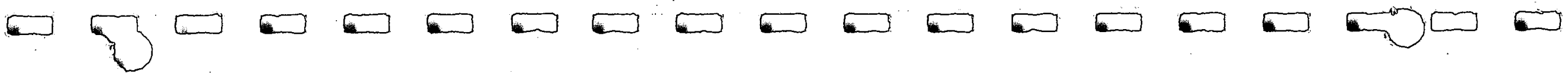

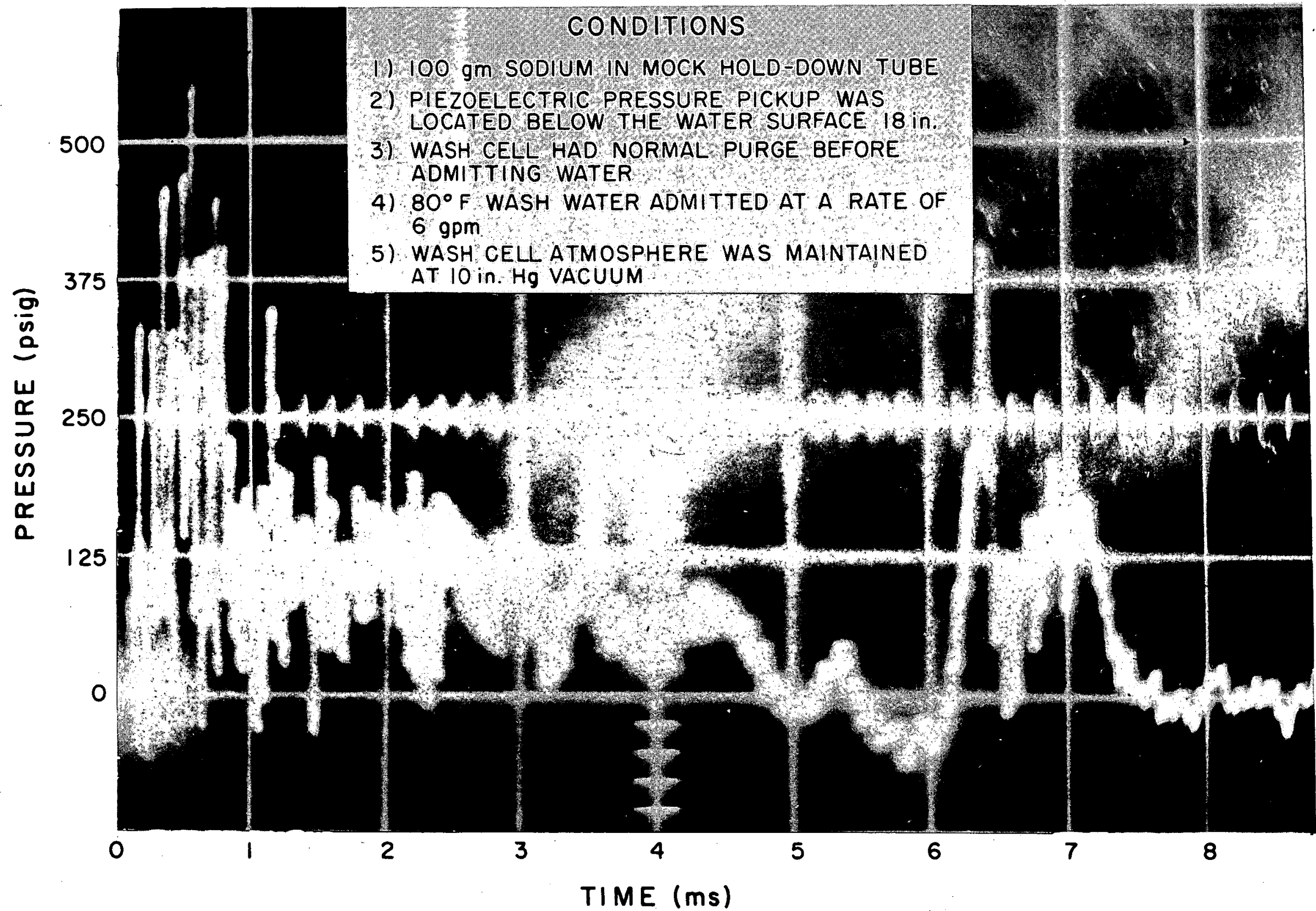




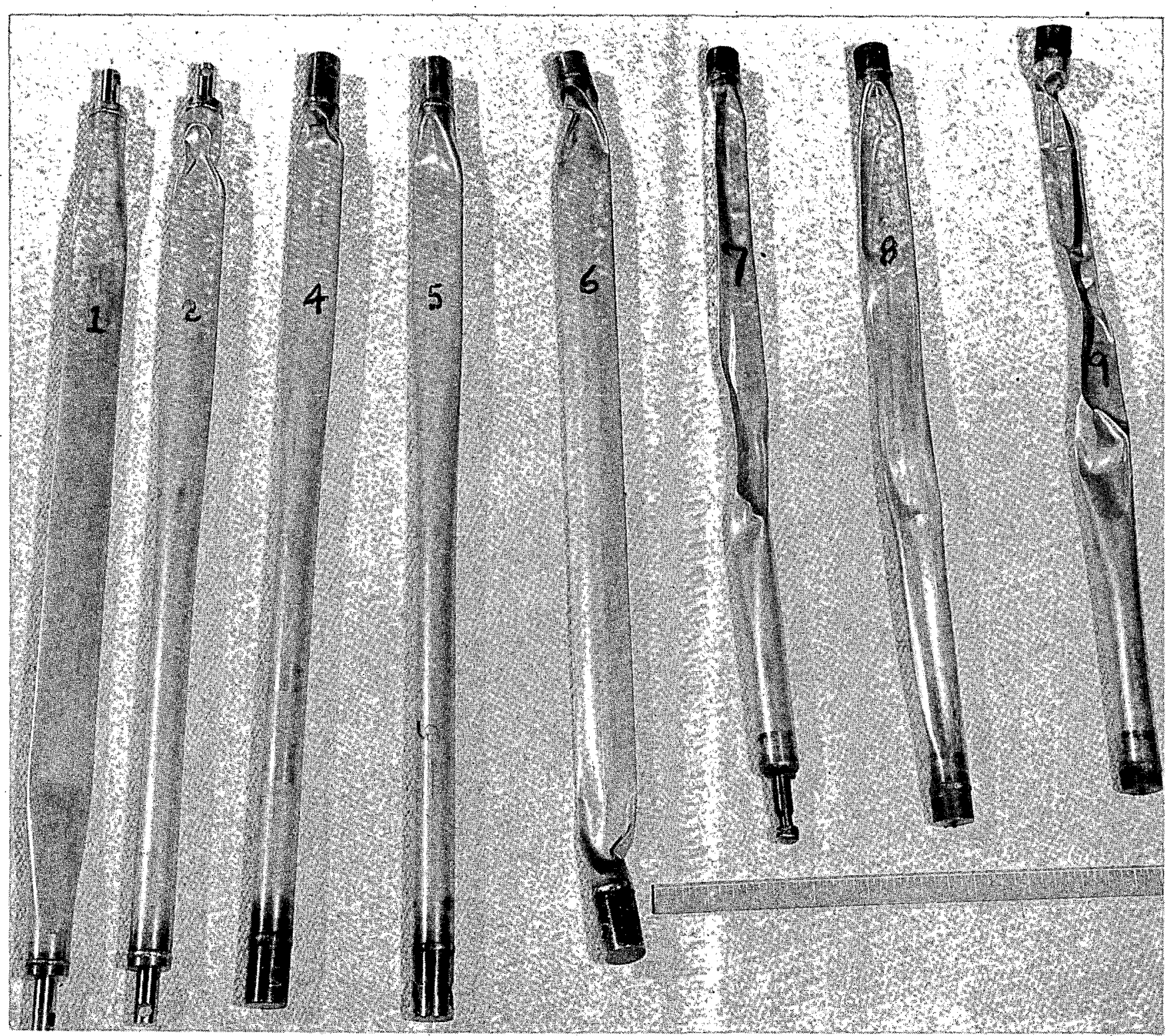

Figure 18. Collapsed Dummy Fuel Rods

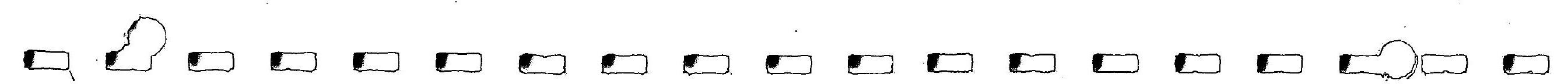


rigorous mathematical analys is of the forces involved, but on the basis of these observations, it is believed that this is the mechanism responsible for the washcell pressure surge of June 4, 1959, and gives sufficient reason for a redesign of the SRE holddown tube.

4. Steam as a Cleaning Medium

Following the tests above, the use of steam as a cleaning medium was investigated. The first tests with steam proved very promising in that large quantities of sodium ( 125 to $200 \mathrm{gm}$ ) could be disposed of without the usual audible reports associated with water washing. The results of these tests have shown that the sodium-water reaction rate can be controlled by the quality of the cleaning steam. As an example: when 80 psig steam was throttled to cell pressure and with little cell preheating, the reaction time was approximately $25 \mathrm{sec}$ for $145 \mathrm{gm}$ of sodium. When the cell and steam piping were preheated prior to the test to improve the steam's quality, the reaction time was extended to around $80 \mathrm{sec}$ for the same amount of sodium. The above information was obtained by a specially constructed test rig. This $r i g$ consisted of a shortened dummy fuel rod equipped with thermocouples both inside and out and having a wire basket surrounding it for the purpose of containing the sodium near the tube and thermocouples.

These tests also indicated that the fuel element parts, etc., that are in the immediate vicinity of the reaction zone, will not be damaged by overheating. This is one of the main concerns if steam is used. In the example given above, the maximum temperature recorded by the thermocouple placed in contact with the fuel rod cladding was $1158^{\circ} \mathrm{F}$ for the $25 \mathrm{sec}$ reaction time. In the other test (80-sec reaction time), a maximum temperature of $497^{\circ} \mathrm{F}$ was recorded by a thermocouple placed in contact with the interior cladding surface.

Observations after washing a sodium-covered test element indicate that a water rinse will be needed subsequent to the steam cleaning process to remove the $\mathrm{NaOH}$ film that remains. When steam is used, a white smoke, $\mathrm{Na}{ }_{2} \mathrm{O}$, was observed leaving the vent to the atmosphere. 


\section{MODIFIED W ASHING SYSTEM}

From the information gained in the above tests and past operating experience, the decision was made to modify the SRE fuel washing system. The major changes are: 1) wash-cell redesign to utilize steam in the quantity and quality required for cleaning; 2) wash-cell vent system changes incorporating hydrogen gas removal units and means for cooling and recirculating inert gas. 'T'wo factors dictated elimination of the hydrogen gas produced in the $\mathrm{H}_{2} \mathrm{O}-\mathrm{Na}$ reaction. The $\mathrm{y}$ a re: 1 ) hydrogen gas can detonate and burn when mixed with oxygen or air in the right proportions; 2) the $S R E$ has a radioactive vent system into which effluent gases from the washing operation a re discharged and in which air in-leakage is frequent and unavoidable.

A flow diagram (Figure 19) indicates the relative positions of the equipment comprising the modification. Figure 20 is a sketch of the modified wash cell. The function of each component may be best described by briefly following a hypothetical flow.

Steam from a small generator is admitted to the bottom of the heated wash cell where it rises enveloping the sodium covered fuel element. Concurrently, a recirculating gas (helium) enters the wash cell at the bottom and in flowing, with the steam, upward and around the fuel element, removes a portion of the afterglow heat given off by the fuel element. The helium and the products of the sodium-steam reaction, hydrogen and sodium hydroxide, pass from the wash cell into a baffle box where the sodium hydroxide, and any other possible radioactive particulate matter, is filtered out by suitable demisters. Later this residue is flushed back to the radioactive liquid waste with water. The remaining hydrogen and helium and some unreacted steam continues on into the hydrogen oxidizer which contains hot $\left(575\right.$ to $\left.620^{\circ} \mathrm{F}\right)$ copper oxide. The hydrogen combines with the oxygen (from the reduction of the copper oxide) in a controlled reaction to form steam at this temperature. The steam and helium, now at a higher temperature, enter the vacuum control tank where a water spray condenses the steam and cools the helium gas.

This tank with its associated fittings alsoprovides a control over the degree of vacuum produced by the vacuum pump. The helium gas and water are pulled from the vacuum control tank by the vacuum pump and discharged into a compression water reservoir where a water-gas separation occurs. The helium gas 


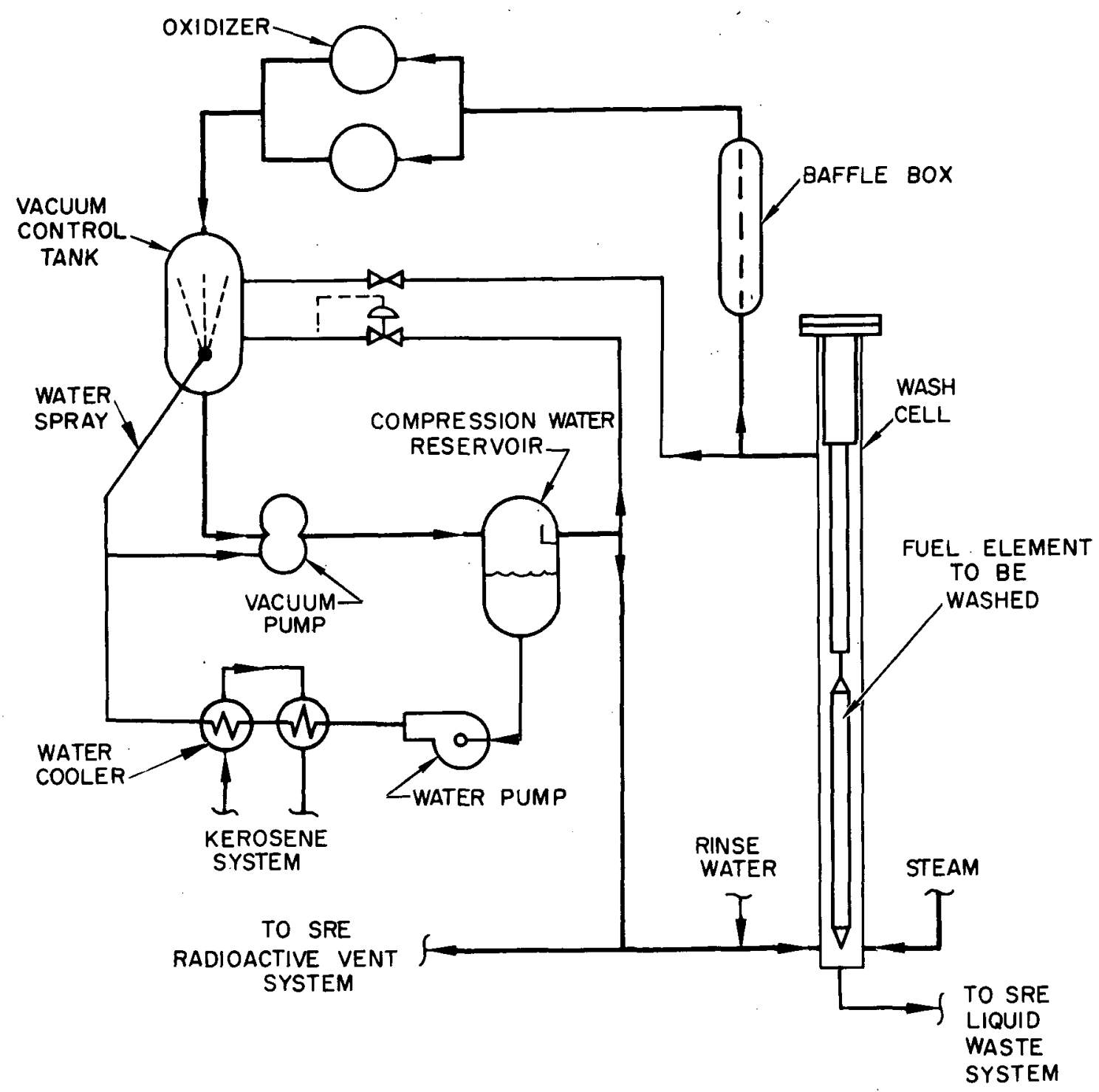

Figure 19. Flow Diagram of Modified Fuel Washing System

can be discharged into the wash cell to repeat the cycle or it can be discharged to the radioactive vent system. The water in the compression water reservoir is cooled and pumped again to the vacuum control tank to complete its cycle.

The fabrication and as sembly of the vent system process unit was completed April 18, 1960, and a completely new wash cell was finished April 25, 1960. Installation of this equipment and control instrumentation in the SRE was completed May 10, 1960. Operational checkouts followed. On May 16, 1960, core component washings commenced. The componentshad not been washed since being removed from the core and were coated with sodium. Visual observations of the components washed indicated that all the sodium had been removed. This series of initial washings has shown the system to be a definite improvement and a safe way to clean SRE core components. 


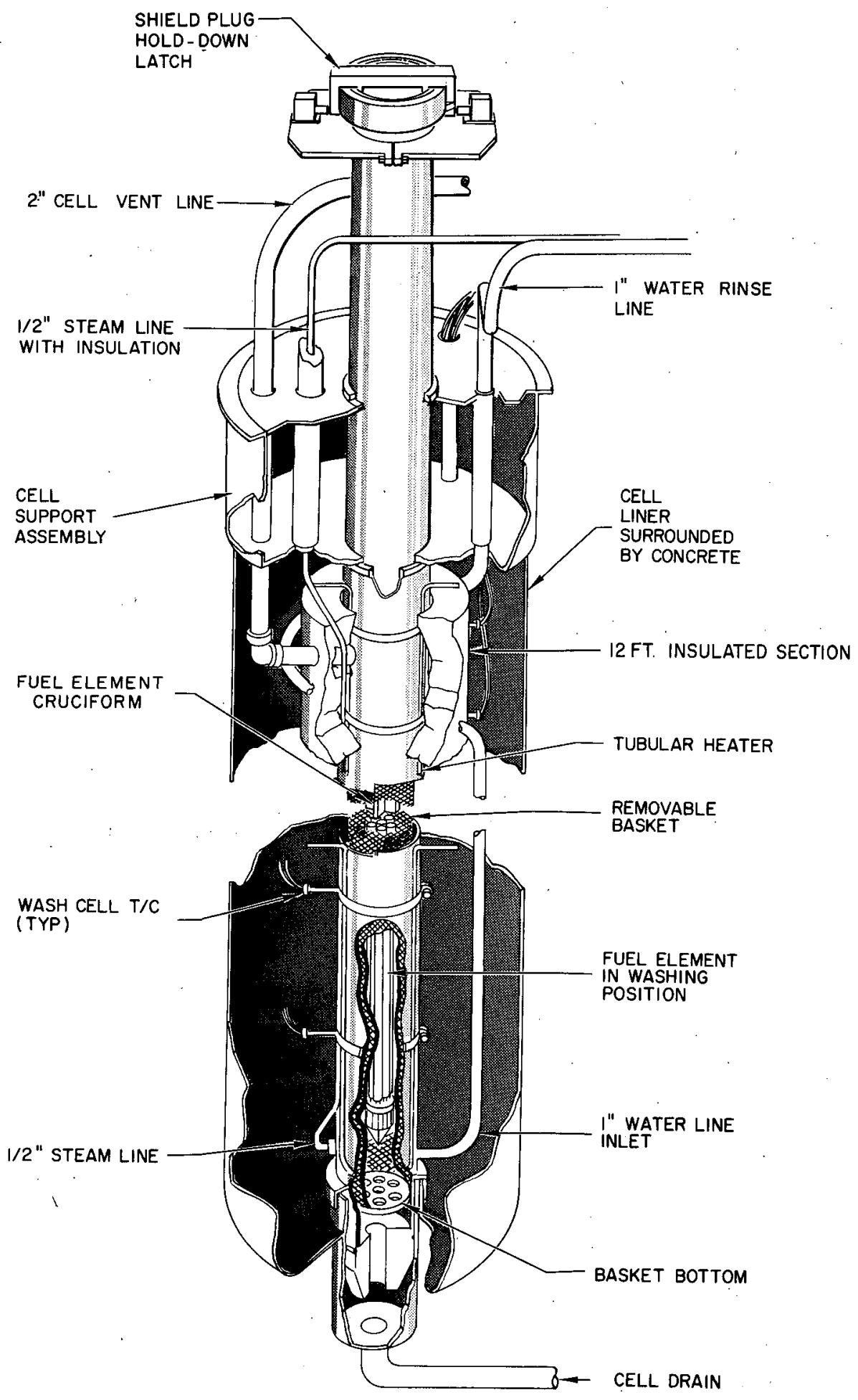

Figure 20. Modified Fuel Washing Assembly 


\section{INSTRUMENTATION}

\section{A. DIAGNOSTIC INSTRUMENTATION}

\section{Fission Product Monitor}

The analysis of gas samples taken after power run 14 indicated a large increase in the quantity of $\mathrm{Xe}^{133}$ present in the reactor cover gas. Sampling techniques were developed, using filters, which demonstrated the feasibility of gas sampling during power operation.

In order to speed the detection of fuel cladding failures, a continuous gas sampling device has been designed for use on the SRE.

A scintillation spectrometer will be employed for detecting fission products in the SRE reactor cover gas. Referring to Figure 21 a continuous flow of reactor cover gas is circulated through a sodium vapor trap, filter, and lead shielded chamber which contains a scintillation detector. A flowmeter with a range of 0.15 to $1.5 \mathrm{scfm}$ is employed to measure the reactor cover gas flowrate. The normal flow rate will be about $0.3 \mathrm{scfm}$. An alarm is provided to give a warning in the event of a loss of gas flow. An analysis of the reactor vapor trap indicates that the transfer of sodium vapor should not exceed a few hundredths of a gram per year with continuous operation. The filter will assure that no sodium particles will circulate through the lead shielded chamber.

The scintillation spectrometer consists of the scintillation detector, linear amplifiers, differential analyzer, log-count-rate meter, and log-countrate recorder. The differential analyzer will reject unwanted energy levels from radioactive particles or noise and pass only those energies that are preselected by adjustment of the pulse height discriminator and window width which will be adjusted for the Xe ${ }^{133} 0.081-\mathrm{Mev} \gamma$ energy level. A fuel element rupture will be detected by a rapid increase in the quantity of $\mathrm{Xe}^{133}$ in the reactor cover gas. When the $\mathrm{Xe}^{133}$ exceeds a predetermined amount, a signal will be provided for the annunciator alarm system.

Purge lines are provided so that the instrumentation can be calibrated with a sample of $\mathrm{Xe}^{133}$. A calibration will be performed approximately every two months to compensate for any drift that may occur in the instrumentation. Sample connections are available so that a more detailed analysis can be conducted when necessary. 


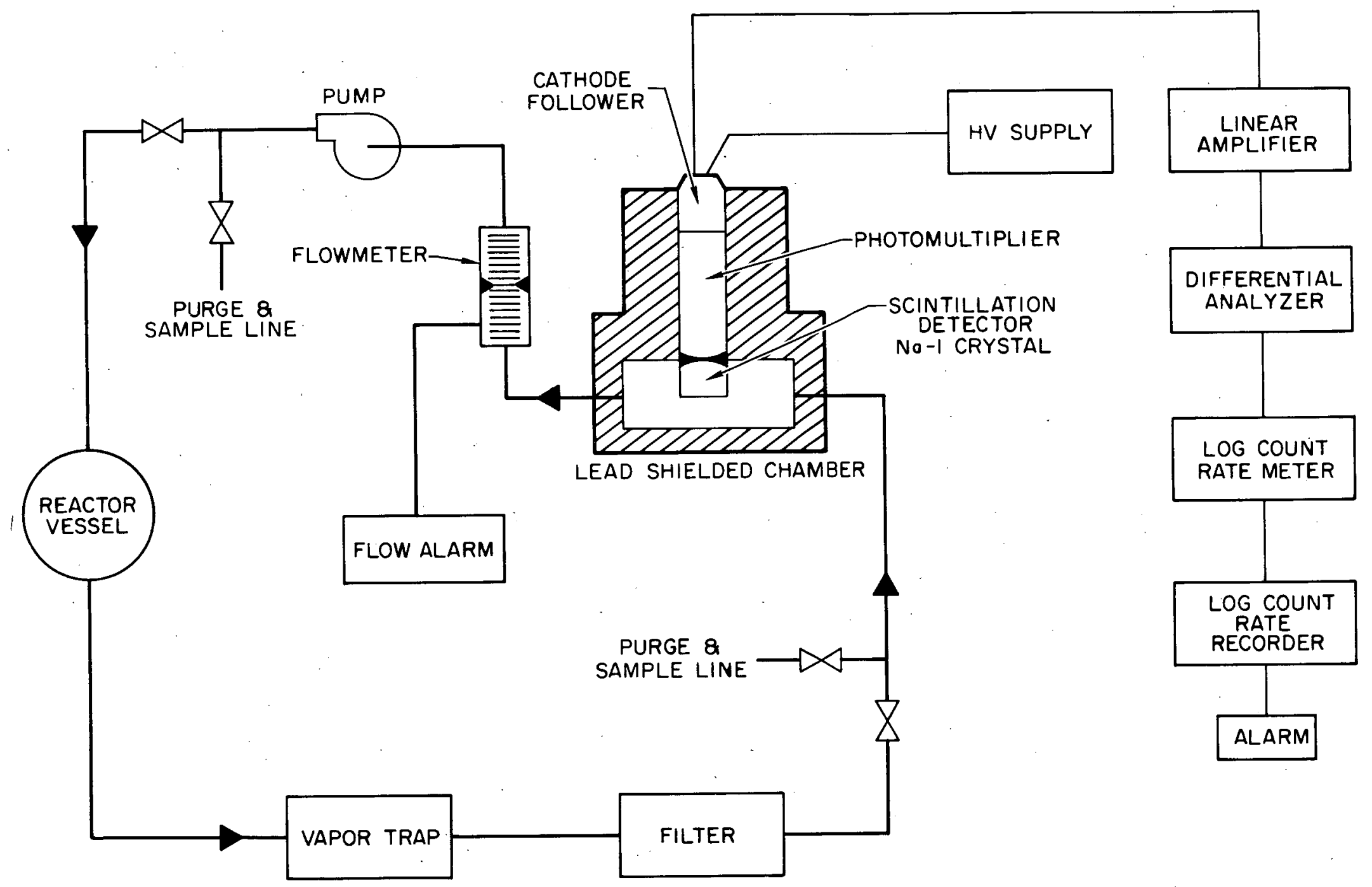

Figure 21. Fission-Product-Monitor Flow Diagram 
The fission-product monitoring system has not yet been tested. Its design is based on data obtained from batch sampling of the reactor cover gas. The effect of the short-lived gaseous isotopes cannot be accurately predicted. The system is theoretically sound but will require some developmental effort.

In conjunction with the piping installation for the xenon detector, the reactor and primary-fill-tank vent lines were modified to permit independent venting of either vessel. Relief valves in these vent lines are now backed with rupture discs to prevent helium leakage into the vent system.

\section{Reactor Transient Monitor}

The SRE transient monitor is a high-speed data system for measuring selected parameters during off-normal conditions. This type of instrumentation is required to facilitate a better evaluation of the behavior of the reactor and heat transfer systems during unprogrammed conditions. When activated, each channel will be recorded continuously at a fast tape speed to permit an analysis of the time relationship of the various signals. The existing SRE strip chart recorders were designed to serve only as operational guides, and do not have adequate time response for measuring transient conditions. The following reactor parameters will be recorded: (a) neutron flux; (b) reactor period; (c) fuel channel temperature; (d) in-fuel temperature; (e) moderator temperature; (f) primary flow; (g) secondary flow.

The reactor transient monitor employs a continuous loop and reel-toreel magnetic tape recorder. Seven channels for recording are provided (Figure 22).

The frequency modulation technique is employed to record signals with a frequency below thirty cycles per second. The amplitude of the information signals modulates an FM carrier. The signals from the FM record amplifiers drive the seven-track record head. 


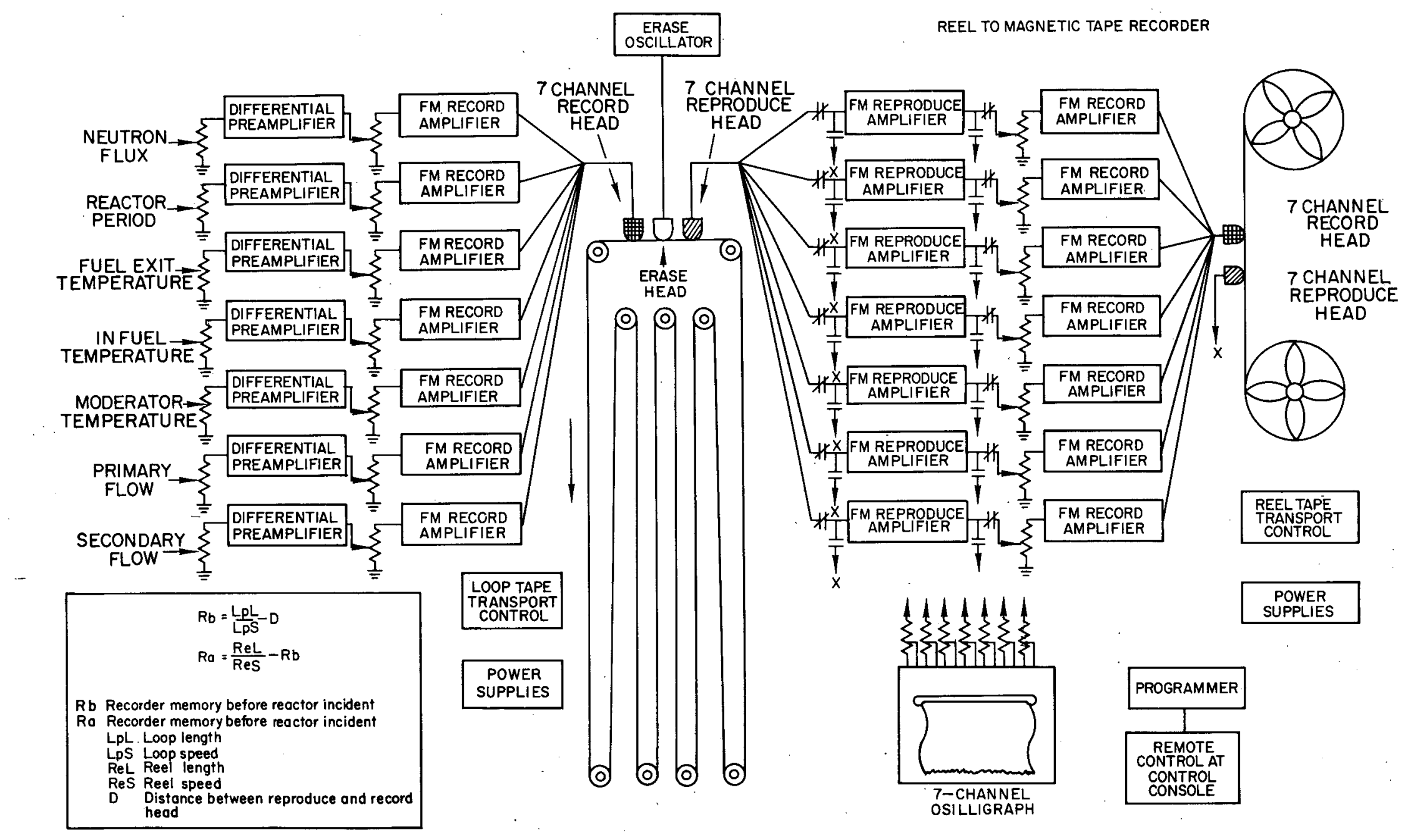

Figure 22. Magnetic Tape Recorder 
Three heads are provided for the continuous-loop magnetic tape recorder; (a) record head; (b) reproduce head; (c) erase head. The signal information that is recorded on the tape travels the full distance of the loop before contact is made with the reproduce head and erase head.

The record head and exase head are in continual operation at all times, except for maintenance of equipment or replacement of a worn tape loop. At the instant of a scram or abnormal operation, the FM reproduce head and amplifiers are energized, and the information on the continuous-loop tape recorder is transferred to the reel-to-reel tape recorder.

The reel tape recorder will provide $8 \mathrm{~min}$ of memory for the data recorded on the continuous-tape loop prior to the reactor scram. Up to 4 hours of recorded data can be stored on the tape reels after recorder activation. A programming switch shuts the reel tape recorder off after a preselected time following a reactor scram. A push-button switch on the SRE control console will start the reel tape recorder; therefore, abnormal reactor behavior that does not initiate a reactor scram can be recorded and stored on the reel-to-reel tape recorder.

The signal information on the reel-to-reel tape recorder is stored until a convenient period for transcribing on a seven-channel oscillograph recorder. All the signals will be reproduced on one oscillograph chart. Therefore, an excellent correlation of the time relationship between the measured reactor parameters will be made available. Transient data with a duration of milliseconds can be reproduced on several inches of oscillograph chart paper.

Signal information cannot be recorded on the reel tape and reproduced on the oscillograph at the same time; to economize on equipment and eliminate the necessity of a duplicate channel of FM reproduce amplifiers, the same amplifiers are employed for both applications.

Other applications for the magnetic-tape-recorder equipment, besides being employed as a reactor transient monitor, are listed below:

a) The magnetic-tape instrumentation will provide data which will differentiate between a spurious reactor scram and a scram 
which is caused by abnormal reactor behavior. This will assist the reactor operator in determining that conditions in the reactor and heat transfer system are normal and the reactor can be returned to power operations

b) The data from the magnetic tape can be fed into IBM computers for analytical studies.

c) The magnetic tape instrumentation can be employed for physics studies. This includes power spectral density analysis studies and autocorrelation function studies.

3. Reactor Temperature Measurements

Two special recorders have been added to the reactor temperature measuring instruments for recording thermocouples that are installed in the fuel, and thermocouples that are installed in the special tubing which serves as wire wrap to separate the fuel rods (see Section VII).

Standard multipoint strip chart recorders have been field modified to provide dual chart and print speeds. During normal reactor operations the chart motion is set at a standard speed of $2 \mathrm{in.} / \mathrm{hr}$. At the instant of a reactor scram, setback, high in-fuel temperature alarm, or high fuel channel outlet temperature alarm, the chart speed and print out speed are increased by a factor of 10. This improves the resolution of the temperature measurement, so that no information is lost during fast temperature changes between print cycles.

The instrumentation will facilitate a better evaluation of the in-fuel temperature measurements. Figure 23 gives elevations of the in-fuel and wraparound thermocouples, and Figure 24 gives the location of the special thermocouples in the reactor core lattice.

By measuring the two in-fuel thermocouples, the wrap-around thermocouple, and the fuel channel outlet thermocouple in sequence on the same chart paper, an excellent historical record can be made for each special fuel element.

Improvements of the hardware for the reactor temperature measurements are the location of the fuel channel outlet thermocouples, and the selection of improved thermocouple materials. These thermocouples are mounted 
$\sqrt{6}$

$\square$

L

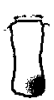

?

[

ए

$\pi$

I

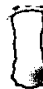

A AND B IN-FUEL THERMOCOUPLES

C WRAP-AROUND THERMOCOUPLE
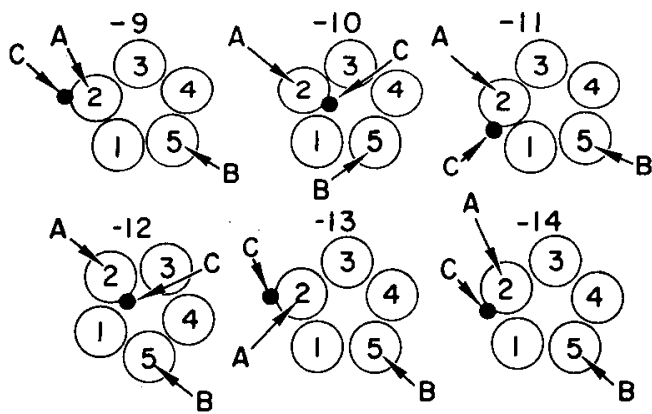

LOCATION OF WRAP-AROUND THERMOCOUPLE ON FUEL CLUSTER AND IN-FUEL THERMOCOUPLES

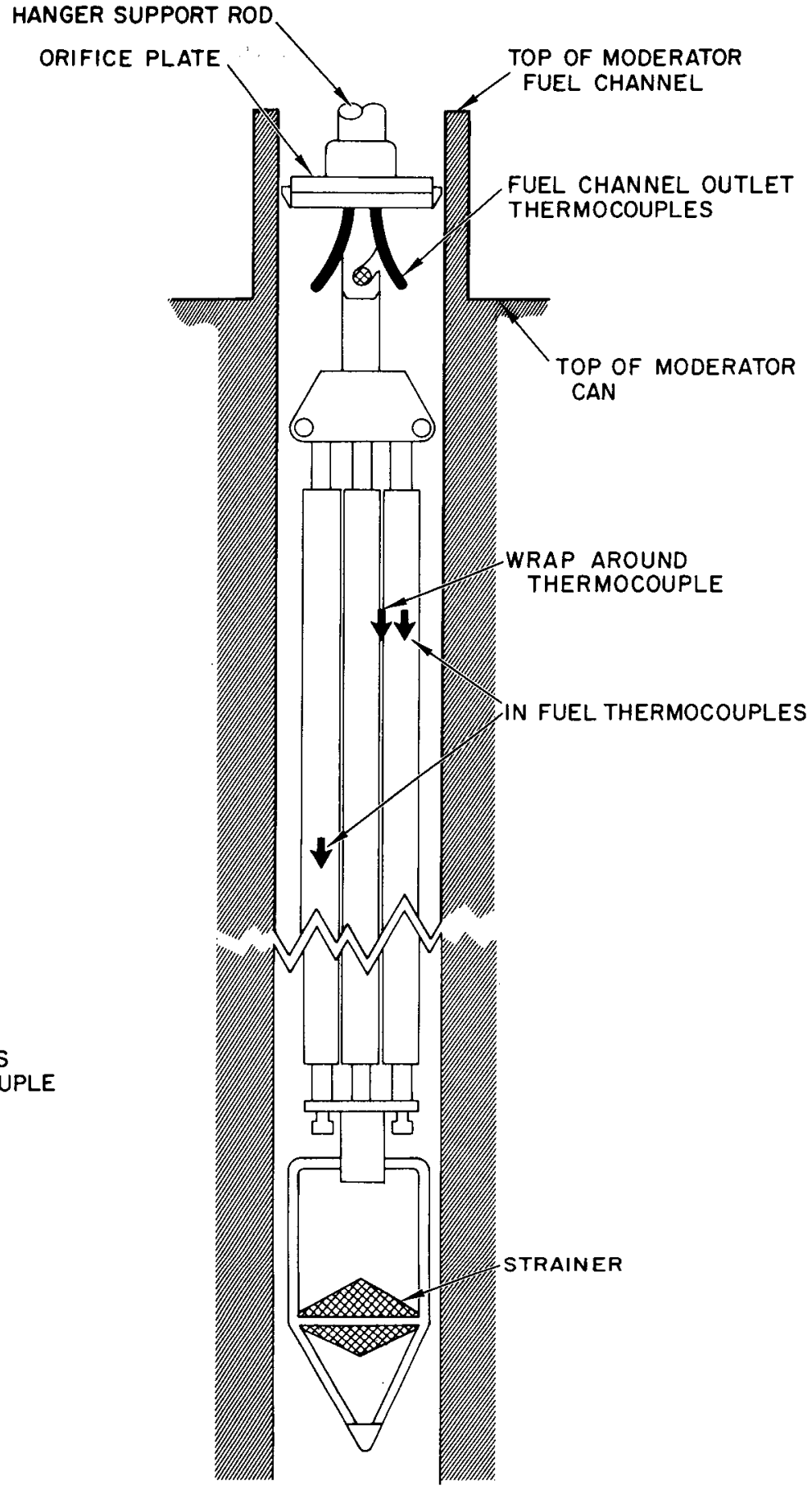

FUEL ELEMENT

ASSEMBLY IN MODERATOR FUEL CHANNEL

Figure 23. Fuel Element Instrumentation 


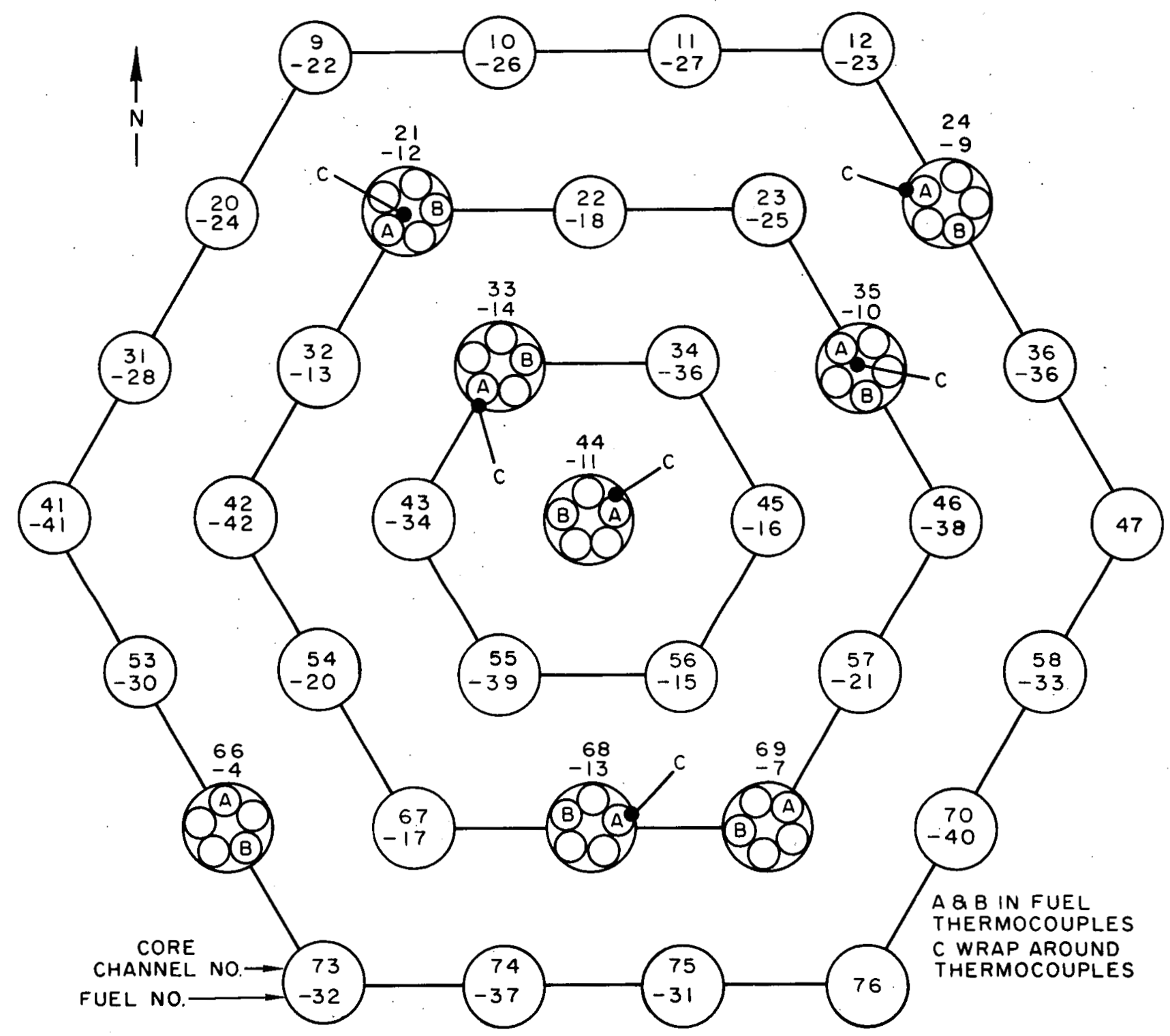

Figure 24. Fuel Thermocouple Location, Second Core Loading

in the sodium stream just above the fuel-rod holddown guide. This new location provides more confidence in the channel exit temperature particularly at low flowrates. The fuel outlet thermocouples have welded tips which are located in the sodium stream. They are shown on Figure 25, a photograph of the fuel channel outlet thermocouple installation on the thorium-uranium fuel element assembly. This will provide a time constant of less than 3 sec for all fuel exit thermocouples. 
The manufacturing and testing of stainless steel clad $\mathrm{MgO}$ thermocouples has improved since the first SRE coreloading. The thermocouples for thethorium-uranium fuel loading have been thoroughly tested for leaks that could cause sodium penetration through the cladding materials.

A thermocouple interconnect panel with receptacles has been installed for all thermocouples that are routed through the loading face shield. This includes in-fuel, wrap around, fuel channel outlet, and other experimental thermocouples. Thermocouple plugs have been installed for all the readout instrumentation. This includes: (a) fuel outlet temperature recorders; (b) infuel temperature recorders; (c) plant protective system; (d) convection flow control system; (e) SRE-Edison plant control system; (f) reactor transient monitor; (g) expanded-scale recorder; $(h)$ experimental instrumentation.

The thermocouple panel will facilitate a better coordination of the temperature measurements associated with the reactor core. It will also eliminate the problem of damaging thermocouple runs in floor boxes while attempting to change thermocouples during reactor operation.

The thermocouple panel will be under the direction of the SRE Operations Supervisor. The door to the panel will be locked, and no the rmocouple plug will be changed unless authorized by the Operations Supervisor or his designated alternate. The patch panel is a very flexible system and will allow switching thermocouple from slow response instruments to fast response instruments.

4. Operations Event Recorder

Three 20-pen recording devices have been installed to monitor the operation of the reactor control and alarm systems. These recorders make available a 60-channel record that will indicate when any one of the 60 functions being monitored is being performed. The recorders will record control and alarm signals with durations of $50 \mathrm{msec}$ and greater. The recorders have synchronous chart drives and the charts simultaneously time marked by the operation of a push button switch. The recorders are the on-off type and therefore measure only the time duration of the events being monitored and not the magnitude. 
The following circuits will be monitored:

10 Reactor scram circuits

9 Reactor scram circuit bypasses

3 Reactor setback circuits

3 Reactor setback circuit bypasses

9 Plant protective system alarms

4 Safety-rod-in drive circuits

4 Safety-rod-out drive circuits

4 Control-rod-in slow drive circuits

4 Control-rod-out slow drive circuits

2 Control-rod-in fast drive circuits

2 Control-rod-out fast drive circuits

2 Types of automatic control (temperature or flux)

4 Control circuit interlock bypasses.

The 60-channel record provided by the recorders will aid considerably in the analysis of the reactor conditions and the operation of the reactor control circuits. They will provide the analytical unit with a means of determining exactly what operation was being performed at any given time. This information can then be compared with other reactor data to determine the temperature, power, or other reactor changes that were caused by the particular manipulations that were being made.

\section{B. CONTROL INSTRUMENTATION}

\section{Neutron Flux/Power Deviation Circuit}

The plant protective systems that have been employed in the first experimental nuclear power reactors are an outgrowth of the technology that was developed for the early research and material testing reactors. The scram shutdown interlocks, reactor period, neutron flux, high temperatures, loss of coolant flow, etc. are employed in the plant protective systems. These shutdown interlocks protect the reactor complex against an incident and excessive power excursions.

Nuclear power plants that operate with large temperature gradients across the reactor, and elevated reactor outlet temperatures, are subject to 
thermal stresses if thermal cycling caused by large temperature variations occur while operating in the power region.

The neutron flux/power deviation limit circuit provides a floating setpoint for neutron flux in the SRE plant protective system. This circuit will be a supplement for the existing scram shutdown interlocks, and will improve the plant protective system during low-power operations. The function of the neutron flux/power deviation limit circuit in the SRE plant protective system is to prevent a large mismatch between heat generation rate and heat removal rate which could cause wide temperature variations and large thermal stresses.

The neutron flux and power measurements that have been recorded on the SRE instruments during power operations have been directly proportional over the entire range from 10 to $100 \%$ of full power.

Neutron flux is compared with thermal power (Figure 26). A deviation between flux and power represents an abnormal condition and provides a trip signal for the plant protective system.

This instrumentation is a unique design that employs transistor and semiconductor circuitry. The thermal power measurement is provided by multiplying the reactor delta $\mathrm{T}$ by the primary flow measurement across a voltage divider network. The neutron flux signal is provided by an ionization chamber and nuclear measuring circuit that are isolated from the other SRE nuclear instruments.

The neutron flux/power comparator circuit employs ac transistorized electronic relays that are free of the inherent drift associated with dc circuits. In the elementary schematic diagram of Figure 26, the neutron flux measurement (R1) is compared with setpoint adjustment (R2) in an ac bridge circuit. The thermal power measurement (R3) is added to the difference voltage between Rl and R2. At any instant when the phase of the voltage across the input to the circuit is reversed, the electronic relay is actuated, and a signal is provided for the plant protective system. This circuit provides a floating setpoint for neutron flux. It requires five electronic circuits to obtain the scram, setback, and alarm conditions that are shown in the graph in Figure 26. 


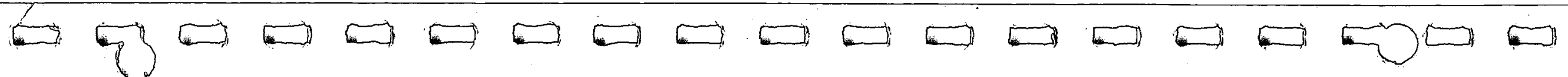
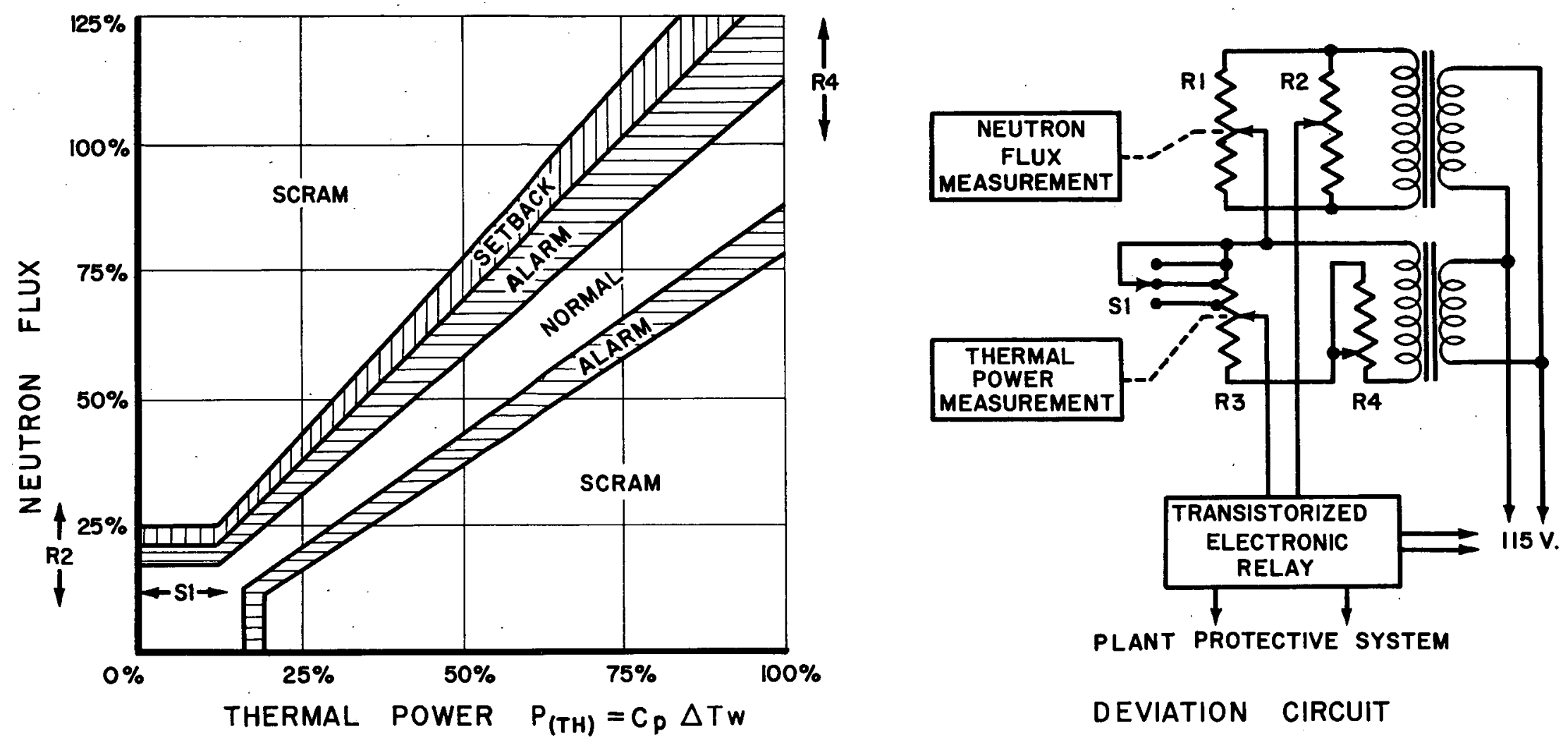

\begin{tabular}{|l|l|l|l|l|l|}
\hline ABNORMAL CONDITION & \multicolumn{1}{|c|}{$\Delta T$} & FLOW & FLUX & POWER & PROTECTION \\
\hline LOSS OF FLOW & CONSTANT & DECREASE & CONSTANT & DECREASE & \\
\hline INCREASED FLOW & CONSTANT & INCREASE & CONSTANT & INCREASE & I. ALARM \\
\hline HIGH COLD LEG TEMP. & DECREASE & CONSTANT & CONSTANT & DECREASE & 2. SETBACK \\
\hline HIGH FLUX TRANSIENT & CONSTANT & CONSTANT & INCREASE & CONSTANT & 3. SCRAM \\
\hline LOW FLUX TRANSIENT & CONSTANT & CONSTANT & DECREASE & CONSTANT & \\
\hline
\end{tabular}


R4 is the adjustment for the trailing edge of the trip level and determines the percent of deviation between flux and power before a trip signal is provided for the plant protective system. Sl adjusts the linearity of the circuit. R2 is the adjustment for the leading edge of the trip level, and is a fixed setpoint, which determines the power level that the neutron flux/power deviation limit becomes operative. Instability of sodium flow indication at low flowrates, improper mixing in the upper sodium plenum, and neutron statistical noise from the ionization chambers cause induced noise during lower power operation; therefore, $\mathrm{R} 2$ will be adjusted between 10 to $25 \%$ power.

By providing an adjustable rate limit on the reactor outlet temperature measuring circuit the time constant of the thermal power measurement can be delayed. This will provide protection against neutron flux transients of a longer duration than the time constant of the upper plenum, yet having sufficient magnitude to introduce thermal problems in the reactor complex. The adjustment of the rate limit circuit will be determined by the maximum rate of temperature change permissible in the reactor core.

Circuit specifications are:

a) Linearity: $0.1 \%$ of full-power range. Refers to the percent deviation of the trip point between flux and power over the entire thermal power range.

b) Circuit drift or repeatability: $0.5 \%$ of full-power range, over a 6-month period. This refers to drift in the deviation circuit that would cause a $0.5 \%$ change in the setpoint over a 6 -month period, providing the instrumentation is not calibrated periodically. This is much less than the drift of the measuring elements. In fact, the periodic calibration of the instrumentation is to compensate for the drift of the sensing elements such as the drift of the magnetic flowmeters over a 12 -month period.

c) Electronic relay deadband: $0.2 \%$ of full-power range. Refers to the recovery time of the deviation limit circuit when an abnormal condition that causes a reactor setback has been corrected. 
d) Time constant of the deviation limit circuit: $260 \mathrm{msec}$.

Refers to the measured time between the occurrence of an exponential increase (from a steady state condition) and the actuating of the trip circuits for the plant protective system. The deviation limit circuit is very flexible and can be adjusted to provide any linear or nonlinear band width; however, after the adjustments have been made the drift in repeatability is only $0.5 \%$ over a 6 -month period.

Meters are provided on the SRE control console to indicate the percent deviation between flux and power. This instrument will be provided with an alarm only during initial power operation until calibration and checkout can be performed.

2. Annunciator Alarm System

The windows for the annunciator alarm system have been relocated on one panel directly behind the control console. These window units were located on individual instrument panels prior to this modification. This modification will facilitate a better coordination of the reactor operations when an abnormal condition initiates an alarm in the control room.

All alarms that require immediate action, such as those abnormal reactor conditions that would cause a reactor scram, will have alarm windows with red lights. 


\section{FUEL ELEMENTS}

\section{A. REASON FOR CHANGE}

Damage to the fuel elements in the SRE just prior to July 26, 1959, indicates the desirability of increasing the annular clearance of the fuel elements in the coolant channels. Review of the indicated temperatures and resultant metallurgical conditions of the fuel also indicates that increased fuel temperature instrumentation is desirable. The possibility of some foreign material remaining in the bulk sodium indicates the desirability for a protective device to prevent these particles from entering the fuel channels. Distortion of the uranium fuel indicates the need for increasing the radial clearance. The fuelelement radial clearance was increased from 29 to 162 mils.

A change in the fuels development program has deleted the alloyed-uranium elements proposed for the seven central channels in the thorium-uranium core loading. The currently proposed core is a 34-element loading of clusters comprised of five standard thorium-uranium peripheral rods rather than the sevenrod clusters originally planned.

\section{B. FUEL ELEMENT GEOMETRY}

Alterations to the fuel element design indicated in Figures 27 and 28 are as follows:

1) Five standard peripheral rods from the previous seven-rod cluster are arranged in a concentric ring around a 3/8-in. -diameter stainless steel support rod.

2) Supporting spiders for the fuel rods have the same basic design as for the seven-rod cluster.

3) Top guide vane has been altered only enough to accommodate the fiverod cluster.

4) Bottom guide hardware (birdcage) has been modified to receive two conical filter sections employing a support ring for the top filter cone in place of the previous orifice plate. 

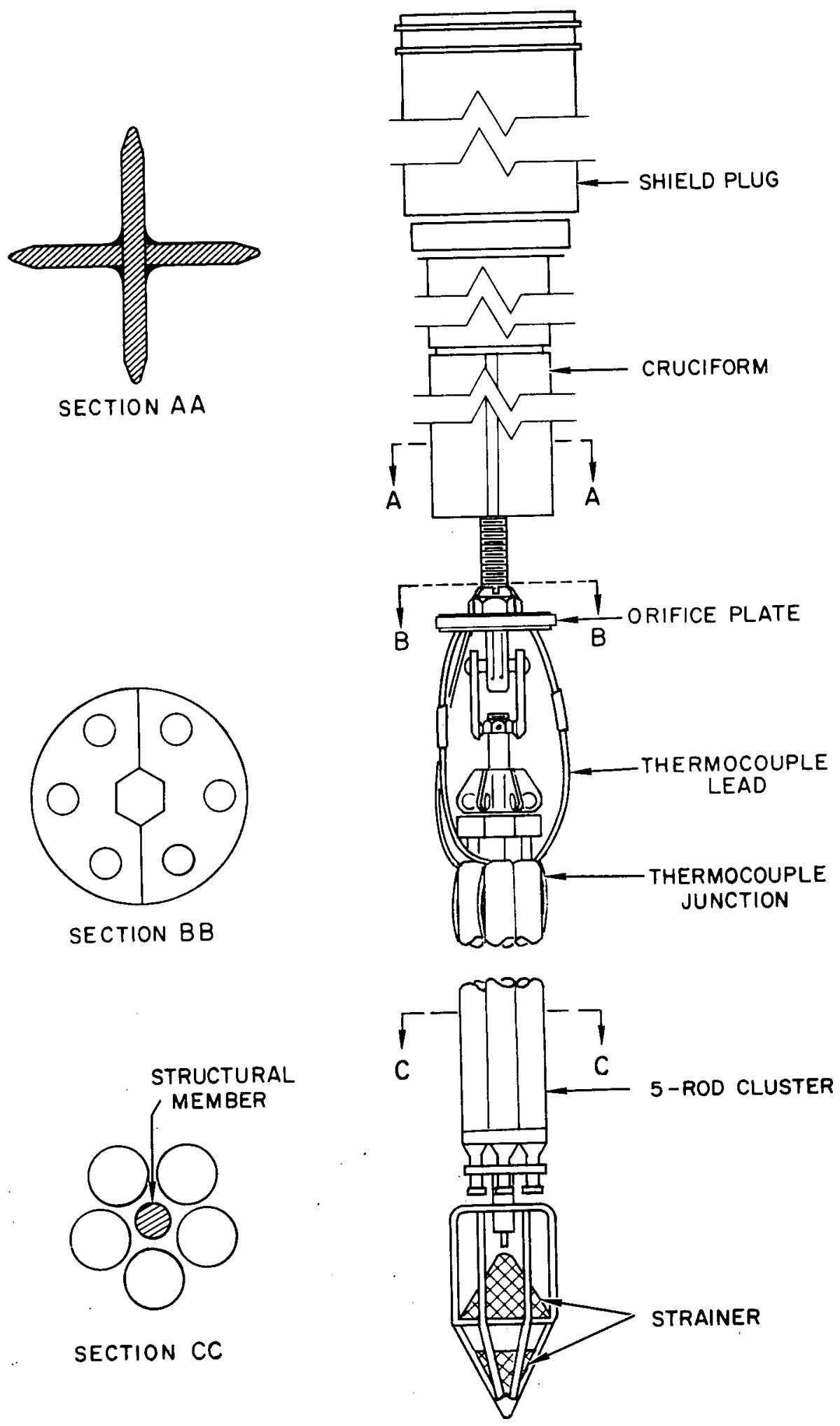

Figure 27. SRE Fuel Element Configuration 

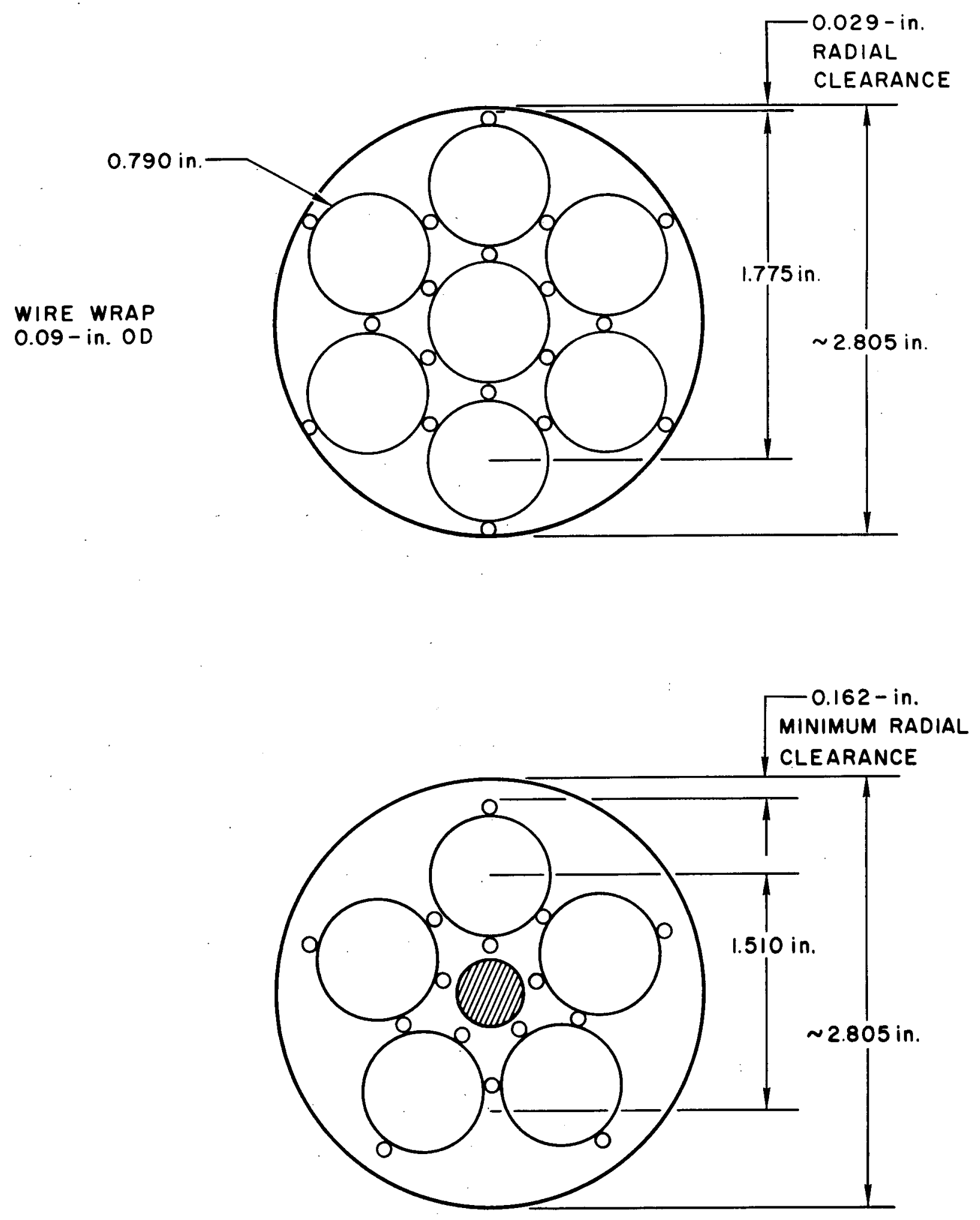

Figure 28. SRE Five-Rod and Seven-Rod Element Clusters 
5) Orifice plate has been moved to the top of the fuel channel and is attached to the hanger rod instead of to the fuel element.

6) Fuel-channel-exit-temperature thermocouple has been extended below the orifice plate and is positioned directly in the coolant stream.

7) Hanger rod and holddown tube from the previous design have been replaced with a cruciform section to reduce potential holdup of sodium and subsequent reactions in the wash cells.

8) Thermocouples have been installed in the fuel of eight elements to provide representative metal-temperature readings.

\section{Rod Geometry}

The radial clearance of the seven-rod cluster was 0.029 in. Five standard rods arranged in a concentric ring around a 3/8-in. stainless steel support rod allow $0.162-i n$. radial clearance between the wire wrap of the fuel rods and the fuel channel. An equivalent amount exists between the wire wrap of the fuel rods and the 3/8-in. stainless steel center support rod. This reduces the possibility that any foreign particle in the sodium stream will lodge and start a nucleation center for additional smaller particles. A filter at the bottom of the element, as described in Section VII-B-4, prevents particles larger than one-third of the clearance stated from entering the fuel channel. The fuel element area in the channel is reduced from $3.47 \mathrm{in.}^{2}$ for the seven-rod element to $2.59 \mathrm{in} .^{2}$ for the five-rod element. The sodium flow cross section is increased from 2.68 in. ${ }^{2}$ to $3.56 \mathrm{in.}^{2}$, an increase of $33 \%$. The velocity is decreased from $3.96 \mathrm{ft} / \mathrm{sec}$ to $2.7 \mathrm{ft} / \mathrm{sec}$ in the average channel and from $4.5 \mathrm{ft} / \mathrm{sec}$ to $3.12 \mathrm{ft} / \mathrm{sec}$ in the maximum power channel. Additional treatment of the core hydraulics is given in Section VII-D, and the fuel loading and nuclear characteristics are given in Section VII $-C$.

2. Supporting Spiders

No effect will be experienced from the support spiders.

3. Top Guide Vanes

No effect will be experienced from the top guide vanes. 


\section{The Bottom Guide}

Two conical screen sections in the bottom guide hardware (birdcage) prevent particles of foreign material (larger than one-third of the radial clearance of 0.162 in. between the fuel rod and the channel wall) from entering the coolant channel. The cones are inverted as shown in Figure 27, and the bottom cone is smaller in diameter to permit flow passage around its perimeter. A solid ring at the base of the top cone directs flow through the filter. Foreign material caught in the top screen, if not lodged securely in the screen, will drop into the bottom cone when the flow velocity is sufficiently decreased. The particles will be removed with the fuel element and disposed of in the wash cycle. Replacement of the screens is readily accomplished in the SRE hot cell. The method of attaching the bottom guide hardware is the same as used previously for seven-rod clusters which have been in the SRE during power operation. The strainer basket is larger than the opening in the moderator-can pedestal and thus it is not possible for it to drop into the lower plenum.

Collection of material on the upper screen can be discerned by slight increases in the channel exit temperature, and the element can be removed for cleaning before flow is sufficiently inpeded to induce detrimental fuel

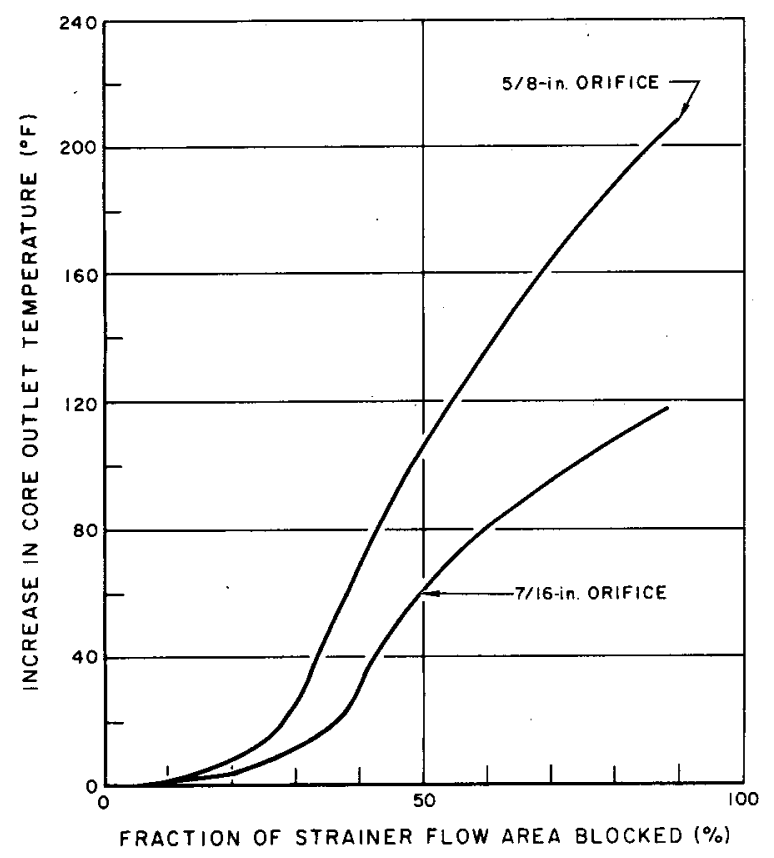

Figure 29. Increase in Core Outlet Temperature Due to Blocking of the Strainer on the Five-Rod Cluster temperatures. Experimental relationship between percentage of screen blockage and resultant fuel channel exit temperature are shown in Figure 29. On an element with a 7/16-in. orifice plate, a $50 \%$ blockage of screen area will increase the temperature gradient across the length of the fuel element by $60^{\circ} \mathrm{F}$. An 0.037-in. radial clearance between the ring at the bottom of the upper screen section and the coolant channel wall permits a certain amount of flow past the filter. If the ring rests against one wall of the channel, the passage will be smaller than the screen mesh in the filter; thus no oversize particles will 
follow this path. However, the sodium flow around this plate does affect the sodium-temperature gradient, and the change in the gradient as shown in Figure 29 would be slightly larger for a given percentage of screen blockage if the annular clearance did not exist. A 50\% blockage of the screen can be readily detected by a $60^{\circ} \mathrm{F}$ change in the temperature gradient. This is well within the range of observation on the fuel-channel-exit-temperature recorder. Operating experience with the first fuel loading in the SRE has established that changes of this magnitude will not be masked by differences in temperature distribution caused by alteration of control rod pattern during power operation.

\section{Orifice Plate}

Moving the orifice plate above the fuel element permits its perimeter to reside within the machined surface of the spacer ring hardware at the top of the moderator can, thus allowing closer tolerances to be maintained and thereby assuring predictable peripheral sodium leakage past the orifice plate. This in turn will permit a more accurate control of the sodium flow in the respective channels and thus more even temperature distribution throughout the core.

\section{Fuel Channel Exit Thermocouple}

Placing the thermocouples directly in the coolant stream will provide a faster rate of response for measurement of fuel-channel sodium exit temperature. Extending the thermocouple below the orifice plate will reduce the possibility of convective flow and/or heat conduction from the upper plenum, thus assuring that the thermocouple will measure the true temperature of sodium in the channel, thereby improving detection of flow restriction in the channel.

7. Hanger Rod and Holddown Tube

The cruciform section supporting the fuel element in the new design provides both support and holddown protection against a rising moderator can as did the previously used hanger rod and holddown tube. It has the added advantage that there are no confined areas or horizontal surfaces to retain sodium when the element is pulled from the reactor, thus minimizing the possibility of damaging fuel elements during the wash cycle. 


\section{NUCLEAR CHARACTERISTICS}

The initial fuel loading will be comprised entirely of five-rod thoriumuranium fuel elements as described above. The fuel material is Th -7.6 wt $\% \mathrm{U}$ $\left(93 \%\right.$ enriched $\left.U^{235}\right) .20$ Clean wet critical loading has been calculated to be $26 \pm 2$ elements. The proposed initial operating load will consist of 34 five rod thorium-uranium elements with graphite dummies in the remaining nine peripheral fuel channels. An equivalent seven-rod thorium-uranium loading would consist of 31 elements. The loading originally planned consisted of 30 seven-rod thorium-uranium elements with seven unalloyed-uranium elements from the first core loading in the central fuel channels.

The total excess reactivity of all fuel elements loaded in the reactor at one time will be limited to approximately one-half the worth of four shim rods, which is approximately one-fourth of the combined shim and safety rod worths. Reactivity worth measurements will be performed on any experimental fuel elements added at a later date to assure compliance with this limitation.

\section{Individual Element Worths}

Danger coefficient measurements in the SGR critical facility indicate the difference in the worth of a five-rod thorium-uranium element and a seven-rod thorium-uranium element to be $-0.185 \% \Delta \mathrm{k} / \mathrm{k}$ with the $3 / 8-\mathrm{in}$. stainless steel center support rod and $-0.119 \%$ without. By comparison, the same tests show, a difference of $0.50 \%$ between the seven-rod thorium-uranium cluster and the seven-rod unalloyed-uranium cluster, corroborating analytical work based on information from the first core loading. Less difference in reactivity worth is expected in the reactor. For example, the difference between the seven-rod thorium-uranium element and seven-rod unalloyed-uranium element in the reactor was measured to be $0.28 \%$ in the center fuel channel compared to the $0.50 \%$ difference in the critical facility stated above. On this basis, the actual difference between the five-rod and seven-rod thorium-uranium element in the reactor is expected to be between $-0.07 \%$ and $-0.14 \%$. Total measured worth of a seven-rod thorium-uranium element in the center fuel channel is approximately $1.4 \%$. 


\section{Reactor Characteristics with Five-Rod Thorium-Uranium Fuel}

Based upon the close correlation between theoretical and experimental (in the SRE and the SGR Critical Facility) worths of individual fuel elements, the total excess reactivity in a 34-element loading of five-rod thorium-uranium clusters will not be significantly different than that with 31 seven-rod thoriumuranium elements. The calsulated excess reactivity will be approximately $3.5 \%$. This is approximately one-half the worth of all four shim rods and approximately one-fourth the combined worth of four shim rods and four safety rods. Shimand safety-rod worths are discussed in Section VII-C-2-a of this report. The general nuclear parameters for the unalloyed uranium, seven-rod thoriumuranium and five-rod thorium-uranium cores are given in Table VI.

a. Control Rod Worths

The four SRE shim rods in the first core unalloyed-uranium loading were calibrated to be worth a total of $7.8 \%$ reactivity when summed individually, or approximately $7 \%$ considering shadowing. The total worth of four safety rods is $5.7 \%$ when summed individually and $5.1 \%$ considering shadowing.

Control rod worths are estimated to be approximately the same for the 34 five-rod thorium-uranium element loading based on the similarity of the pertinent nuclear constants. The core nuclear constants of interest in comparing control-rod worths for the different fuel loadings are the fast diffusion coefficient $\left(D_{\text {fast }}\right)$ and the thermal diffusion coefficient $\left(D_{\text {slow }}\right)$, the effective fast diffusion area $(\tau)$ and the thermal diffusion area ( $L^{2}$ ). These constants are presented in Table VI for 43 unalloyed-uranium elements, 31 seven-rod thorium-uranium elements, and 34 five-rod thorium-uranium elements. The similarity in these constants and the flux distribution in the core for the three loadings indicates very little change in the control rod worths. The maximum reactivity insertion rates from individual or combined shim and regulating action of the four shim rods remains approximately as described in the "Hazards Summary for Thorium-Uranium Fuel in the SRE," 20 (i.e., regulating motion for one $\operatorname{rod}$ is $3.9 \times 10^{-2} \%$ / sec max; shim motion for one rod is $2.9 \times 10^{-3} \% / \sec \max$; and shim motion for four rods is $1.16 \times 10^{-2} \% / \sec \max$ ).

With the excess reactivity loading, as determined experimentally by individual fuel element insertions, limited to $3.5 \%$, the control margin remains 
TABLE VI

CALCULATED PHYSICS PARAMETERS FOR THE FIRST AND SECOND CORES

\begin{tabular}{|c|c|c|c|c|}
\hline & $\begin{array}{l}\text { First } \\
\text { Core }\end{array}$ & $\begin{array}{l}7 \text { - Ród } \\
\text { ThU. }\end{array}$ & $\begin{array}{c}\text { 5-Rod } \mathrm{ThU}^{*} \\
\text { (Clean } \\
\text { Cold } \\
\left.340^{\circ} \mathrm{F}\right) \\
\end{array}$ & $\begin{array}{c}\text { 5-Rod ThU } \\
\text { (Hot, Full- } \\
\text { Power } \\
\text { Poisoned) }\end{array}$ \\
\hline$\eta$ & 1.823 & 1.818 & 1.818 & \\
\hline$\epsilon$ & 1.043 & 1.012 & 1.010 & \\
\hline $\mathrm{p}$ & 0.816 & 0.845 & 0.879 & \\
\hline$f$ & 0.814 & 0.863 & 0.936 & \\
\hline$\tau$ & 371 & 371 & 374 & \\
\hline $\mathrm{L}^{2}$ & 148 & 128 & 149 & \\
\hline$D_{\text {fast }}$ & 1.077 & 1.077 & 1.087 & \\
\hline$D_{\text {slow }}$ & 0.960 & 0.966 & 0.968 & \\
\hline$\sum^{\text {fuel }}$ & & & & \\
\hline$\angle a$ & 0.7225 & 1.158 & 1.158 & \\
\hline Excess reactivity $(\%)$ & & & & \\
\hline 37 elements & 1.70 & 7.2 & $7.1^{\dagger}$ & \\
\hline 33 elements & - & - & 3.5 & 1.4 \\
\hline 30 elements & - & 3.8 & - & \\
\hline
\end{tabular}

* The above parameters for the 5-rod clusters do not include the effect of the steel rod.

†From experimental measurements in the critical facility the excess reactivity of 34 clusters of 5 -rod assemblies with a steel support rod in the center of each cluster is calculated to be $3.5 \%$. 
at $3.5 \%$. The combined reactivity of the four safety rods $(5.1 \%)$ provides an adequate margin over the excess reactivity stated.

\section{b. Reactivity Coefficients}

Reactivity coefficients of fuel temperature, overall isothermal temperature, power; and sodium void are listed in Tables VII, VIII, and IX for the cores being compared. Coefficients for the five-rod thorium-uranium loading lie between those of the unalloyed uranium and those of the seven-rod thoriumuranium loadings which were previously approved. Fuel temperature coefficients are strongly negative for all three cases. Isothermal temperature coefficients are all positive at low temperatuies approaching zero at the average core temperatures for power operation. The graphite moderator temperature coefficient of reactivity is positive, but its effect is relatively slow (10-min time constant) compared to the negative reactivity effect of fuel temperature changes (9-sec time constant). The fast response of the strong negative metal temperature coefficient provides protection against rapid reactivity excursions, even though the overall isothermal temperature coefficient of reactivity may be positive for the conditions that exist at any one time. The power coefficients are estimated to be negative in all power ranges with the possible exception of below $10 \%$ of full power. The steady-state power coefficients of reactivity for the thoriumuranium cores with both five-rod and seven-rod clusters are more strongly negative than that of the unalloyed-uranium core and may remain negative even below $10 \%$ of full power. Values of the power coefficient indicated are based upon steadystate reactor conditions. The power coefficient is negative because the fueltemperature rise is significantly greater than the graphite temperature rise which results from a small power increase throughout the normal power range. A short fuel time constant $(9 \mathrm{sec}$ ) compared to the relatively long graphite time constant (10 min or longer) maintains prominence of the negative factor in the power coefficient for short-term transients (in the order of seconds). The fuel channel sodium void coefficient of reactivity for the five-rod thorium-uranium core is about midway between those of the unalloyed uranium core and the seven-rod thoriumuranium core.

Two sets of temperature coefficients (Table VII) and power coefficients (Table VIII) are shown for each of the cores under comparison. The 
TABLE VII

CALCULATED TEMPERATURE COEFFICIENTS OF REACTIVITY (All numbers in units of $10^{-5} \Delta \mathrm{k} / \mathrm{k}$ per ${ }^{\circ} \mathrm{F}$ )

\begin{tabular}{|c|c|c|c|c|}
\hline & & 7-Rod ThU & $\underline{5-\operatorname{Rod} T h U}$ & $\begin{array}{c}\text { First } \\
\text { Core U }\end{array}$ \\
\hline & $\alpha_{f}$ & -2.2 & -1.7 & -1.4 \\
\hline & $\alpha_{c}$ & $\begin{array}{l}+0.3 \\
+0.1\end{array}$ & $\begin{array}{l}+0.3 \\
+0.2\end{array}$ & $\begin{array}{l}+0.3 \\
+0.3\end{array}$ \\
\hline $300^{\circ} \mathrm{F}$ & $\alpha_{\mathrm{m}}$ & $\begin{array}{l}+2.3 \\
+3.6\end{array}$ & $\begin{array}{l}+2.3 \\
+2.9\end{array}$ & $\begin{array}{l}+2.3 \\
+2.3\end{array}$ \\
\hline $800^{\circ} \mathrm{F}$ & $a_{m}$ & $\begin{array}{l}+1.2 \\
+2.0\end{array}$ & $\begin{array}{l}+1.2 \\
+1.5\end{array}$ & $\begin{array}{l}+1.2 \\
+1.2\end{array}$ \\
\hline $300^{\circ} \mathrm{F}$ & $\alpha_{1}$ & $\begin{array}{l}+0.4 \\
+1.5\end{array}$ & $\begin{array}{l}+0.9 \\
+1.4\end{array}$ & $\begin{array}{l}+1.2 \\
+1.2\end{array}$ \\
\hline $800^{\circ} \mathrm{F}$ & $a_{1}$ & $\begin{array}{l}-0.7 \\
-0.1\end{array}$ & $\begin{array}{r}-0.2 \\
0.0\end{array}$ & $\begin{array}{l}+0.1 \\
+0.1\end{array}$ \\
\hline
\end{tabular}

where $\alpha_{f}=$ Fuel-temperature coefficient $\boldsymbol{a}_{1}=\underset{\substack{\text { Isothermal-temperature } \\ \text { coefficient }}}{ }$

$a_{\mathrm{m}}=\underset{\substack{\text { Moderator } \\ \text { coefficient }}}{\text { temperature }}$

$a_{c}=\underset{\text { coefficient }}{\text { Coolant-temperature }}$

T ABLE VIII

CALCULATED STEADY-STATE POWER COEFFICIENTS

(All numbers in units of $10^{-5} \Delta \mathrm{k} / \mathrm{k}$ per Mwt)

\begin{tabular}{|c|c|c|c|c|}
\hline & & 7 -Rod ThU & 5-Rod ThU & $\begin{array}{c}\text { First } \\
\text { Core U } \\
\end{array}$ \\
\hline $300^{\circ} \mathrm{F}$ & $\mathrm{H}_{\mathrm{SS}}$ & $\begin{array}{l}-11.8 \\
-\quad 1.5\end{array}$ & $\begin{array}{l}-5.4 \\
-\quad 1.3\end{array}$ & $\begin{array}{l}+0.90 \\
+0.90\end{array}$ \\
\hline $800^{\circ} \mathrm{F}$ & $\mathrm{H}_{\text {ss }}$ & $\begin{array}{l}-19 \\
-10.5\end{array}$ & $\begin{array}{l}-12.6 \\
-\quad 8.9\end{array}$ & $\begin{array}{l}-7.0 \\
-7.0\end{array}$ \\
\hline
\end{tabular}

TABLE IX

CALCULATED VOID COEFFICIENTS

(AIl numbers in $10^{-5} \Delta \mathrm{k} / \mathrm{k}$ per $\%$ void)

\begin{tabular}{|c|c|c|c|}
\hline & 7-Rod ThU & 5 -Rod ThU & $\begin{array}{c}\text { First } \\
\text { Core U } \\
\end{array}$ \\
\hline Void Coefficient & +4.9 & +6.5 & +8.6 \\
\hline
\end{tabular}


two were determined by different calculational methods. The assumptions used in these calculations are as follows:

1) Moderator and coolant coefficients were considered to be the same as those established experimentally for the original unalloyed-uranium core.

2) Moderator and coolant coefficients were modified from those in case 1) to allow that:

a) Coolant coefficient is proportional to the percent of neutrons absorbed in the coolant.

b) Part of the moderator coefficient due to leakage is proportional to the amount of leakage.

c) Part of the moderator coefficient due to thermal flux dis tribution in the cell is proportional to the flux depression in the fuel.

Calculated void coefficients are given in Table IX.

Experimental determination of the reactivity coefficients and their time constant on the first core loading are discussed in Reference 18 .

c. Reactivity Changes Due to Long-Term Effects with ThoriumUranium Alloy Fuel

The accumulation of reactivity from $\mathrm{U}^{233}$ formation is less for the five-rod element loading than for the seven-rod element core. After $1500 \mathrm{Mwd} / \mathrm{T}$ of full-power operation, and 100 days of decay, the reactivity buildup is $0.23 \%$ for the five-rod element core compared to $0.25 \%$ for the seven-rod element core. This amount is small for both cases compared to the control margin available in the control rods.

\section{HYDRAULIC CHARACTERISTICS OF FUEL CHANNELS}

Hydraulic characteristics of the fuel channels will not be significantly different for the five-rod clusters than for the seven-rod clusters.

\section{Normal Flow Conditions}

The normal flow cross section in the channel is increased from $2.68 \mathrm{in.} 2$ for the seven-rod cluster to $3.56 \mathrm{in} .^{2}$ for the five-rod cluster, an increase of $33 \%$. 
The velocity is decreased from 3.96 to $2.71 \mathrm{ft} / \mathrm{sec}$ in the average channel and from 4.55 to $3.12 \mathrm{ft} / \mathrm{sec}$ in the maximum power channel. The wetted perimeter is decreased from 2.17 to $1.86 \mathrm{ft}$.

From the changes in hydraulic characteristics, the film coefficient for heat transfer (h) is reduced from 7500 to $5000 \mathrm{Btu} / \mathrm{hr}-\mathrm{ft}^{2}$, a decrease of $35 \%$. The effects of this change in heat transfer on fuel temperature are reflected in Section VII-E. The pressure drop across the core with the five-rod elements is maintained close to that with the seven-rod clusters. A larger percentage of the drop occurs across the orifice plate, which permits more accurate flow control by orificing sizing. Experimental pressure drops across the various parts of the five-rod fuel element are illustrated in Figures 30 and 31 . At an average flowrate of $3.3 \mathrm{lb} / \mathrm{sec}$, the drop across the fuel element with 3/8-in. holes in the orifice plate is 1.4 psi compared to 0.28 psi without the orifice plate.

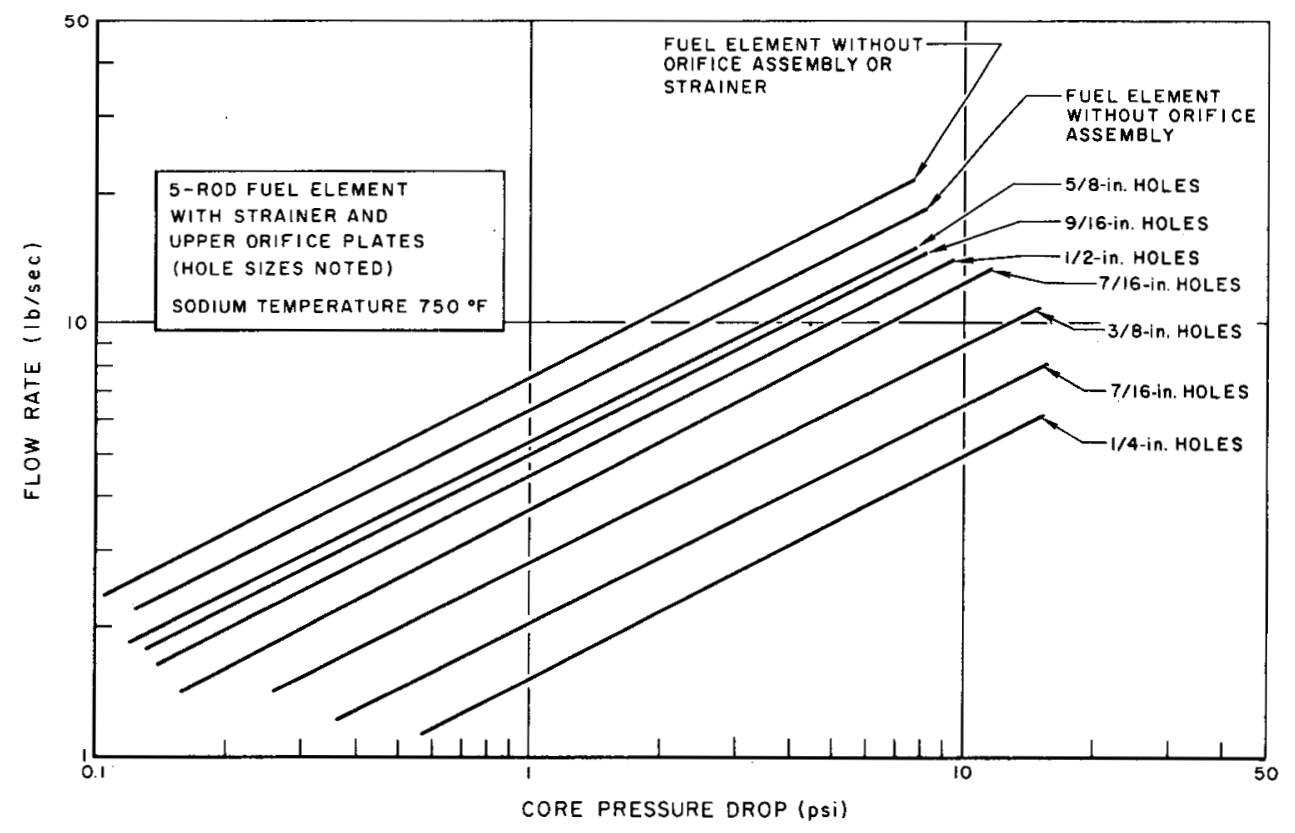

Figure 30. Core Pressure Drop vs Channel Flowrate

\section{E. FUEL TEMPERATURES}

The maximum central fuel temperatures and the maximum surface fuel temperature have been calculated to be 1190 and $1010^{\circ} \mathrm{F}$ respectively in the maximum power channel under normal operating conditions of $20 \mathrm{Mwt}$. If hot channel conditions exist, the maximum central fuel and fuel surface temperatures 
may increase to 1255 and $1085^{\circ} \mathrm{F}$ respectively. Axial fuel temperature distributions are shown for the 34 five-rod elements in Figure 32 and for the 31 sevenrod elements in Figure 33. The calculations for these numbers are based upon the following conditions:

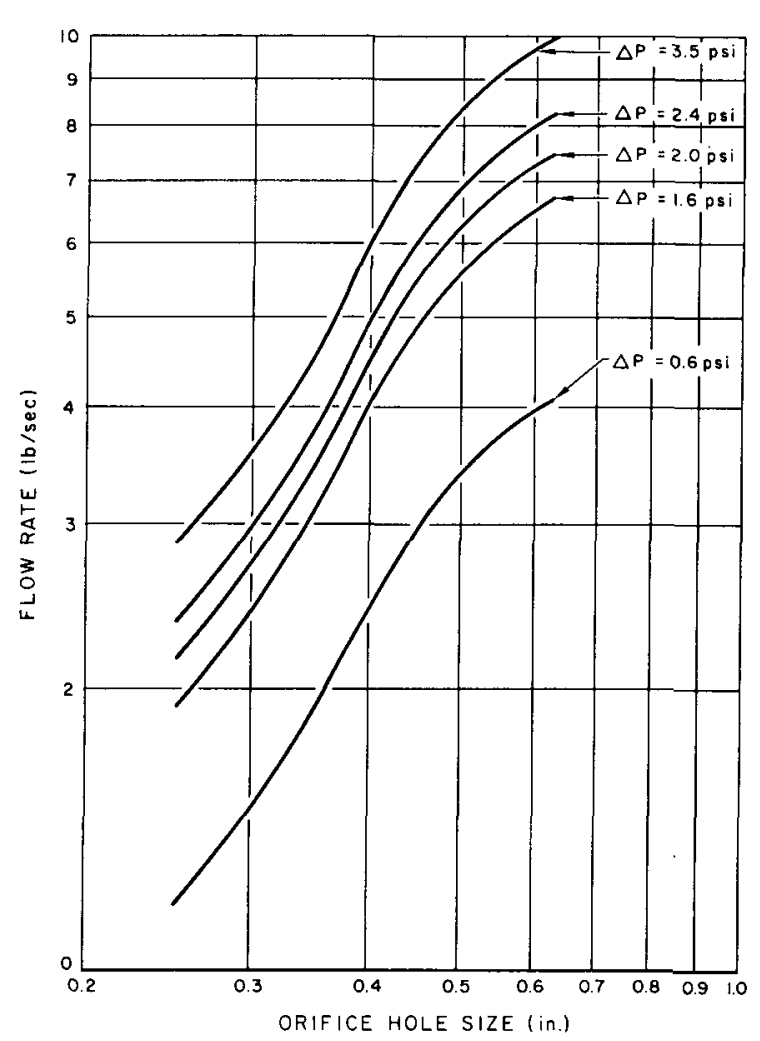

Figure 31. Orifice Hole Size vs Channel Flowrate (five-rod cluster)
Reactor Power (Mwt)

Sodium Flowrate ( $\mathrm{b} / \mathrm{hr}$ )

Reactor Outlet Temperature $\left({ }^{\circ} \mathrm{F}\right)$

Reactor Inlet Temperature $\left({ }^{\circ} \mathrm{F}\right) \quad 500$

Heat Loss from the Reactor $(\%) \quad 1$

Axial Peak-to-Average Power $\quad 1.24$

Radial Peak-to-Average Power 1.15

Hot Channel Factor 1.16

Heat Generated in Fuel (\%) $\quad 90.0$

High temperature limitations for the fuel are established by eutectic formation thresholds at the fuel cladding interface as follows:

$\mathrm{ThFe}$

ThCr

$\mathrm{ThNi}$

$\mathrm{Th}-7.6 \mathrm{wt} \% \mathrm{U}$ $1580^{\circ} \mathrm{F}$ $2230^{\circ} \mathrm{F}$ $1830^{\circ} \mathrm{F}$

$1580^{\circ} \mathrm{F}$
$2230^{\circ} \mathrm{F}$
$1830^{\circ} \mathrm{F}$
$2000^{\circ} \mathrm{F}$
(weak reaction
only)

The maximum surface fuel temperature of $1085^{\circ} \mathrm{F}$ is well within these limits. The beta-gamma phase shift in thorium is very slight at $2800^{\circ} \mathrm{F}$, well above the maximum central fuel temperature of $1255^{\circ} \mathrm{F}$. Phase changes in thoriumuranium fuel are discussed in Reference 19. No geometrical differences resulting from phase changes of uranium in $\mathrm{Th}-7.6 \mathrm{wt} \% \mathrm{U}$ fuel have been observed.

These parameters are design objectives. The actual temperatures for fuel and sodium will be controlled within limits compatible to the impurities in the sodium. 20 


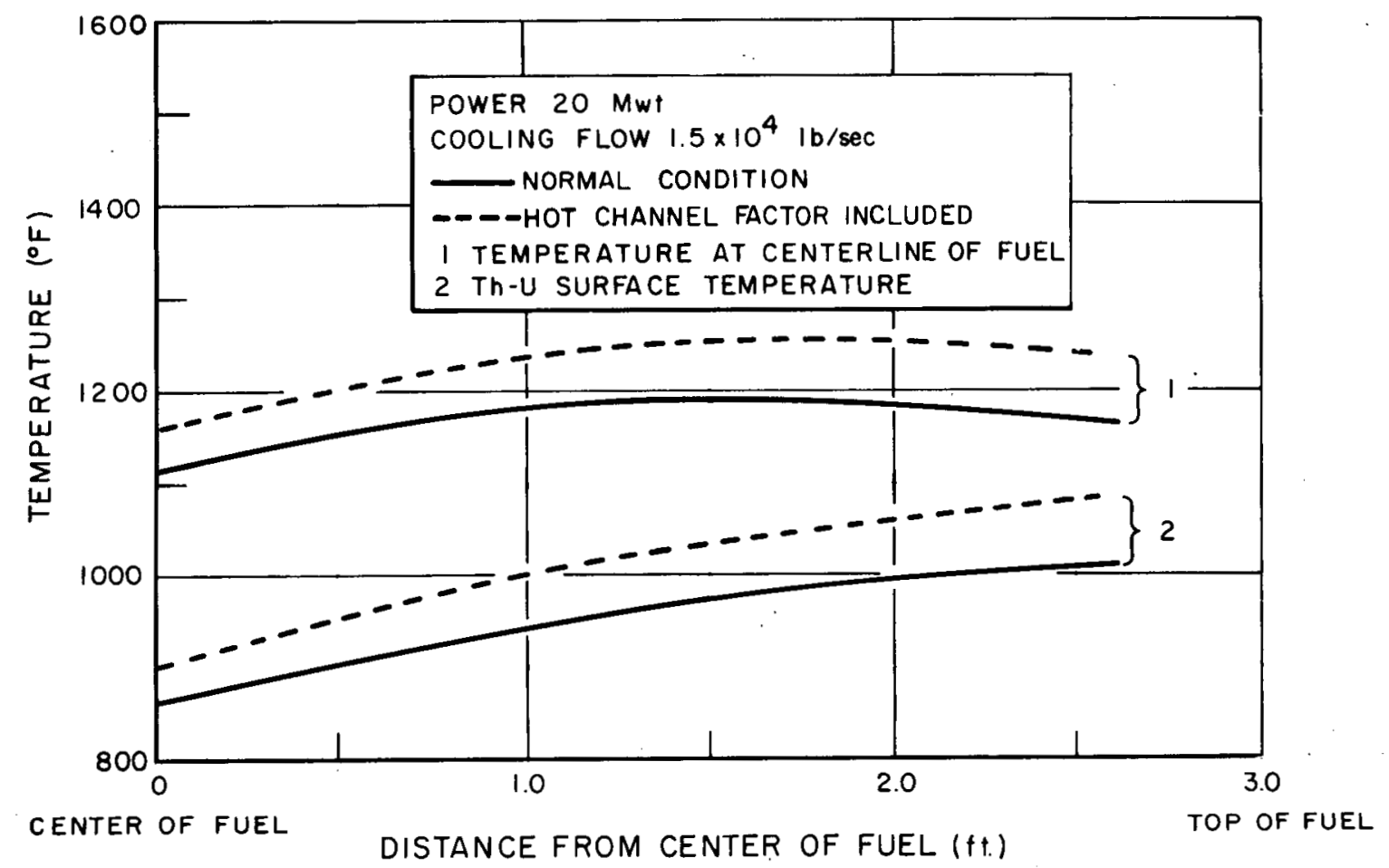

Figure 32. Axial Fuel-Temperature Distribution for 34 Five-Rod Elements

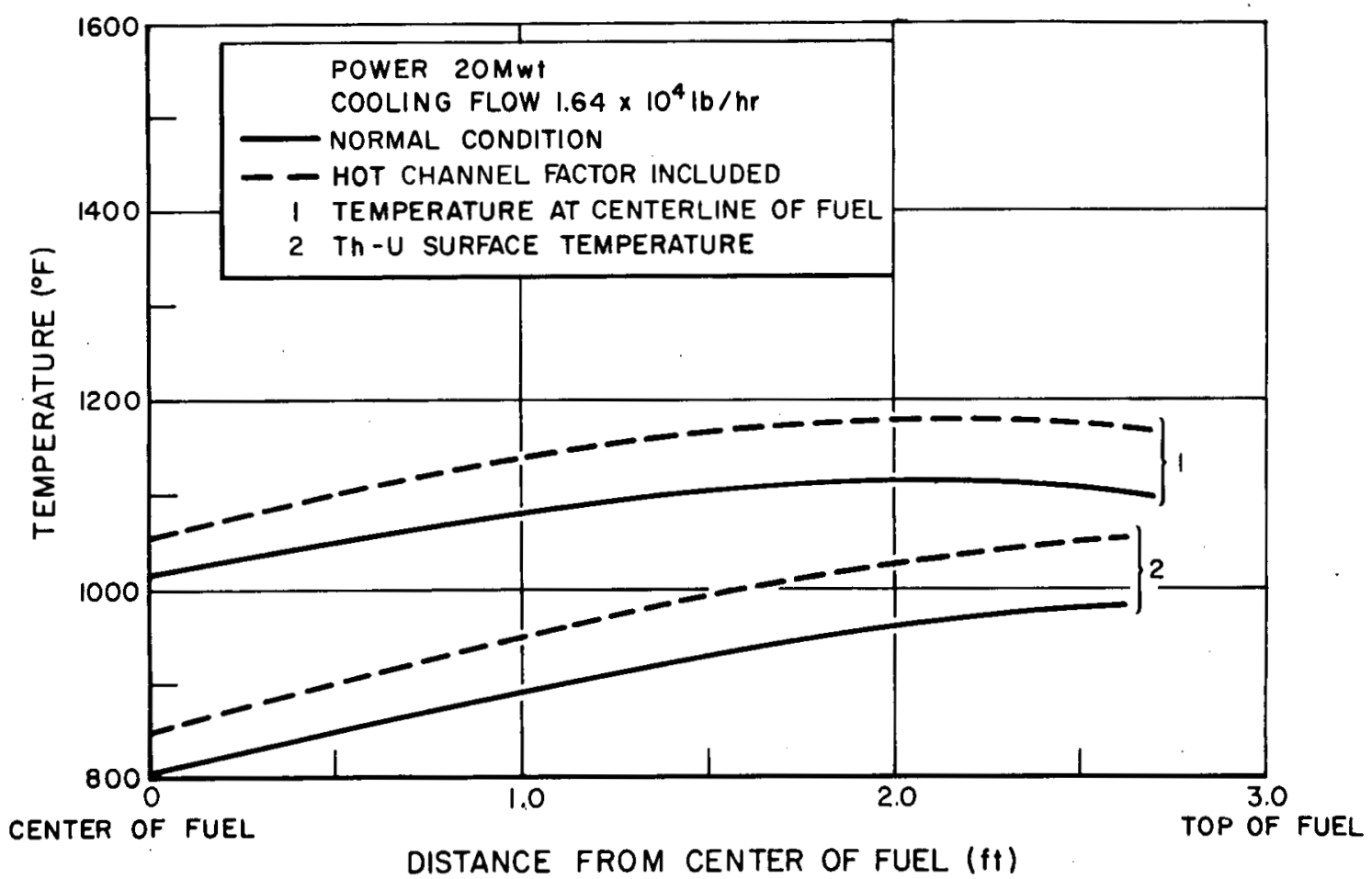

Figure 33. Axial Fuel-Temperature Distribution for 31 Seven-Rod Elements 


\section{REFERENCES}

1. R. L. Ashley, et al, "SRE Fuel Element Damáge, "NAA-SR-4488 (November 30, 1959).

2. Merck \& Co., Inc., The Merck Index of Chemicals and Drugs, (6th ed., Rahway, New Jersey, 1952).

3. J. S. McDonald and J. E. Owens, "Investigation of Tetralin Explosion," NAA-SR-4803 (March 1, 1960).

4. P. Barbour, "Liquid Coolant Replacement for Tetralin in Sodium Graphite Reactors," (unpublished letter, Atomics International, Canoga Park, California, 1959).

5. National Fire Protection Association, The National Fire Codes, Vol. I, "Flammable Liquids and Gases," (Boston, Massachusetts, 1958), Chapter I.

6. R. L. McKisson and K. E. Horton "The Behavior of Tetralin in Liquid Sodium," NAA-SR-1771 (February 1, 1957).

7. N. I. Sax, Handbook of Dangerous Materials (New York, Reinhold Publishing Corporation, 1951) p 241

8. Edwards Air Force Base Staff, "Safety Procedures for Rocket Propellants," FTR-TM-58-1 (November, 1958) Chapter 4.

9. Liquid Propellant Information Agency, Liquid Propellants Safety Manual, (Applied Physics Laboratory, Johns Hopkins University, Silver Springs, Maryland, 1958) Chapter 10.

10. Supplied by C. Fuller, American Airlines, in a conversation with T. Staggs, Atomics International, May, 1960.

11. J. S. McDonald, "Valve Stem Freeze Seal for High Temperature Sodium," NAA-SR-4869 (1960).

12. R. B. Hinze, "Control of Oxygen in a Large Sodium System," NAA-SR-3638 December 1, 1959).

13. American Society of Mechanical Engineers, ASME Boiler and Pressure Vessel Code, Section VIII, "Unfired Pressure Vessels," (1956).

14. R. Cygan, "HNPF Cold Trap Evaluation," NAA-SR-4382 (December 15, 1959).

15. W. J. Anderson and G. V. Sneesby, "Carburization of Austenitic Stainless Steel in Sodium," NAA-SR-5282 (1960).

16. J. E. Gosline and M. P. O'Brien, "The Water Jet Pump," University of California Publication in Engineering, Vol. 3, No. 3, (1942) p 167-190

17. G. C. Gower, "Progress Report on Wash Cell Testing," (unpublished TDR 4550, Atomics International, Canoga Park, California, (October 5, 1959).

18. C. W. Griffin and J. G. Lundholm, "Mea surement of the SRE Power Coefficients and Reactor Parameters Utilizing Oscillation Techniques," NAA-SR-3763 (to be published). 


\section{REFERENCES}

19. O. G. Bentle, "A Physical Metallurgical Study of Thorium-Rich, ThoriumUranium Alloys," NAA-SR-2069 (January 15, 1958).

20. Atomics Intexnational Staff "Hazards Summary for Thorium-Uranium Fuel in the Sodium Reactor Experiment," NAA-SR-3175 (Rev.) July 1, 1959.

21. To provide a single document which contains all of the modifications to the SRE made in FY 1960, Section VII of this report was extracted from NAA-SR-3175 (Rev.) Supplement, by D. H. Johnson, with only minor changes. 


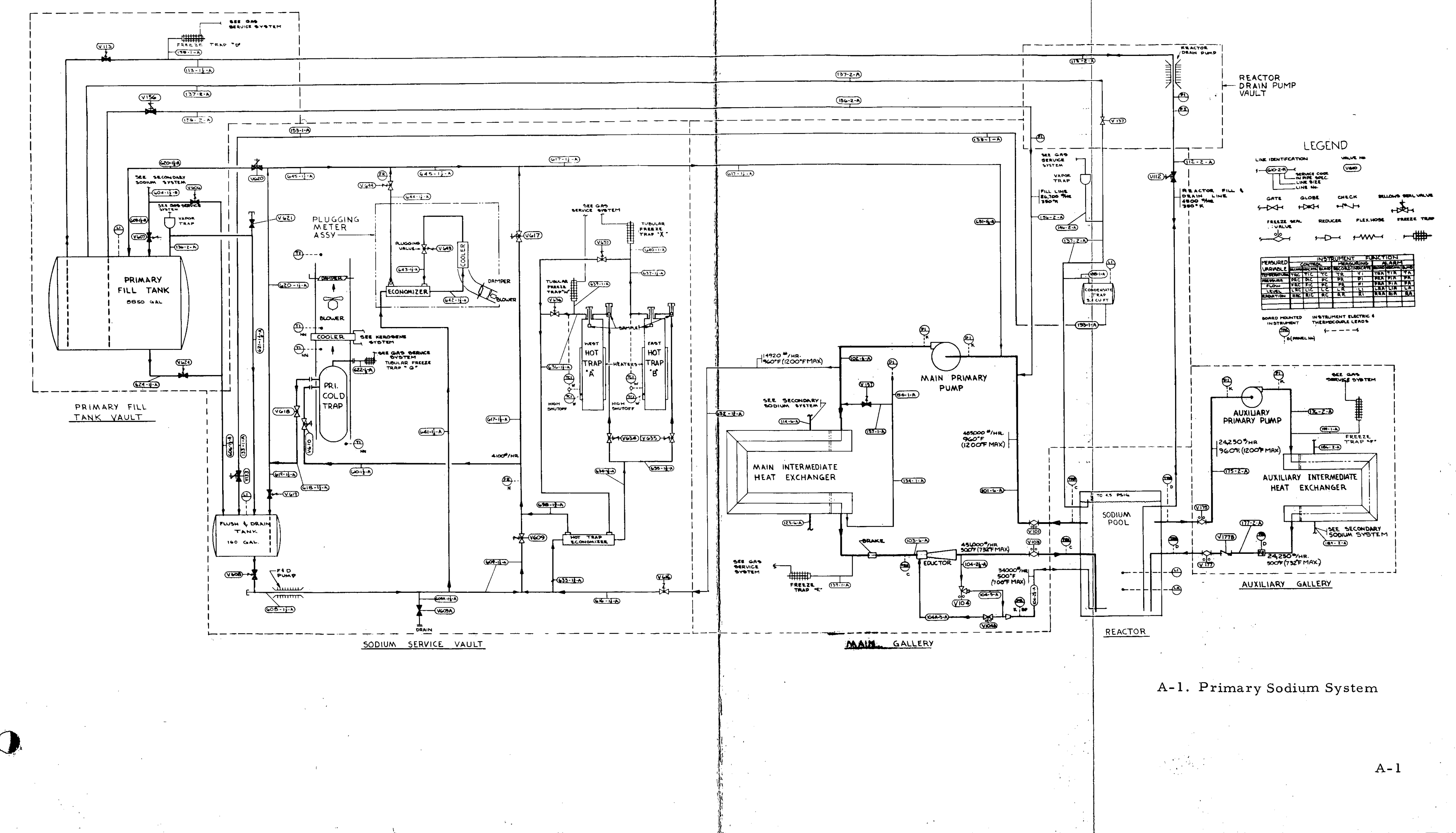



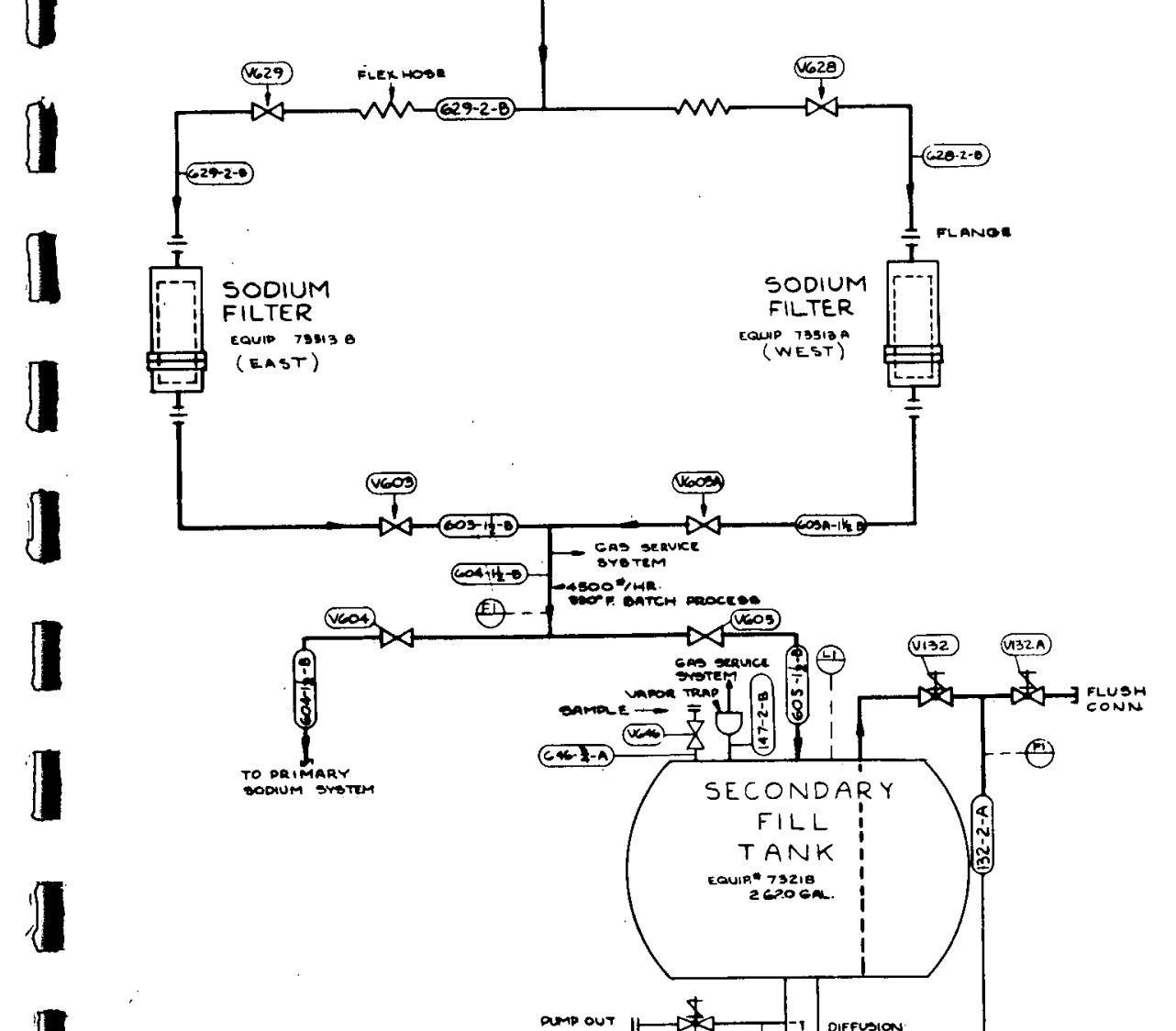

and

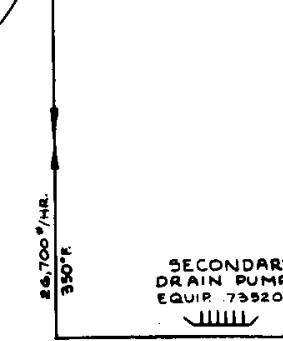

(1124)

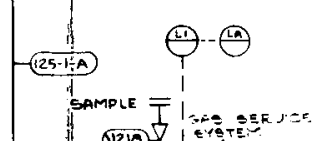

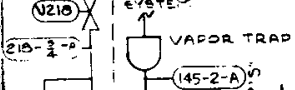

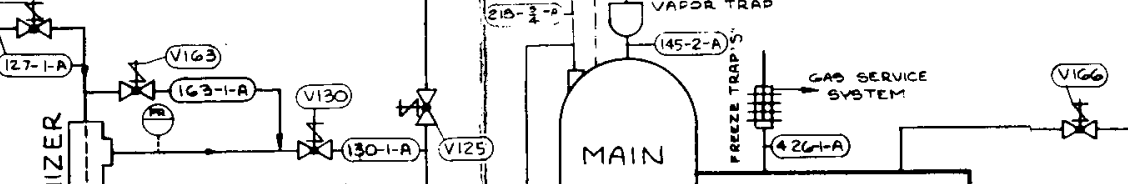

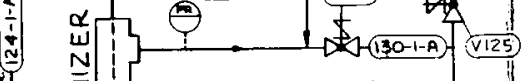

政

SEC EXPAN

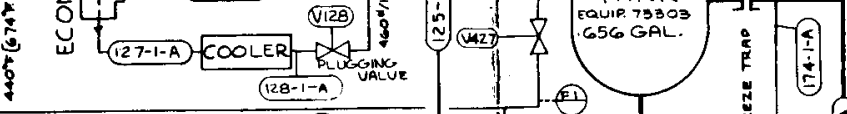

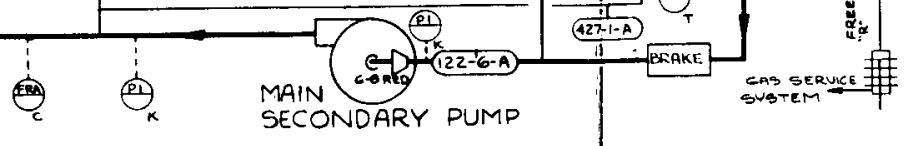

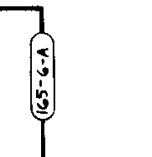

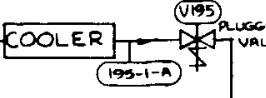

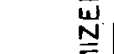
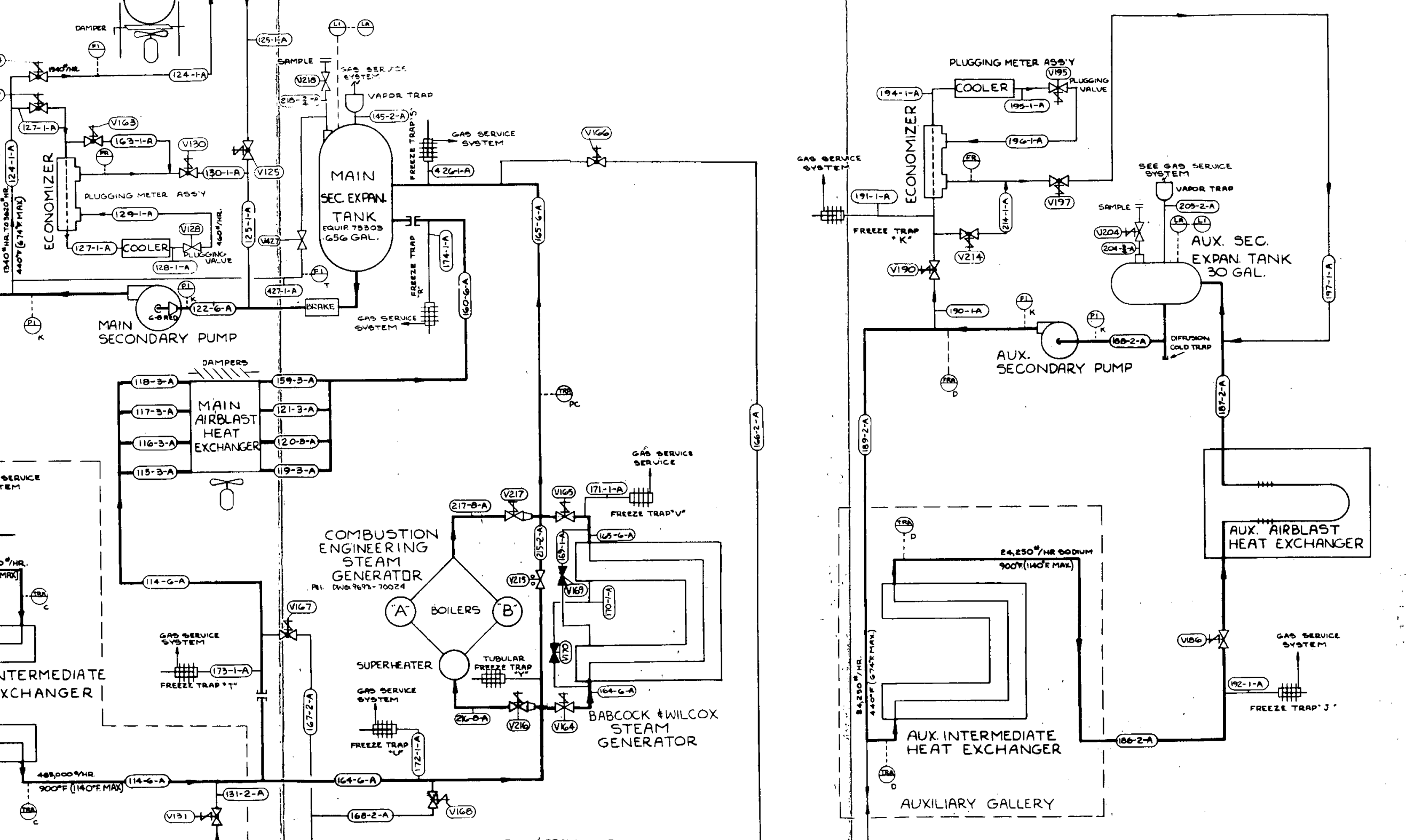

$\operatorname{mis}_{c}$

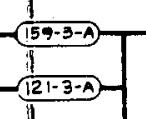
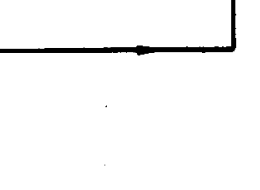

$-\infty$

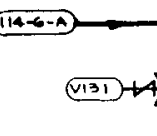

(2n)
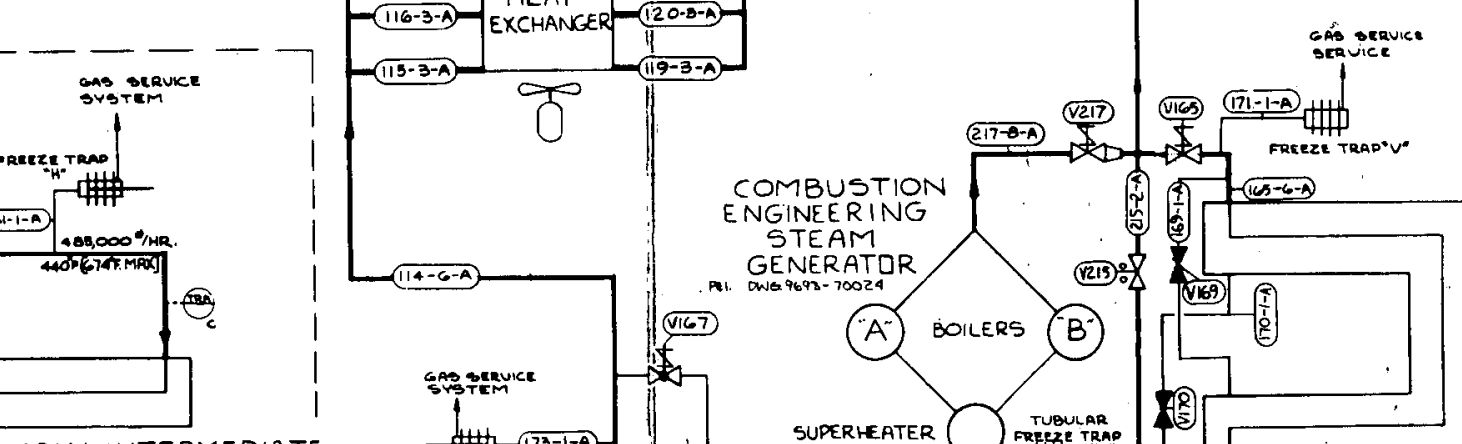

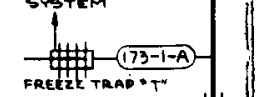

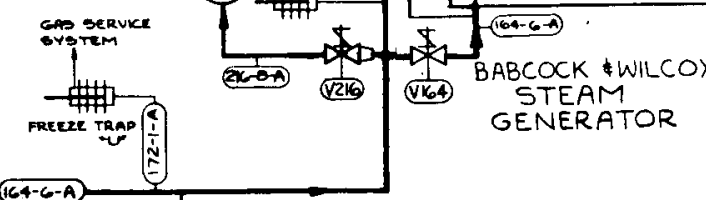

auXILIRYY GalLery

A-2. Secondary Sodium System 


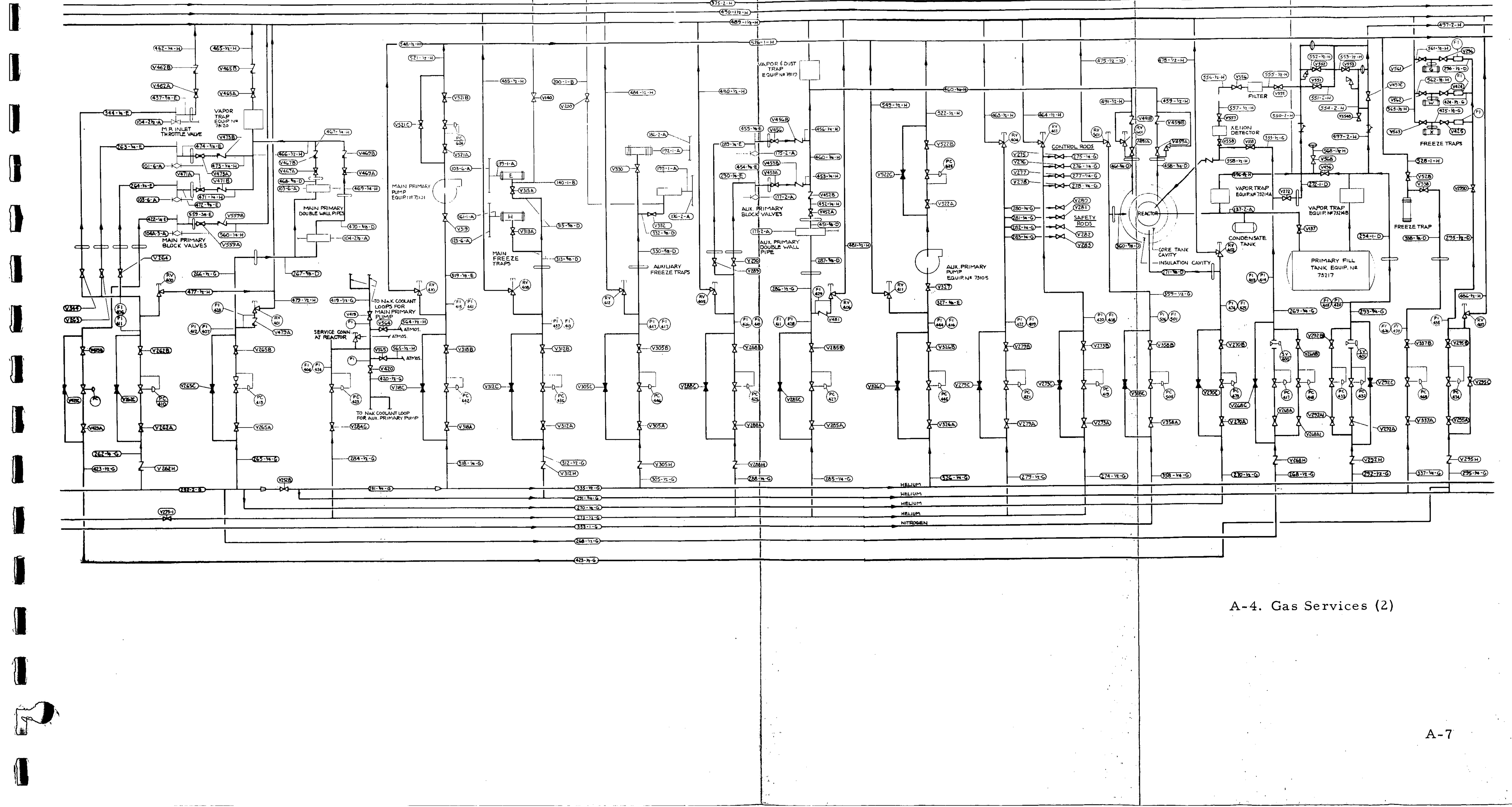




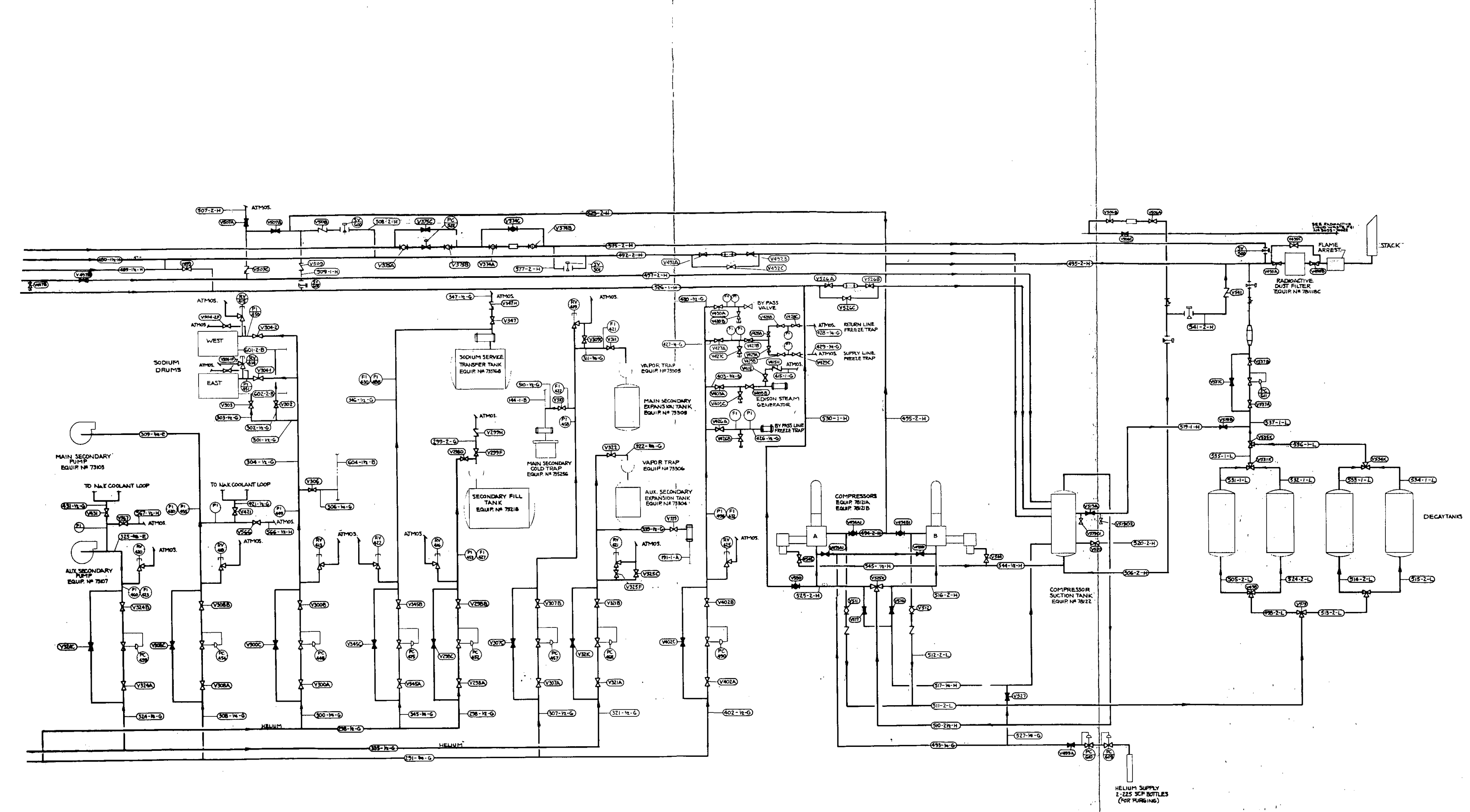

A-5 Gas Services (3) 

